\title{
I mpulse Purchases, Gun Ownership and Homicides: Evidence from a Firearm Demand Shock
}

\author{
Christoph Koenig \\ David Schindler
}

Discussion Paper 20 / 730

16 May 2020

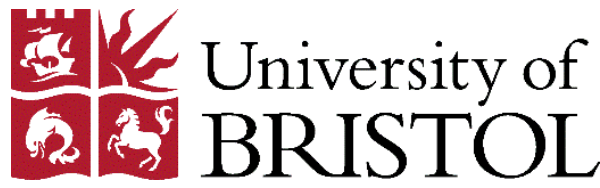

School of Economics

University of Bristol

Priory Road Complex

Bristol BS8 1TU

United Kingdom 


\title{
Impulse Purchases, Gun Ownership and Homicides:
}

\author{
Evidence from a Firearm Demand Shock*
}

\author{
Christoph Koenig ${ }^{\dagger} \quad$ David Schindler ${ }^{\ddagger}$
}

May 16, 2020

\begin{abstract}
Do firearm purchase delay laws reduce aggregate homicide levels? Using variation from a 6-month countrywide gun demand shock in 2012/2013, we show that U.S. states with legislation preventing immediate handgun purchases experienced smaller increases in handgun sales. Our findings indicate that this is likely driven by comparatively lower purchases among impulsive consumers. We then demonstrate that states with purchase delays also witnessed comparatively $2 \%$ lower homicide rates during the same period. Further evidence shows that lower handgun sales coincided primarily with fewer impulsive assaults and points towards reduced acts of domestic violence.
\end{abstract}

JEL codes: K42, H76, H10, K14

Keywords: Guns, homicides, gun control

${ }^{*}$ This paper supersedes a previous version entitled "Dynamics in Gun Ownership and Crime Evidence from the Aftermath of Sandy Hook". We thank participants of seminars at Bristol, Central European University, Essex, Gothenburg, Haifa, Kassel, Munich, Rotterdam, Tilburg, Vienna, Wharton and Warwick, as well as conference attendants at the 2019 CESifo Area Conference on Public Sector Economics, the CEP/LSE/Glasgow Workshop on "The Economics of Crime and Policing", 2018 EEA meeting, the 2018 ASSA meetings, the 2017 ESEM, the 2017 GEA Christmas meeting and the 2017 TWEC. The paper benefited from helpful comments by Bocar Ba, Sascha O. Becker, Aaron Chalfin, Amanda Chuan, Florian Englmaier, Stephan Heblich, Alessandro Iaria, Judd Kessler, Martin Kocher, Botond Kőszegi, Florentin Krämer, Katherine Milkman, Takeshi Murooka, Emily Owens, Arnaud Philippe, Alex Rees-Jones, Marco Schwarz, Simeon Schudy, Peter Schwardmann, Hans H. Sievertsen, Lisa Spantig, Uwe Sunde, Ben Vollaard, Fabian Waldinger, Mark Westcott, Julia Wirtz, Daniel Wissmann, Noam Yuchtman and Yanos Zylberberg. David Schindler would like to thank the Department of Business Economics \& Public Policy at The Wharton School, where parts of this paper were written, for its hospitality.

${ }^{\dagger}$ University of Bristol \& CAGE. Email: Christoph.Koenig@bristol.ac.uk

${ }^{\ddagger}$ Corresponding author, d.schindler@uvt.nl, Tilburg University, Department of Economics, PO Box 90153, 5000 LE Tilburg, The Netherlands \& CESifo Munich. 


\section{Introduction}

The relationship between firearm ownership and criminal activity has been one of the most polarizing topics in U.S. politics over the past decades. Supporters of gun rights often claim that arming citizens will lead to decreases in crime, while supporters of gun control point to the high numbers of victims from gun-related violence. Fowler et al. (2015) report that 32,000 Americans are killed and another 67,000 injured by firearms every year. Based on their calculations, any policy measure effectively reducing these numbers would thus have the potential for welfare gains of almost $\$ 50$ billion each year. Curbing gun violence was also the intention behind many of the 130 gun control policy measures which have been enacted so far across U.S. states (Siegel et al., 2017).

One group of such policy measures, specifically targeted at preventing impulsive acts of gun violence, are firearm purchase delay laws. These measures, by now in place in 15 U.S. states, create a temporal distance between the decision to buy a gun and its eventual receipt. Delays can last from 2 days up to 6 months and occur through mandatory waiting periods or bureaucratic hurdles associated with obtaining purchasing permits. Both measures provide gun buyers with a "cooling-off period" during which those with short-lived suicidal or homicidal intentions may reconsider their planned actions (Cook, 1978; Andrés and Hempstead, 2011). Since delay laws should also keep impulsive consumers without violent intentions from buying guns, they offer a unique avenue to investigate whether and how prevented firearm purchases by such individuals translate into reduced gun violence. However, such analysis would require a reasonably large shift in impulse purchases unrelated to local crime levels.

In this paper, we exploit one of the largest aggregate shocks to U.S. firearm demand to study the effects of handgun purchase delay laws. In a first step, we show that the existence of purchase delays led to a relative reduction in handgun sales during the six months after the 2012 Presidential election and the shooting at Sandy Hook Elementary School. During this period, fear of more restrictive gun control legislation and higher perceived need of self-defense capabilities led to record sales of firearms across the entire United States (Vox, 2016; CNBC, 2012). We use a difference-in-differences (DiD) framework, comparing handgun sale background checks in states with handgun purchase delays to states without such delays during the six-month window of increased firearm demand. Our baseline results indicate that states with purchase delay laws 
witnessed an 7-8\% relative decrease in handgun sales. Differences in gun popularity and other types of firearm legislation cannot explain these results.

Next, we present evidence suggesting that lower purchasing levels were indeed more likely driven by impulsive buyers. We start by analyzing Google search data and show that delay laws did not lead to comparatively lower public interest in buying firearms during the demand shock. Handgun purchase laws thus did not seem to affect intentions to buy firearms, but only whether consumers' interest translated into actual purchases. Using state variation in delay lengths, we also do not observe a relationship between our estimated effect size and the length of the delay. For deliberate and exponentially discounting consumers, these should have been positively correlated, since delays smoothly reduce the discounted net present value of owning a gun. This discontinuous impact of delay lengths on purchases lends further credibility to the presence of impulsive consumers.

In the second part of our analysis, we investigate the effect of delay laws on homicides. Using the same DiD framework, we find that counties in states with purchasing delays experienced a relative $2 \%$ decrease in overall homicide rates during the demand spike, which is entirely driven by homicides involving handguns. Our baseline estimate implies that about 200 lives could have been saved in the six-month period alone if handgun purchase delays had been in place in all U.S. states. An extensive set of robustness checks shows that our results are specific to the period of the demand hike and not driven by single states or choice of the sample. Looking into the characteristics of the additional homicides in states without handgun purchase delays, we find evidence in line with the notion that gun ownership among impulsive buyers is associated with crimes of passion. ${ }^{1}$ For female victims, the evidence points towards instances of domestic violence, as the majority of additional female homicides occurred inside the victim's home and arose from an argument. The affected killings of males occurred mainly outside of their home but were similarly strongly related to arguments.

This study is related to three important streams of research. First, we add to the literature investigating the impact of firearm legislation, and in particular purchase delays, on crime rates. Previous studies found either decreases (Rudolph et al., 2015; Edwards et al., 2018; Luca, Malhotra, and Poliquin, 2017) or zero effects (Ludwig

\footnotetext{
${ }^{1}$ All statements regarding a relative increase in handgun sales and homicides in states without handgun purchase delays are just the flip side of the relative decrease in handgun sales and homicides in states with such delays.
} 
and Cook, 2000) on violent crime or homicides. As the adoption of firearm purchase delay laws may not be exogenous and law changes can be anticipated by prospective gun buyers, our paper substantially advances this literature by providing novel and credible identification through exploiting a sudden and unanticipated demand shock in conjunction with pre-existing delay laws. We also provide suggestive evidence that our empirical setup mainly picks up the behavior of impulsive consumers without violent intentions and offers insights into the types of homicides prevented through purchase delays.

Second, we contribute to the large literature in economics, criminology and public health studying the impact of firearm ownership on violent crime. ${ }^{2}$ The majority of studies finds a positive relationship (see e.g. Cook and Ludwig, 2006; Duggan, 2001; Miller, Azrael, and Hemenway, 2002; Miller, Hemenway, and Azrael, 2007; Siegel, Ross, and King, 2013). Some studies, however, also report no effect (Duggan, Hjalmarsson, and Jacob, 2011; Moody and Marvell, 2005; Kovandzic, Schaffer, and Kleck, 2013; Lang, 2016). A recent paper by Levine and McKnight (2017) shows with a different identification strategy that elevated gun exposure after the Sandy Hook shooting translated into higher rates of firearm-related accidents. ${ }^{3}$ We confirm the positive link between gun ownership and homicides found in previous studies but are the first to look specifically into firearm homicide characteristics and highlight the role of impulsiveness.

Third, our evaluation of gun purchase delay laws contributes to the growing literature analyzing how policies can mitigate the consequences of behavioral biases (overviews are provided in Chetty, 2015; Bernheim and Taubinsky, 2018). To the best of our knowledge, we are the first to study impulsive behavior in the context of gun ownership. Few other studies at the intersection between behavioral economics and economics of crime have also linked impulsiveness to criminal activity and acts of violence (Dahl and DellaVigna, 2009; Card and Dahl, 2011; Heller et al., 2017). We advance this literature by providing the first study to establish a link between firearm availability and fatal consequences of impulsive behavior.

\footnotetext{
${ }^{2}$ Due to space constraints we confine ourselves to the most relevant literature. An excellent survey discussing in particular the early contributions is provided by Hepburn and Hemenway (2004), newer contributions are discussed by Kleck (2015).

${ }^{3}$ While gun-related accidents are not at the heart of our paper, supplementary results reported in the Appendix based on our own identification strategy cannot replicate those findings. Our main results suggest that the primary detrimental effect of increased gun ownership after the Sandy Hook shooting was an increase in gun-related homicides.
} 
This paper is organized as follows: Section 2 provides relevant background information regarding U.S. gun laws and the gun demand shock we consider. Sections 3 and 4 introduce the data and empirical strategy used in this paper, respectively. Our first set of results on handgun sales are presented in Section 5. The discussion of delay laws' effects on homicide rates and their circumstances follow in Section 6. Section 7 concludes.

\section{Background}

\subsection{Purchase Delay Laws in the United States}

The Second Amendment to the United States Constitution protects the fundamental right of citizens to keep and bear arms. Federal, state and local governments, however, have enacted laws making it harder and more cumbersome for citizens to acquire firearms. On the federal level, two important pieces of legislation are the Gun Control Act of 1968 and the Brady Handgun Violence Prevention Act. The Gun Control Act requires all professional gun dealers to have a Federal Firearms License (FFL). Only they can engage in inter-state trade of handguns, are granted access to firearm wholesalers and can receive firearms by mail. The Brady Act of November 1993 mandated background checks for all gun purchases through FFL dealers and imposed a five-day waiting period to conduct these checks. Upon successful lobbying by the National Rifle Association (NRA), these waiting periods were set to expire when the FBI's National Instant Criminal Background Check System (NICS) was introduced in 1998. Since then, the NICS handles all background checks related to the sales of firearms. While there is comparatively little regulation on gun ownership at the federal level, there is substantial heterogeneity in restrictions imposed by U.S. states. ${ }^{4}$ Constraints on private firearm ownership at the state level predominantly attempt to either prohibit potentially dangerous people such as convicted felons from acquiring guns or restrict the usefulness of firearms for unlawful purposes independent of the buyer.

In this study, we focus on handguns since these, unlike long guns, have to be purchased in the state of residence, are a popular choice for self-defense, can be carried concealed, and are used in homicides substantially more often than long guns (Federal

\footnotetext{
${ }^{4}$ Overviews of all current restrictions in the respective states can be found in NRA (2018) and Giffords Law Center to Prevent Gun Violence (2018).
} 
Bureau of Investigation, 2016). We utilize two types of delays between the decision to purchase and the moment the handgun is actually transferred. The first measure are mandatory waiting periods. While the initial aim of waiting periods in the Brady Act was to give law enforcement agencies sufficient time to conduct background checks, they also provide a "cooling-off" period and can therefore help to prevent impulsive acts of violence (Cook, 1978; Andrés and Hempstead, 2011). In practice, buyers will perform a purchase (pass a NICS background check and pay for the chosen gun), but can only receive their handgun after the waiting period has elapsed. The second measure are state requirements for licenses to lawfully possess or buy a handgun. Due to bureaucratic hurdles in the licensing process these impose a de-facto waiting time. Prospective buyers have to request the permit at a local authority (e.g. a sheriff's office), pass a NICS background check and pay the associated fee. ${ }^{5}$ Only after the permit has been processed and issued, they may proceed to conduct the firearm purchase at their local dealer (usually without a renewed background check).

In order to accurately determine the presence of delay laws and minimize misclassification, we utilize several sources and apply a rigorous coding procedure outlined with all details and sources in Appendix Section A.1. The final state classification is reported in Table 1, which shows that during the period of our study, from November 2009 to October 2013, 15 states and the District of Columbia had adopted some form of delay laws throughout. Nine states (California, Florida, Hawaii, Illinois, Maryland, Minnesota, New Jersey, Rhode Island, Wisconsin) and the District of Columbia had imposed mandatory waiting periods on the purchase of handguns. ${ }^{6}$ Connecticut, Hawaii, Illinois, Maryland, Massachusetts, New Jersey, New York, Nebraska, North Carolina, and Rhode Island all require a purchasing permit during the period of our study. Michigan abolished their handgun permit requirement in December 2012 and is thus the only state switching its delay legislation during our period of study. For the remainder of this paper, we will refer to a state which implemented a mandatory waiting period,

\footnotetext{
${ }^{5}$ Fees can range from $\$ 1$ plus notary fee in Michigan to $\$ 340$ in New York City ( $\$ 100$ in the state of New York). See https://www.cga.ct.gov/2013/rpt/2013-R-0048.htm.

${ }^{6} \mathrm{Wisconsin}$ repealed its 48 hour waiting time on handguns only in 2015 and can thus be included in our analysis.
} 
Table 1: Handgun waiting Periods and handgun purchasing LiCense Delay by State as of NOVEMBER 2012

\begin{tabular}{|c|c|c|c|c|c|c|c|c|c|}
\hline State & $\mathrm{AL}$ & AK & $\mathrm{AZ}$ & AR & $\mathrm{CA}$ & $\mathrm{CO}$ & CT & $\mathrm{DE}$ & FL \\
\hline Mandatory Waiting Period & 0 & 0 & 0 & 0 & 10 & 0 & 0 & 0 & 3 \\
\hline Maximum Purchasing Permit Delay & 0 & 0 & 0 & 0 & $0^{*}$ & 0 & $60^{*}$ & 0 & 0 \\
\hline State & GA & $\mathrm{HI}$ & ID & IL & IN & IA & KS & KY & LA \\
\hline Mandatory Waiting Period & 0 & 14 & 0 & 3 & 0 & 3 & 0 & 0 & 0 \\
\hline Maximum Purchasing Permit Delay & 0 & $20^{*}$ & 0 & 30 & 0 & 0 & 0 & 0 & 0 \\
\hline State & $\mathrm{ME}$ & MD & MA & MI & MN & MS & $\mathrm{MO}$ & MT & $\mathrm{NE}$ \\
\hline Mandatory Waiting Period & 0 & 7 & 0 & 0 & 7 & 0 & 0 & 0 & 0 \\
\hline Maximum Purchasing Permit Delay & 0 & $30^{\dagger}$ & 40 & $5^{\dagger \S}$ & 0 & 0 & 0 & 0 & 2 \\
\hline State & NV & $\mathrm{NH}$ & NJ & NM & NY & $\mathrm{NC}$ & ND & $\mathrm{OH}$ & OK \\
\hline Mandatory Waiting Period & 0 & 0 & 7 & 0 & 0 & 0 & 0 & 0 & 0 \\
\hline Maximum Purchasing Permit Delay & 0 & 0 & 30 & 0 & 180 & 30 & 0 & 0 & 0 \\
\hline State & OR & $\mathrm{PA}$ & RI & $\mathrm{SC}$ & $\mathrm{SD}$ & $\mathrm{TN}$ & TX & $\mathrm{UT}$ & VT \\
\hline Mandatory Waiting Period & 0 & 0 & 7 & 0 & 0 & 0 & 0 & 0 & 0 \\
\hline Maximum Purchasing Permit Delay & 0 & 0 & $0^{*}$ & 0 & 0 & 0 & 0 & 0 & 0 \\
\hline State & VA & WA & WV & WI & WY & $\mathrm{DC}$ & & & \\
\hline Mandatory Waiting Period & 0 & 0 & 0 & $2^{\top}$ & 0 & 10 & & & \\
\hline Maximum Purchasing Permit Delay & 0 & 0 & 0 & 0 & 0 & 0 & & & \\
\hline
\end{tabular}

Mandatory Waiting Period refers to the legal minimum amount of time (in days) to pass between the purchase and the receipt of a firearm. If a state has different waiting periods for different types of firearms, the number refers to the purchase of handguns. Maximum Purchasing Permit Delay refers to the legal maximum time (in days) which can pass before a permit that will allow the holder to purchase one or more handguns will be issued or denied. 0 means that no permit is needed or will be issued instantaneously. * Also requires a safety certificate through completing a safety course lasting only a few hours. $\dagger$ No legally defined maximum time, inferred from U.S. Department of Justice (2005). § Abolished in December 2012. @ Repealed in 2015, i.e. after the end of the sample period. Sources for each state are reported in Table 10 in Appendix A.1.

required a purchasing permit, or both, according to Table 1 as a Delay state. ${ }^{7}$ We refer to all other states as NoDelay states.

\subsection{The Firearm Demand Shock of 2012/2013}

Our analysis focuses on the firearm demand spike after the re-election of President Obama in November 2012 and the Sandy Hook shooting in December 2012. We decided for these two particular events to study the impact of delay laws on gun sales and homicides for two main reasons: first, these events by then marked the largest hike in handgun sales since background data was collected in 1999. Such a strong shock is required in order to detect any statistically significant effects on firearm purchases and homicides. Secondly, unlike the numerous later shootings that grabbed nationwide attention, our setup features a pre-treatment period uncontaminated by other events which is essential to accurately account for the seasonal nature of the data. In the following, we briefly describe the two events and the firearm demand hike of 2012/2013.

\footnotetext{
${ }^{7}$ For purchasing permits, Table 1 states the maximum delay allowed by law. There is no reliable information on average delays that we are aware of. As we binarize the treatment, averaging would be inconsequential for our analysis.
} 
In the Presidential Election on 6 November 2012, President Barack Obama ran for a second term against Republican candidate Mitt Romney. While Romney took a more liberal position towards gun rights and was endorsed the NRA, President Obama favored stricter gun control laws. In October 2012, almost all polls showed the race as within the margin of error and President Obama's victory came so unexpected for Romney on election night that he had apparently not even prepared a concession speech as internal polls had showed him winning (International Business Times, 2012; Real Clear Politics, 2012; Silver, 2012). Similarly to President Obama's first election in 2008, gun sales increased after his re-election but this time with considerably larger magnitude (CNN, 2008; CNN Money, 2012; Depetris-Chauvin, 2015). This was likely because the President had started to speak more openly about favoring increased gun control measures in the wake of recent mass shootings, especially the one at a movie theater in Aurora, Colorado in July 2012.

About a month later, on 14 December 2012, then 20-year-old Adam Lanza of Newtown, Connecticut first shot and killed his mother at their home before driving to Sandy Hook Elementary School. There he shot and killed six adult school employees and 20 students aged six to seven years. Lanza committed suicide shortly after the first law enforcement officers arrived at the scene. His motives are still not fully understood, but it has been suggested that he had a history of mental illness (New Yorker, 2014). The massacre was the deadliest ever U.S. school shooting and the third deadliest mass shooting in U.S. history at the time. This and the fact that most of the victims were defenseless children sparked a renewed and unprecedented debate about gun control in the United States.

A few days after the shooting, President Barack Obama announced that he would make gun control a central issue of his second term and quickly assembled a gun violence task force led by Vice President Joe Biden to collect ideas how to curb gun violence and prevent future mass shootings. The task force presented their suggestions to President Obama in January 2013, who announced to implement 23 executive actions. These were aimed at expanding background checks, addressing mental health issues and insurance coverage of treatment, as well as enhancing safety measures for schools and law enforcement officers responding to active shooter situations. Additionally, the task force proposed twelve congressional actions, including renewing the Federal Assault 


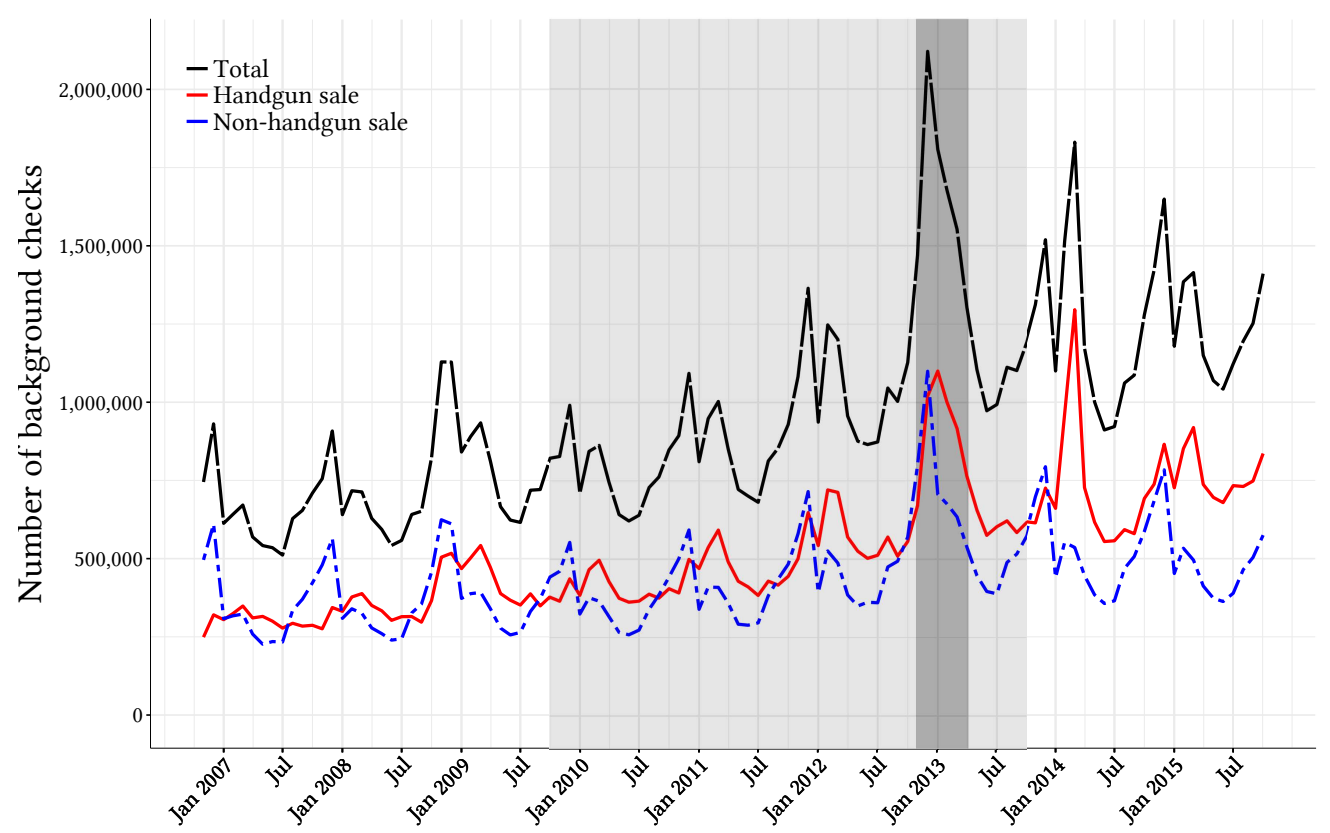

Figure 1: NICS BACKGROUND CHECKS

Monthly federal NICS background checks plotted over time between November 2007 and October 2015 in absolute numbers. The sample encompasses data for all states consistently included in our main specification (see section 3.1 for details). The light gray area is our sample window, the dark grey area depicts the six months after the 2012 election and the shooting at Sandy Hook. The red line shows background checks for handguns, the blue line all other firearm-related background checks, and the black line displays the sum of the two.

Weapons Ban, expanding criminal background checks to private transactions, banning high capacity magazines, and increasing funds for law enforcement agencies.

The proposals were met by fierce opposition from the NRA and some Republican legislators. At the end of January 2013, Senator Dianne Feinstein introduced a bill to reinstate the Federal Assault Weapons Ban. While the bill passed the Senate Judiciary Committee in March 2013, it eventually was struck down on 17 April 2013 by the Senate 40-60 with all but one Republicans and some Democrats opposing the bill. A bipartisan bill to be voted on at that same day, introduced by Senators Joe Manchin and Pat Toomey, aimed at introducing universal background checks, also failed to find the necessary three-fifths majority with 54-46, leaving federal legislation eventually unaffected.

Even though no new federal regulations followed, gun sales soared further in the months after the Sandy Hook shooting. Fear of tougher gun legislation and a higher perceived need of self-protection drove up sales for both, handguns and rifles (Vox, 2016). While gun sales had surged after every prior mass shooting during the Obama administration, the surge after the shooting at Sandy Hook was unprecedented. The 
extreme demand shift even created supply problems for some dealers while others were hoping for sales increases of a magnitude of up to 400\% (CNBC, 2012; Huffington Post, 2013). Several executives in the gun industry have stated that they view mass shootings as a boon to their business, attracting especially first-time gun owners (The Intercept, 2015). In line with these anecdotes, Figure 1 shows a clear spike in gun sales starting in November/December 2012 after the Presidential election and the Sandy Hook shooting. While gun sales generally increase at the end of the year, this particular spike is far more pronounced and prolonged than in the years immediately before and after.

\section{Data}

\subsection{Handgun Purchases}

One of the main challenges in our analysis is the absence of a central database of gun owners and firearm sales. To overcome this, researchers have often turned to proxy variables from surveys, vital statistics, crime data and gun magazine subscriptions. While some of these indicators performed quite well in cross-sectional estimation, they have been found unsuitable for tracking gun ownership over time (Kleck, 2004). Since November 1998, Federal law dictates that an electronic NICS background check be carried out for every firearm transaction through an FFL dealer. This publicly available data has the advantage of being comparable across time, providing high coverage at monthly frequency and distinguishes between different types of transactions and firearms. ${ }^{8}$ The main variable in the first part of our analysis are NICS background checks for handgun sales in a given state between November 2010 and October 2013, divided by the 2010 population in 100,000. In order to interpret our results as semi-elasticities and reduce the influence of outliers while keeping potential zero observations, we apply the inverse hyperbolic sine transformation (arcsinh) instead of taking natural logarithms (Burbidge, Magee, and Robb, 1988). ${ }^{9}$

As pointed out in few recent studies, the NICS data also exhibits important drawbacks (Lang, 2013, 2016; Levine and McKnight, 2017). First, it does not allow any inference on the stock of firearms and ownership levels, but can only measure flows

\footnotetext{
${ }^{8}$ The data can be downloaded at https://www.fbi.gov/file-repository/nics_firearm_checks_month_year_by_state_type.pdf.

${ }^{9}$ For convenience, we refer to the arcsinh transformation as $\log$ throughout the paper. We provide robustness checks in levels for our main specifications in the Appendix.
} 
of weapons. Second, these flows might be substantially understated as about $22 \%$ of firearm sales are between private parties and occur in states which do not require background checks for private transactions (Miller, Hepburn, and Azrael, 2017). Third, a background check can occur for the purchase of multiple weapons, as well as an exchange of an old for a new firearm. Fourth, the data does not distinguish between approved and rejected background checks. Finally, some states require a background check for a concealed carry permit application but not for a handgun purchase itself. Other states are running regular or irregular re-checks on permit holders regardless of guns being bought and thereby inflate the counts or produce outliers.

We believe that our setup mitigates some of these problems. To start with, the aforementioned anecdotes, as well as findings in Studdert et al. (2017) indicate that many handgun purchases during the demand shock in late 2012 were made by new gun owners. With few sales to pre-existing gun owners, this should strengthen the correlation between handgun sale background checks and changes in firearm ownership. Sales outside the NICS through private transactions and particularly gun shows are a concern but would only invalidate our results if they were more common in NoDelay states during the sales hike. Since many consumers were first-time buyers, we deem it more likely they were buying from a regular FFL dealer than privately. ${ }^{10}$ Multiple purchases are less problematic given our interest in the extensive margin of gun ownership. A boost in exchanges of old for new guns in Delay states could also overstate increases in firearm ownership in those states. Since the likelihood of such exchanges should be correlated with pre-existing levels of gun ownership, we are able to control for this concern in additional robustness checks. Furthermore, recent work by Mueller and Frandsen (2017) has shown that only about 1.5\% background checks across the U.S. are actually rejected which severely limits the impact of this potential source of error. There should also be no reason to believe that the demand shock affected the rejection probability asymmetrically across Delay and NoDelay states. Finally, we add background checks for permits to our measure of handgun sales to capture cases in which buyers obtain a permit in order to purchase a handgun. ${ }^{11}$

\footnotetext{
${ }^{10}$ In further analyses, available on request, we show that neither the supply of nor the demand for gun shows (the latter measured by Google Search results) witnessed a stronger impact of the demand shock in NoDelay over Delay states, effectively showing that displacement to these states does not seem to be a cause for concern.

${ }^{11}$ This procedure could not be applied for Hawaii, Illinois and Massachusetts as permit checks in these states may also include permits for long guns. Permits were also not added to handgun sale checks
} 
A closer investigation of the NICS data revealed several outliers and reporting issues. We therefore removed Hawaii, Illinois, Kentucky, Massachusetts, Pennsylvania and Utah, as well as parts of the series for Iowa, Maryland and Wisconsin from the sample. ${ }^{12}$ Furthermore, we drop Connecticut and Michigan. The former was host to the Sandy Hook shooting and thus may invalidate our identification assumptions, while the latter switched treatment status during our period of observation from requiring a permit to not requiring a permit. Performing the steps above yields our baseline sample consisting of 43 U.S. states for investigating the effect of delay laws on handgun sales $(B L 1)$. While we prefer this restricted sample for our analysis of the NICS data, robustness checks for our main results show that alternative (and less restrictive) sample definitions generate qualitatively similar results.

\subsection{Homicide and Mortality}

For our main outcome of interest, homicides, there are two main statistical sources in the United States: death certificates from the National Vital Statistics System (NVSS) and police reports from the FBI's Uniform Crime Reporting Program (UCR). Despite the UCR data being widely used to study crime, they are known to suffer from reporting issues that need to be taken into account by removing areas with unreliable data from the sample (Targonski, 2011). Coverage is therefore not universal. The NVSS data, on the other hand, contains all U.S. death certificates in a given year. We obtained the data via the Center for Disease Control and Prevention (CDC) for the entire sample period between November 2010 and October 2013. The data set contains ICD-10 codes for the underlying cause of each death, as well as the victim's demographics, county of residence and circumstances of the injury such as location and date. The ICD-10 codes allow us to distinguish not only between homicides, suicides and fatal accidents but also whether any of these were inflicted through a handgun or not. ${ }^{13}$ In order to increase the power of our statistical analysis, we make use of the detailed geographical information

for Florida where, for no apparent reason, almost all months report 0 permit checks (and single digits for non-zero months) until April 2013, when they suddenly jump to 15,000-30,000 per month for the remainder of the sample period. Any further reference to handgun background checks implicitly includes background checks made for permits, unless otherwise stated.

${ }^{12}$ Outliers are mainly due to permit re-checks and law changes associated with large mechanic jumps in background check activity. We provide explicit reasoning for these choices in Appendix Section A.2.

${ }^{13}$ Our measure of handgun-related incidents also encompasses instances when an undetermined type of firearm was used. This should not bias our estimates in any way, and it is corroborated by the fact that the vast majority of homicides are carried out with handguns. 


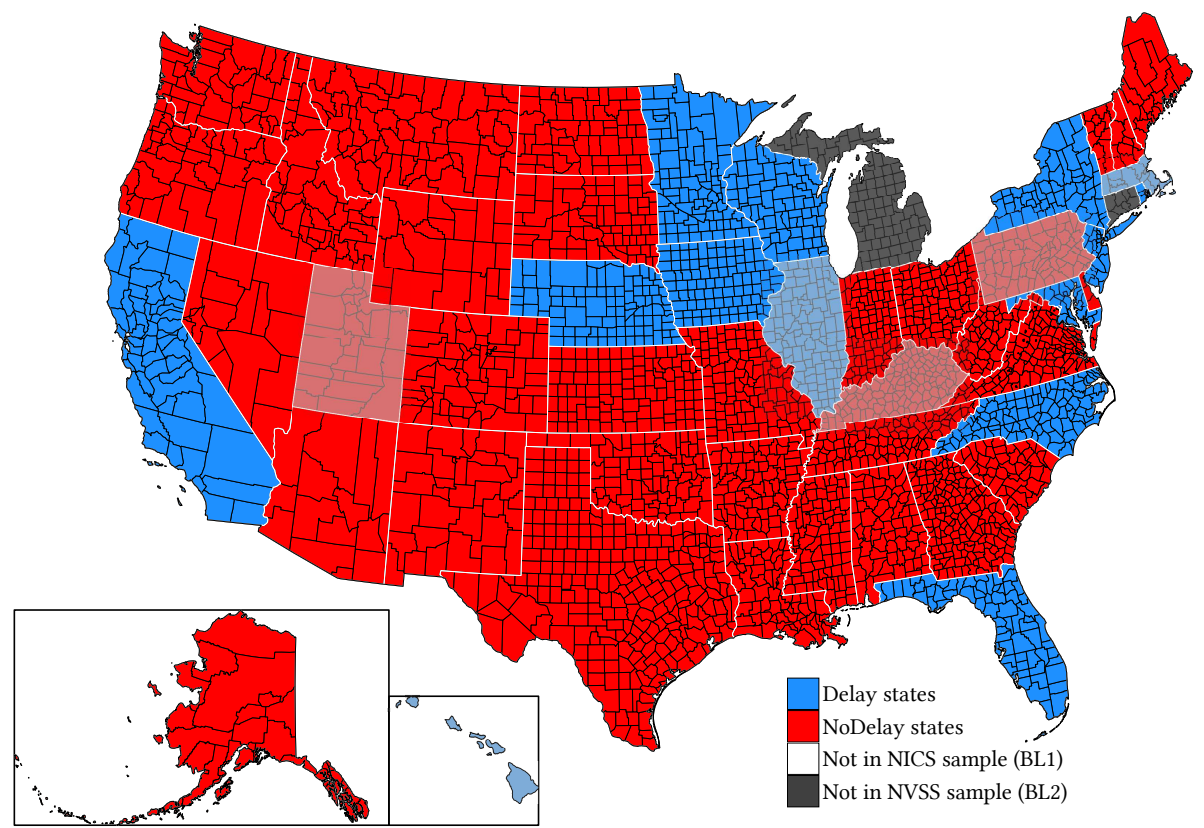

Figure 2: States and COUnties Represented in the NICS AND NVSS SAMPles

Map of the United States showing the states contained in the NICS background check data and counties contained in the NVSS homicide data. Red counties are located in NoDelay states. Blue counties are located in Delay states. Shaded states are dropped in their entirety from the NICS sample. Dark grey counties are not present in the NVSS sample.

in the NVSS and use disaggregated data at the county-month level. This provides us with a balanced panel of homicide counts for 3,047 counties which we normalize by the county's 2010 population in 100,000. This second baseline sample, denoted as BL2, covers every U.S. state apart from Connecticut and Michigan for the same reasons as stated above and we use it in all analyses based on non-NICS data. Figure 2 shows the counties represented in our NVSS sample BL2 and highlights states which were removed in the NICS sample BL1. In our robustness checks, we show that applying more or less stringent sample restrictions yield very similar results.

In order to cross-validate our results and delve deeper into homicide circumstances, we also use the Supplementary Homicide Reports (SHR) series from the aforementioned UCR data, bearing in mind the limitations of the data. These reports are compiled from voluntary submissions by individual law enforcement agencies to the FBI and contain detailed information such as demographics of victim and offender, the type of weapon used as well as murder circumstances (e.g. argument or gang-related crime). We clean the SHR data following the procedure described in Appendix A.4 and then collapse observations into a balanced monthly panel for 2,229 counties. Counts are normalized using the aggregate population in 100,000 covered by the reporting agencies within a 
specific county in 2010. Both UCR and NVSS crime rates are converted into logs using the same arcnsinh transformation as for the NICS data.

\subsection{Gun Interest and Controls}

In order to assess whether consumers in states with and without handgun purchase delays have similar preferences, we need to separate initial intentions to buy handguns from actual purchases. While we use NICS data to measure the latter, we rely on internet search data from Google Trends as a proxy for people's intention to purchase firearms. We focus on searches for the term "gun store", which has been shown to be a good predictor of firearm purchasing intentions by prior research (Scott and Varian, 2014). Since Google search data is not readily available in absolute numbers we adopt a technique similar to the one used by Durante and Zhuravskaya (2018) to construct a state-level panel of weekly Google searches for "gun store". ${ }^{14}$

In addition to this, we use several control variables to account for potential confounders as well as differences in socio-economic characteristics across counties and states. Our core set of covariates includes log of population, the shares of population living in rural areas and below the poverty line as well as the percentages of black and hispanic inhabitants. All variables were obtained from the 2010 U.S. Decennial Census at the county level (and aggregated for state-level analyses). In addition, we collected state-level data on the percentage of households with internet access from the 2010 American Community Survey which we include in regressions using Google search data. In selecting these control variables, we broadly followed the choices made in prior studies which have investigated the relationship between firearm prevalence and crime (e.g. Cook and Ludwig, 2006; Duggan, 2001). To allow for a dynamic impact of our cross-sectional control variables, we interact each of them with a full set of year-month fixed effects. Further variables used only for robustness checks, such as measures of gun supply, are introduced and explained where appropriate.

\footnotetext{
${ }^{14}$ Further details on this procedure are reported in Appendix Section A.5.
} 


\section{Empirical Strategy}

\subsection{Difference-in-Differences Approach}

To estimate the effect of delay laws on handgun purchases and mortality during the demand shock, we use a Difference-in-Differences (DiD) regression model, which overlays the cross-sectional variation in pre-existing purchase delay laws with time-series variation from the six-month surge in firearm demand across the United States. To take into account location-specific seasonality, all our outcome variables are seasonally differenced by subtracting their 12-month lag (denoted as $\Delta_{12}$ ). Our main specifications thus read as follows:

$$
\begin{aligned}
\Delta_{12} \log \left(\text { HandgunSales }_{s t}\right) & =\alpha+\beta_{1}\left(\text { Delay }_{s} \times \text { Post }_{t}\right)+\beta_{2}\left(\text { Delay }_{s} \times \text { Post }_{t}\right) \\
& +\delta_{\mathbf{t}} \mathbf{X}_{\mathbf{s}}+\lambda_{t}+\gamma_{s}+\phi_{s} \times t+\epsilon_{s t} \\
\Delta_{12} \log \left(\text { Homicides }_{c t}\right) \quad & =\alpha+\beta_{1}\left(\text { Delay }_{s} \times \text { Post }_{t}\right)+\beta_{2}\left(\text { Delay }_{s} \times \text { Post }_{t}\right) \\
& +\delta_{\mathbf{t}} \mathbf{X}_{\mathbf{c}}+\lambda_{t}+\gamma_{c}+\phi_{c} \times t+\epsilon_{c t}
\end{aligned}
$$

We use Equation 1 to estimate the effect of the demand surge on handgun sales in Delay over NoDelay states. Equation 2 is effectively the county-level analogue of Equation 1 but instead uses homicide rates as outcome variables. In these equations, the specific effect of delay laws during the demand shock captured via Delay ${ }_{s} \times$ Post $_{t}$ can be regarded as a shifter for new gun owners. Delay $y_{s}$ is a dummy variable for states with delay laws as described in Section 2.1 and summarised in Table 1, i.e. California, Florida, Hawaii, Illinois, Iowa, Maryland, Massachusetts, Minnesota, Nebraska, New Jersey, New York, North Carolina, Rhode Island, Wisconsin and the District of Columbia. This state indicator is interacted with $\operatorname{Post}_{t}$, a dummy for time periods starting after the Obama re-election on November $6^{\text {th }}, 2012$ and ending after April $17^{\text {th }}, 2013$ when the proposals for a renewed assault weapons ban and universal background checks were defeated in the U.S. Senate. Our primary coefficient of interest is $\beta_{1}$ and captures the average proportionate difference in HandgunSales and Homicides between Delay and NoDelay states during the demand shock. We also include a second interaction using the time dummy Post $2_{t}$ for time periods starting after April $17^{\text {th }} 2013$ to investigate 
effects beyond the initial six months. This also allows testing whether Delay states experience comparatively fewer handgun purchases over the entire time period or if this is compensated by more sales later on.

Apart from location (state or county) and time fixed-effects $\gamma_{s}, \gamma_{c}$ and $\lambda_{t}$, the DiD regressions also allow for location-specific linear trends $\phi_{s} \times t$ and $\phi_{c} \times t$ to account for the possibility that some areas may deviate from general trends in background checks and homicides. Furthermore, our regression models each also feature a set of control variables X. We avoid concerns about "bad controls" by using interactions of pre-determined, time-invariant factors and time fixed effects. The variables included in this way are $\%$ hispanics, $\%$ black, $\%$ rural, $\log$ of population, and \% poverty. ${ }^{15} \epsilon$ denotes the residual. The standard errors used for inference are clustered by state as the level of treatment assignment to account for serial correlation in the error terms. Regressions are weighted by the state/county population to reduce the impact of less densely populated areas and to obtain U.S. wide average effects. ${ }^{16}$

A potential alternative to our approach would be to estimate a gun owner-homicide elasticity using Delay $\times$ Post $_{t}$ as an instrument. Our preference for the somewhat cruder reduced-form relationship stems from two factors. The first are the limitations of the NICS data discussed above. NICS background checks do not allow to draw direct inference on changes in the existing population of gun owners, making an elasticity hardly comparable to other studies. This concern is compounded by issues of measurement error, as not all background checks lead to firearm purchases and not all purchases are reflected in the background check counts. Our second concern is that we do not expect the effect of gun owners on homicides to be overly large since the vast majority of gun owners are law-abiding citizens (Fabio et al., 2016). In order to precisely estimate such a small effect, one would need a fairly large sample at the county level for which, however, no NICS data exists. We thus estimate the raw effect of handgun purchase frictions on sales and homicide rates during the demand shock but do not pin down a precise elasticity given the absence of reliable panel data on firearm ownership.

\footnotetext{
${ }^{15}$ This approach prescribes a parsimonious use of control variables. The exact choice of covariates does not seem to be crucial to the results. In an earlier version of this paper where we used a slightly altered set of covariates, we obtain very similar results. See http://www.bristol.ac.uk/efm/media/ workingpapers/working_papers/pdffiles/dp18694.pdf.

${ }^{16}$ Each of these estimation decisions is reassessed in sections 5.1 and 6.2 and we provide supplementary results in the Appendix.
} 


\subsection{Validity of Identifying Assumptions}

In order for our DiD design to yield causal effects, two assumptions need to be fulfilled. The first, commonly referred to as the parallel trends assumption, requires outcomes to have evolved similarly in the absence of treatment. This may particularly be a concern as delay laws have not been exogenously assigned to states, and as such, any differential reaction to the shock may just be an expression of differences in unobservables. We take several measures to alleviate concerns that this assumption may be violated. First, we show that our outcome measures were following similar trends in Delay and NoDelay states prior to the demand shock to prevent that our estimates are simply picking up pre-treatment divergence. As we can see from Figures 3 and 4, handgun sales and homicides in both groups of states are sharply diverging during the six month window of increased firearm demand. There is also a slight divergence for handgun sales in preceding years which highlights the need for seasonal differencing. ${ }^{17}$ Second, we report results with location-specific linear time trends for all our specifications as a first robustness check. In order to credibly identify pre-existing trends, our baseline sample length uses an asymmetric sample period 36 months before to 12 months after the 2012 election (November 2009 to October 2013) in the spirit of Wolfers (2006). ${ }^{18}$ Finally, we also perform an event-study analysis to investigate concerns about non-linear pre-trends.

The second prerequisite is the absence of correlated shocks, i.e. other events coinciding with the demand hike and being positively (negatively) correlated with the existence of delay laws but negatively (positively) with background checks and homicide rates. As argued above, the outcome of the 2012 election as well as the timing of the Sandy Hook shooting are unrelated to any relevant outcome variables, and were arguably the most notable events at the time. We tackle remaining concerns in three ways. First, all regressions control for socio-demographic factors known to be correlated with both gun ownership and crime. Second, we corroborate the role of delay laws by running a series of horserace regressions where we add interactions of Post1 and Post2 with potential confounders such as other types of gun laws and correlates of gun popularity like gun owners and gun stores per capita. The latter also indirectly addresses concerns about a supply side response. Finally, in our mechanism section we use Google search data

\footnotetext{
${ }^{17}$ Appendix Figures 18/19 and 20/21 depict the evolution of both variables in levels and 12-month growth rates.

${ }^{18}$ Note that after applying seasonal differencing, the nominal sample period starts in November 2010 and covers 24 months before and 12 months after treatment onset.
} 


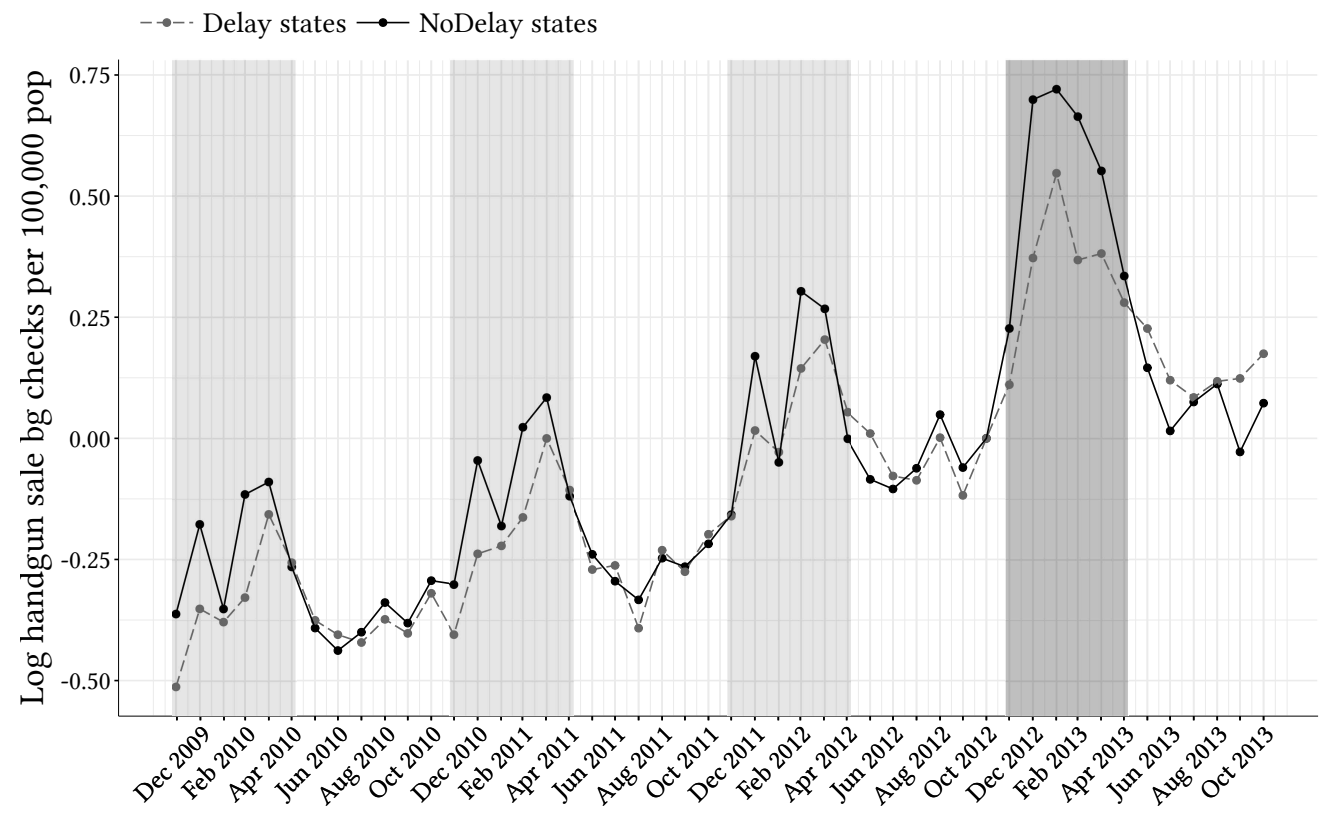

Figure 3: Log Background Check Rate for handguns in Delay vs NoDelay states

Log of monthly NICS handgun background checks per 100,000 inhabitants in Delay states and NoDelay states between November 2009 and October 2013. The sample encompasses data for all states consistently included in our main specification. The dark grey-shaded area includes the first six months after the 2012 election, i.e. November 2012 to April 2013. Light grey-shaded areas are marking the same period for preceding years. For better visibility, each series has been re-scaled to 0 on the last observation before the treatment.

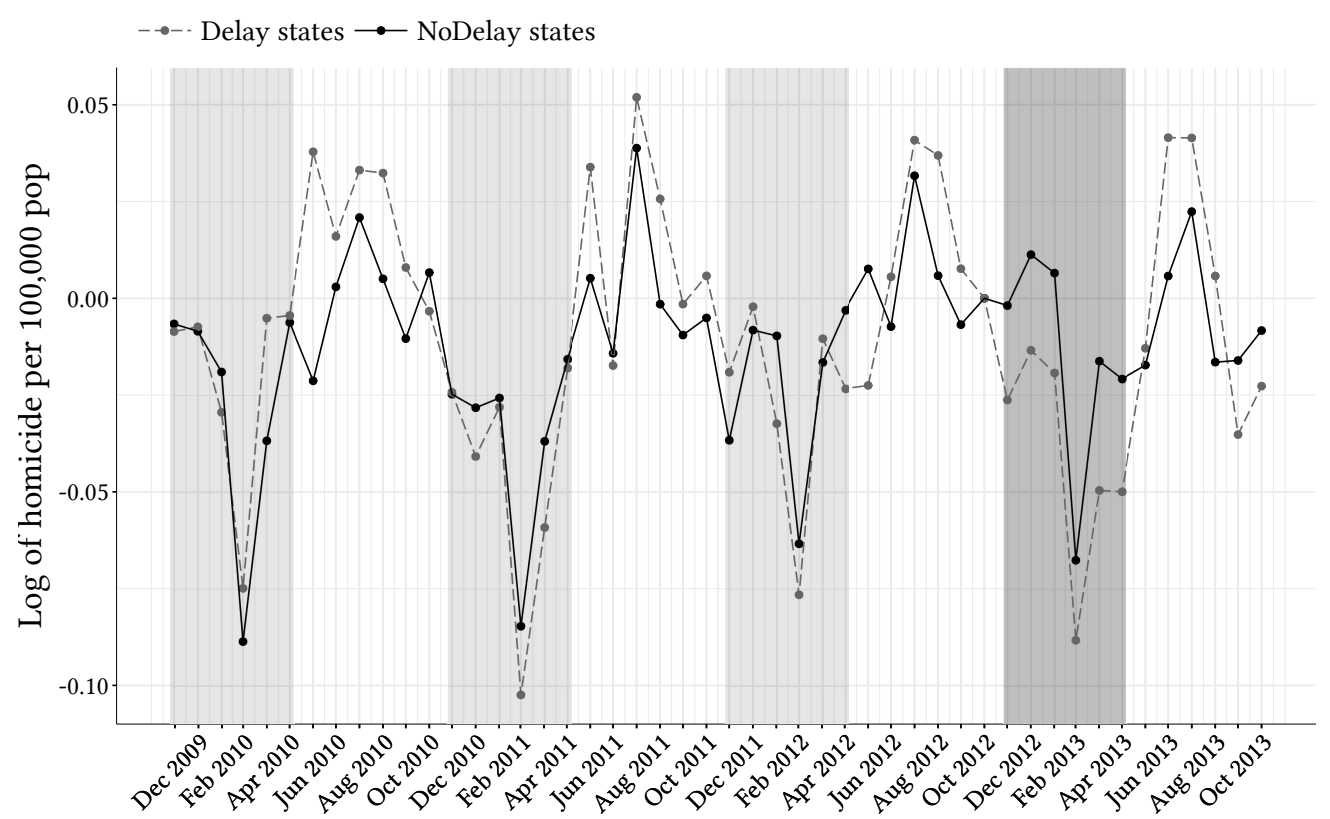

Figure 4: Log homicide Rate in Delay vs NoDelay states

Log of monthly homicides per 100,000 inhabitants in Delay states and NoDelay states between November 2009 and October 2013. The sample encompasses data from all counties consistently included in our main specification. The dark grey-shaded area includes the first six months after the 2012 election, i.e. November 2012 to April 2013. Light grey-shaded areas are marking the same period for preceding years. For better visibility, each series has been re-scaled to 0 on the last observation before the treatment. 
to show that the divergence in gun sales following the shock does not coincide with a similar divergence in the interest to purchase a firearm.

\section{The Effect of Delay Laws on Firearm Purchases}

\section{$5.1 \quad$ Results}

In Table 2 we estimate the differential impact of the 6-month demand hike in Delay states on our handgun sale measure. The table also reports results for total and nonhandgun sale background checks per capita. The main coefficient of interest is $\beta_{1}$ from Equation 1 which represents the percentage difference of the sales rate response to the demand shock in Delay states compared to NoDelay states. Column 1 shows a significant negative effect in the first six months after the Presidential election and a positive nonsignificant effect in the second period of about half. This potential postponement effect, however, disappears when adding controls in column 2, while the coefficient for the Post1 period remains marginally significant. When accounting for potentially diverging pre-trends by adding state-specific linear time trends in column 3 , the estimate for $\beta_{1}$ gains precision while $\beta_{2}$ decreases further. A very likely explanation for this result would be that this specification reduces noise from diverging trends in smaller states without a large influence on the overall (weighted) coefficient.

Our preferred estimate is the more conservative specification in column $3 .^{19}$ The results imply that sales rates were $7.3 \%$ lower in Delay states during the first six months than in NoDelay states. Columns 4 to 7 show that firearm purchase delay laws did not significantly affect overall background checks as well as other gun-related transactions (e.g. sales of long guns).

\subsection{Robustness Checks}

As highlighted in Section 4.2, our identification strategy hinges on the validity of the parallel trends assumption and the absence of correlated shocks. Even though our results in Table 2 are robust to the inclusion of state-specific linear trends, one may argue that this does not accurately capture non-linear pre-trends. We investigate this

\footnotetext{
${ }^{19}$ Both specifications are informative, however, in our view. As we do not know whether the 'true' model exhibits trends, it is ex ante unclear whether column 2 or 3 should be preferred. We therefore report specifications with and without trends for all results in order to provide a more complete picture.
} 
TABle 2: HANDGun SAlE BACKGROUnd CHECKS

\begin{tabular}{|c|c|c|c|c|c|c|c|}
\hline & \multicolumn{7}{|c|}{$\Delta_{12} \log$ of background checks per 100,000 inhabitants } \\
\hline & \multicolumn{3}{|c|}{ Handgun Sale } & \multicolumn{2}{|c|}{ Total } & \multicolumn{2}{|c|}{ Other } \\
\hline \multirow{3}{*}{ Delay $\times$ Post 1} & (1) & (2) & (3) & (4) & (5) & (6) & (7) \\
\hline & $-0.112^{* * *}$ & $-0.081^{*}$ & $-0.073^{* *}$ & -0.039 & -0.030 & 0.009 & 0.021 \\
\hline & $(0.041)$ & $(0.044)$ & $(0.033)$ & $(0.027)$ & $(0.023)$ & $(0.052)$ & $(0.048)$ \\
\hline \multirow[t]{2}{*}{ Delay $\times$ Post 2} & 0.057 & 0.010 & 0.007 & 0.043 & 0.048 & 0.102 & 0.116 \\
\hline & $(0.062)$ & $(0.064)$ & $(0.084)$ & $(0.055)$ & $(0.062)$ & $(0.096)$ & $(0.094)$ \\
\hline Year-Month FE & Y & Y & $\mathrm{Y}$ & $\mathrm{Y}$ & $\mathrm{Y}$ & $\mathrm{Y}$ & $\mathrm{Y}$ \\
\hline Controls & $\mathrm{N}$ & $\mathrm{Y}$ & $\mathrm{Y}$ & $\mathrm{Y}$ & Y & $\mathrm{Y}$ & $\mathrm{Y}$ \\
\hline State Trends & $\mathrm{N}$ & $\mathrm{N}$ & $\mathrm{Y}$ & $\mathrm{N}$ & Y & $\mathrm{N}$ & $\mathrm{Y}$ \\
\hline States & 43 & 43 & 43 & 43 & 43 & 43 & 43 \\
\hline Observations & 1,516 & 1,516 & 1,516 & 1,516 & 1,516 & 1,516 & 1,516 \\
\hline $\mathrm{R}^{2}$ & 0.446 & 0.539 & 0.594 & 0.689 & 0.724 & 0.678 & 0.757 \\
\hline
\end{tabular}

Notes: Observations are at the state-month-level. The sample period is November 2010 until October 2013, i.e. an asymmetric 36-month window 2 years before and 1 year after the 2012 election. Where no seasonal differencing is applied, the nominal sample period starts in November 2009. Standard errors clustered at the state-level are in parentheses: ${ }^{*} \mathrm{p}<0.1 ;{ }^{* *} \mathrm{p}<0.05 ;{ }^{* *} \mathrm{p}<0.01$. Included control variables are $\log$ (population), $\%$ rural, $\%$ below poverty line, $\%$ blacks and \% hispanics. All variables are as of 2010 and interacted with Month FE. Regressions are weighted by the state population.

possibility using an event-study design based on column 2 in Table 2 in which we allow for month-by-month treatment effects. The results are depicted in Figure 5 and show no indication non-linear pre-trends. In the two years before November 2012, we do not observe a clear pattern of up- or downward trends in our estimation. After the 2012 Presidential election, however, the effect of Delay states on handgun sales starts becoming increasingly negative and peaks in size in January 2013. After that, the coefficients gradually move back to the pre-period level and remain insignificant for the entire Post2 period. This also provides additional evidence against the possibility that firearm purchases were merely postponed.

The hypothesis of no correlated shocks mandates that no other factors related to the existence of delay laws should affect handgun sales during the demand shock. One fundamental competing explanation would be that lower sales were produced by unobserved heterogeneity in actual preferences for firearms. Similarly, supply side responses, such as discount sales during the demand shock, may be more frequent in NoDelay states. Finally, purchase delays could also be masking the impact of other restrictive firearm laws. We test the plausibility of these alternative explanations by including additional treatment variables and assessing their impact on the baseline results. 


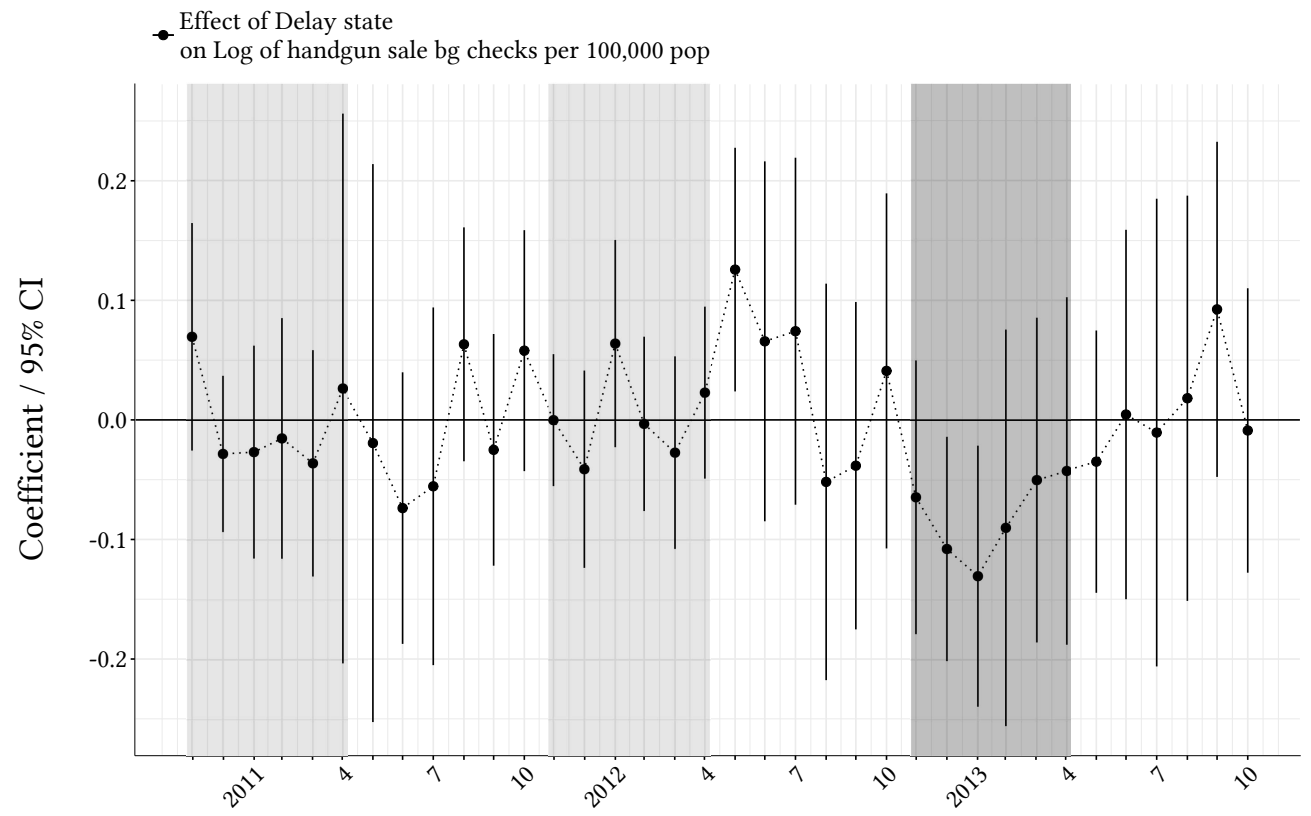

Figure 5: Event STUdy GRAPH FOR NICS BACKGROUND CHECKS

Coefficients and $95 \%$ confidence intervals for the effect of being in a Delay state on $\Delta_{12}$ Log of NICS handgun background checks per 100,000 inhabitants for each month between November 2010 and October 2013. The dark grey-shaded area includes the first six months after the 2012 election, i.e. November 2012 to April 2013. Light grey-shaded areas are marking the same period for preceding years.

In Table 3 we first explore the impact of gun popularity and firearm supply capacity: 1) estimates for the 2013 state-level rate of gun ownership from YouGov published by Kalesan et al. (2015) in columns 3 and 4, and 2) gun stores per capita as of December 2010 calculated from data by the Bureau of Alcohol, Tobacco, Firearms and Explosives (2010) in columns 5 and 6 . We then run similar horse-race regression with two different types of restrictive gun legislation obtained from Siegel et al. (2017): 1) the absence of stand-your-ground laws which give immunity for shooting an intruder in one's home (columns 7 and 8), and 2) prohibiting domestic violence offenders from possessing firearms (columns 9 and 10). Our coefficient of interest remains stable. Differences in firearm preferences, supply and other restrictive gun laws thus do not seem to be driving our results on handgun sale background checks. ${ }^{20}$ Appendix Section B.1 provides results from placebo checks and sensitivity analyses regarding sample composition, data transformation and weighting.

\footnotetext{
${ }^{20}$ In additional regressions, available upon request, we also demonstrate that gun sales had not simply been displaced to secondary markets by analyzing the demand and supply for gun shows, respectively.
} 
TAble 3: Handgun background Checks (Gun PREFEREnCes \& Other Gun laws)

\begin{tabular}{|c|c|c|c|c|c|c|c|c|c|c|}
\hline \multirow{3}{*}{$\begin{array}{l}\text { Confounder } \\
\text { represents... }\end{array}$} & \multicolumn{10}{|c|}{$\Delta_{12} \log$ of handgun sale background checks per 100,000 inhabitants } \\
\hline & \multirow[b]{2}{*}{ (1) } & \multirow[b]{2}{*}{$(2)$} & \multicolumn{2}{|c|}{$\begin{array}{l}\text { Gun Owners } \\
\text { p.c. }\end{array}$} & \multicolumn{2}{|c|}{$\begin{array}{l}\text { Gun Stores } \\
\text { p.c. }\end{array}$} & \multicolumn{2}{|c|}{$\begin{array}{l}\text { No Stand-your- } \\
\text { ground law }=1\end{array}$} & \multicolumn{2}{|c|}{$\begin{array}{c}\text { Domestic Abu- } \\
\text { ser's Law = } 1 \\
\end{array}$} \\
\hline & & & (3) & $(4)$ & $(5)$ & $(6)$ & $(7)$ & $(8)$ & (9) & $(10)$ \\
\hline Delay $\times$ Post 1 & $\begin{array}{l}-0.081^{*} \\
(0.044)\end{array}$ & $\begin{array}{c}-0.073^{* *} \\
(0.033)\end{array}$ & $\begin{array}{r}{ }^{*}-0.074^{*} \\
(0.044)\end{array}$ & $\begin{array}{r}-0.065^{*} \\
(0.033)\end{array}$ & $\begin{array}{l}-0.071^{*} \\
(0.042)\end{array}$ & $\begin{array}{c}-0.063^{* *} \\
(0.032)\end{array}$ & $\begin{array}{r}-0.071^{*} \\
(0.038)\end{array}$ & $\begin{array}{l}-0.067^{* *} \\
(0.030)\end{array}$ & $\begin{array}{c}-0.082^{*} \\
(0.046)\end{array}$ & $\begin{array}{l}-0.073^{* *} \\
(0.033)\end{array}$ \\
\hline Delay $\times$ Post 2 & $\begin{array}{c}0.010 \\
(0.064)\end{array}$ & $\begin{array}{c}0.007 \\
(0.084)\end{array}$ & $\begin{array}{c}0.001 \\
(0.069)\end{array}$ & $\begin{array}{c}-0.006 \\
(0.091)\end{array}$ & $\begin{array}{l}-0.003 \\
(0.066)\end{array}$ & $\begin{array}{c}-0.007 \\
(0.086)\end{array}$ & $\begin{array}{c}0.000 \\
(0.066)\end{array}$ & $\begin{array}{l}-0.008 \\
(0.080)\end{array}$ & $\begin{array}{l}-0.004 \\
(0.061)\end{array}$ & $\begin{array}{l}-0.009 \\
(0.084)\end{array}$ \\
\hline Confounder $\times$ Post 1 & & & $\begin{array}{c}0.131 \\
(0.136)\end{array}$ & $\begin{array}{c}0.134 \\
(0.143)\end{array}$ & $\begin{array}{r}0.002^{*} \\
(0.001)\end{array}$ & $\begin{array}{c}0.002^{*} \\
(0.001)\end{array}$ & $\begin{array}{r}-0.048^{*} \\
(0.025)\end{array}$ & $\begin{array}{l}-0.028 \\
(0.023)\end{array}$ & $\begin{array}{c}0.011 \\
(0.028)\end{array}$ & $\begin{array}{c}0.025 \\
(0.030)\end{array}$ \\
\hline Confounder $\times$ Post 2 & & & $\begin{array}{l}-0.208 \\
(0.363)\end{array}$ & $\begin{array}{l}-0.264 \\
(0.411)\end{array}$ & $\begin{array}{l}-0.002 \\
(0.002)\end{array}$ & $\begin{array}{c}-0.002 \\
(0.002)\end{array}$ & $\begin{array}{c}0.051 \\
(0.078)\end{array}$ & $\begin{array}{c}0.072 \\
(0.088)\end{array}$ & $\begin{array}{l}0.145^{* *} \\
(0.058)\end{array}$ & $\begin{array}{l}0.172^{* *} \\
(0.071)\end{array}$ \\
\hline Year-Month FE & $\mathrm{Y}$ & $\mathrm{Y}$ & $\mathrm{Y}$ & Y & $\mathrm{Y}$ & $\mathrm{Y}$ & $\mathrm{Y}$ & Y & $\mathrm{Y}$ & $\mathrm{Y}$ \\
\hline Controls & $\mathrm{Y}$ & $\mathrm{Y}$ & $\mathrm{Y}$ & $\mathrm{Y}$ & $\mathrm{Y}$ & $\mathrm{Y}$ & Y & $\mathrm{Y}$ & $\mathrm{Y}$ & $\mathrm{Y}$ \\
\hline State Trends & $\mathrm{N}$ & Y & $\mathrm{N}$ & $\mathrm{Y}$ & $\mathrm{N}$ & $\mathrm{Y}$ & $\mathrm{N}$ & Y & $\mathrm{N}$ & $\mathrm{Y}$ \\
\hline $\mathrm{R}^{2}$ & 0.539 & 0.594 & 0.540 & 0.596 & 0.544 & 0.599 & 0.543 & 0.598 & 0.556 & 0.613 \\
\hline
\end{tabular}

Notes: All regressions use 1,516 observations from 43 states. Observations are at the state-month-level. The sample period is November 2010 until October 2013, i.e. an asymmetric 36-month window 2 years before and 1 year after the 2012 election. Where no seasonal differencing is applied, the nominal sample period starts in November 2009. Standard errors clustered at the state-level are in parentheses: ${ }^{*} \mathrm{p}<0.1 ;{ }^{* *} \mathrm{p}<0.05 ;{ }^{* *} \mathrm{p}<0.01$. Included control variables are $\log$ (population), $\%$ rural, $\%$ below poverty line, $\%$ blacks and $\%$ hispanics. All variables are as of 2010 and interacted with Month FE. Regressions are weighted by the state population.

\subsection{Mechanisms}

Having established different reactions in handgun sales between Delay and NoDelay states, we now evaluate whether our findings could be driven by impulsive consumers. A first way to characterize impulsive agents is the potential divergence between plans and actions. In other words, impulsive consumers may decide to buy a firearm under the influence of transient emotions but eventually do not buy since these emotions have already passed. This should not be observed for regular, non-impulsive consumers if they make a fully rational purchase decision. However, a delay in receiving the gun makes the purchase also less attractive for non-impulsive consumers since it reduces the item's net present value. If, however, the decision not to buy is driven predominantly by standard exponential discounting, we should observe that longer delays reduce purchases substantially more than shorter delays. Impulsive agents, however, would be deterred by any delay since they cannot get hold of the firearm while being in a particular emotional state. A second characteristic of impulsiveness would thus be that even very short delays should have a notable impact on the likelihood to buy. ${ }^{21}$

\footnotetext{
${ }^{21}$ These predictions can also be formally derived in a theoretical framework which is available on request but omitted here for the sake of space.
} 
Table 4: Online Searches \& Handgun Background checks (Delay length)

\begin{tabular}{|c|c|c|c|c|c|c|c|c|c|c|}
\hline \multirow{3}{*}{$\begin{array}{l}\text { Maximum } \\
\text { delay } \\
\text { length }\end{array}$} & \multicolumn{2}{|c|}{$\begin{array}{l}\Delta_{52} \text { Log std'zed } \\
\text { share of Google } \\
\text { searches for } \\
\text { "gun store" }\end{array}$} & \multicolumn{8}{|c|}{$\Delta_{12} \log$ of handgun background checks per 100,000 inhabitants } \\
\hline & \multirow[b]{2}{*}{ (1) } & \multirow[b]{2}{*}{$(2)$} & \multicolumn{2}{|c|}{$\begin{array}{c}\text { Baseline } \\
(=12 \text { delay states })\end{array}$} & \multicolumn{2}{|c|}{$\begin{array}{c}D \leq 30 \\
\text { Drop NY } \\
(=11)\end{array}$} & \multicolumn{2}{|c|}{$\begin{array}{c}D \leq 14 \\
\text { Drop MD, NC, } \\
\text { NJ }(=8)\end{array}$} & \multicolumn{2}{|c|}{$\begin{array}{c}D \leq 3 \\
\text { Drop CA, DC } \\
\text { MN, RI }(=4)\end{array}$} \\
\hline & & & $(3)$ & $(4)$ & $(5)$ & $(6)$ & $(7)$ & $(8)$ & $(9)$ & $(10)$ \\
\hline Delay $\times$ Post 1 & $\begin{array}{c}0.037 \\
(0.082)\end{array}$ & $\begin{array}{c}-0.017 \\
(0.090)\end{array}$ & $\begin{array}{r}-0.081^{*} \\
(0.044)\end{array}$ & $\begin{array}{l}-0.073^{* *} \\
(0.033)\end{array}$ & $\begin{array}{c}-0.072 \\
(0.049)\end{array}$ & $\begin{array}{l}-0.073^{*} \\
(0.035)\end{array}$ & $\begin{array}{r}* 0.103^{*} \\
(0.053)\end{array}$ & $\begin{array}{l}-0.087^{* *} \\
(0.042)\end{array}$ & $\begin{array}{l}-0.071^{* *} \\
(0.036)\end{array}$ & $\begin{array}{l}{ }^{*}-0.075^{*} \\
(0.038)\end{array}$ \\
\hline Delay $\times$ Post 2 & $\begin{array}{l}-0.027 \\
(0.097)\end{array}$ & $\begin{array}{l}-0.081 \\
(0.133)\end{array}$ & $\begin{array}{c}0.010 \\
(0.064)\end{array}$ & $\begin{array}{c}0.007 \\
(0.084)\end{array}$ & $\begin{array}{c}0.013 \\
(0.074)\end{array}$ & $\begin{array}{l}-0.000 \\
(0.094)\end{array}$ & $\begin{array}{l}-0.001 \\
(0.080)\end{array}$ & $\begin{array}{l}-0.006 \\
(0.116)\end{array}$ & $\begin{array}{l}-0.131^{* *} \\
(0.059)\end{array}$ & $\begin{array}{r}-0.174 \\
(0.120)\end{array}$ \\
\hline Year-Time FE & $\mathrm{Y}$ & $\mathrm{Y}$ & $\mathrm{Y}$ & $\mathrm{Y}$ & Y & $\mathrm{Y}$ & Y & $\mathrm{Y}$ & Y & $\mathrm{Y}$ \\
\hline Controls & $\mathrm{Y}$ & $\mathrm{Y}$ & $\mathrm{Y}$ & $\mathrm{Y}$ & $\mathrm{Y}$ & $\mathrm{Y}$ & $\mathrm{Y}$ & $\mathrm{Y}$ & $\mathrm{Y}$ & $\mathrm{Y}$ \\
\hline State Trends & $\mathrm{N}$ & $\mathrm{Y}$ & $\mathrm{N}$ & $\mathrm{Y}$ & $\mathrm{N}$ & Y & $\mathrm{N}$ & $\mathrm{Y}$ & $\mathrm{N}$ & Y \\
\hline States & 49 & 49 & 43 & 43 & 42 & 42 & 39 & 39 & 35 & 35 \\
\hline Observations & 7,693 & 7,693 & 1,516 & 1,516 & 1,480 & 1,480 & 1,374 & 1,374 & 1,230 & 1,230 \\
\hline $\mathrm{R}^{2}$ & 0.230 & 0.247 & 0.539 & 0.594 & 0.546 & 0.600 & 0.561 & 0.605 & 0.613 & 0.663 \\
\hline$p\left(\beta_{1}=-0.073\right)$ & & & & & 1 & 1 & 0.57 & 0.73 & 0.97 & 0.96 \\
\hline
\end{tabular}

Notes: Observations are at the state-week-level (Google) or state-month-level (NICS). The sample period is November 2010 until October 2013, i.e. an asymmetric 36-month window 2 years before and 1 year after the 2012 election. Where no seasonal differencing is applied, the nominal sample period starts in November 2009. Standard errors clustered at the state-level are in parentheses: ${ }^{*} \mathrm{p}<0.1 ;{ }^{* *} \mathrm{p}<0.05 ;{ }^{* * *} \mathrm{p}<0.01$. Included control variables are $\log$ (population), $\%$ rural, $\%$ below poverty line, $\%$ blacks, $\%$ hispanics and $\%$ with internet access (Google only). All variables are as of 2010 and interacted with Week FE (Google) or Month FE (NICS). Regressions are weighted by the state population.

We start by investigating the congruence between plans to buy firearms and actual sales. This analysis uses Google searches for the term "gun store" which serves as a proxy for public interest in buying a gun and has been identified as a strong predictor for firearm purchasing intentions in previous research by Scott and Varian (2014). Columns 1 and 2 in Table 4 repeat our preferred regression specifications using Google searches for "gun store" as the dependent variable. We do not detect large or significantly different changes in search results which provides evidence that the different evolution of gun sales in the wake of the demand shock was not driven by different preferences for and intentions to buy firearms. ${ }^{22}$ This is additional evidence that our results are unlikely to be driven by unobserved heterogeneity across states. More importantly, these findings indicate a mismatch between intentions to purchase a firearm and actual sales in Delay states. However, these results could also reflect that potential buyers do not know their state's firearm laws while searching for a gun store, but only learn about purchase

\footnotetext{
${ }^{22}$ Figure 22 in the Appendix shows the development of Google searches between November 2009 and October 2013 graphically. A regression using levels and producing similar results can be found in Appendix Table 21.
} 
delays at a later point and then deliberately decide not to buy. For such non-impulsive consumers, we should observe that decreasing delay lengths smoothly reduce the effect, something we test for next.

Our second test checks whether states with very short delays show a similar pattern as states with longer delays. In columns 3 to 10 in Table 4, we use our two main specifications from Table 2 and gradually exclude states with delay lengths exceeding 30, 14 and 3 days. The table also features tests for coefficient equality of $\beta_{1}$ in the short-delay and the baseline sample. Overall, we do not detect strong variations in the estimated coefficients for $\beta_{1}$. In the most restrictive specifications 9 and 10 with only 4 treatment states and at most 3 days of delay, the estimates are still very close to the baseline in columns 3 and 4 . The Wald tests can never confidently reject the null hypothesis of coefficient equality for $\beta_{1}$. The absence of a systematic decrease in the effect size suggests that gun buyers may in fact respond more to the presence of a delay per se, rather than its length. ${ }^{23}$ This evidence lends further support to the above conjecture that the difference in sales between the two group of states is predominantly driven by impulsive consumers.

\section{The Effect of Delay Laws on Homicides}

\subsection{Results}

Starting from the observation that handgun sales increased significantly less in $D e$ lay states during the 2012 firearm demand shock, we investigate if there was also a corresponding effect on homicide rates. ${ }^{24}$ Table 5 shows the results from Equation 2. Observations are now at the county-month level, and the sample includes all states which were previously omitted due to measurement error in the background check data. Column 1 shows that Delay states experienced a significant relative drop in gun homicide rates by $2.4 \%$ after the start of the firearm demand shock, and an insignificant further $1.4 \%$ relative decrease during Post2. Controlling for observables in column 2 yields a significant $2.2 \%$ relative drop in Delay states' handgun homicide rates during the

\footnotetext{
${ }^{23}$ In Appendix Table 22 we also show that including transaction costs from e.g. gun licensing fees in our regressions does not qualitatively change our findings regarding the effect of purchase delay laws.

${ }^{24}$ In unreported results, we also investigate the effect on crime other than murder, providing a test of the "more guns, less crime" hypothesis, without being able to detect a systematic deterrence effect of guns. These findings are available upon request. In Appendix Section B.3, we study the effect on suicides and accidents.
} 
TABle 5: Baseline: Homicide RATES

\begin{tabular}{|c|c|c|c|c|c|c|c|}
\hline \multirow[b]{4}{*}{ Delay $\times$ Post 1} & \multicolumn{7}{|c|}{$\Delta_{12} \log$ of homicides per 100,000 inhabitants } \\
\hline & \multicolumn{3}{|c|}{ Handgun } & \multicolumn{2}{|c|}{ Any } & \multicolumn{2}{|c|}{ Other } \\
\hline & (1) & (2) & (3) & (4) & $(5)$ & (6) & (7) \\
\hline & $\begin{array}{l}-0.024^{* * *} \\
(0.009)\end{array}$ & $\begin{array}{l}-0.022^{* * *} \\
(0.008)\end{array}$ & $\begin{array}{l}-0.019^{* *} \\
(0.010)\end{array}$ & $\begin{array}{l}-0.024^{* *} \\
(0.012)\end{array}$ & $\begin{array}{c}-0.021 \\
(0.016)\end{array}$ & $\begin{array}{c}-0.002 \\
(0.010)\end{array}$ & $\begin{array}{c}-0.001 \\
(0.013)\end{array}$ \\
\hline Delay $\times$ Post 2 & $\begin{array}{c}-0.014 \\
(0.012)\end{array}$ & $\begin{array}{l}-0.018 \\
(0.015)\end{array}$ & $\begin{array}{c}-0.015 \\
(0.018)\end{array}$ & $\begin{array}{c}0.002 \\
(0.017)\end{array}$ & $\begin{array}{l}0.005 \\
(0.023)\end{array}$ & $\begin{array}{l}0.022^{* * *} \\
(0.008)\end{array}$ & $\begin{array}{l}0.024^{*} \\
(0.011)\end{array}$ \\
\hline Year-Month FE & $\mathrm{Y}$ & $\mathrm{Y}$ & $\mathrm{Y}$ & $\mathrm{Y}$ & $\mathrm{Y}$ & $\mathrm{Y}$ & $\mathrm{Y}$ \\
\hline Controls & $\mathrm{N}$ & $\mathrm{Y}$ & $\mathrm{Y}$ & $\mathrm{Y}$ & $\mathrm{Y}$ & $\mathrm{Y}$ & $\mathrm{Y}$ \\
\hline County Trends & $\mathrm{N}$ & $\mathrm{N}$ & Y & $\mathrm{N}$ & Y & $\mathrm{N}$ & Y \\
\hline Counties & 3,047 & 3,047 & 3,047 & 3,047 & 3,047 & 3,047 & 3,047 \\
\hline Observations & 109,692 & 109,692 & 109,692 & 109,692 & 109,692 & 109,692 & 109,692 \\
\hline $\mathrm{R}^{2}$ & 0.002 & 0.008 & 0.019 & 0.006 & 0.016 & 0.005 & 0.014 \\
\hline
\end{tabular}

Notes: Observations are at the county-month-level. The sample period is November 2010 until October 2013, i.e. an asymmetric 36-month window 2 years before and 1 year after the 2012 election. Where no seasonal differencing is applied, the nominal sample period starts in November 2009. Standard errors clustered at the state-level are in parentheses: ${ }^{*} \mathrm{p}<0.1 ;{ }^{* *} \mathrm{p}<0.05 ;{ }^{* *} \mathrm{p}<0.01$. Included control variables are $\log$ (population), $\%$ rural, $\%$ below poverty line, $\%$ blacks and $\%$ hispanics. All variables are as of 2010 and interacted with Month FE. Regressions are weighted by the county population.

treatment period Post1 and an insignificant relative decline of $1.8 \%$ in Post2. The inclusion of county trends in column 3 mainly leads to a loss in precision but only slightly diminishes $\beta_{1}$ to -0.019 , which is still significant at $5 \%$.

Columns 4 and 5 show that the Post 1 effect for handgun homicides is also reflected in decreased aggregate homicide rates of about the same magnitude. This effect is significant at the $5 \%$ level without county trends, but loses significance when trends are included. Notably, there is virtually no impact of delay laws on overall homicides in the Post2 period. The reason for this becomes apparent when looking at the results for nonhandgun homicides in specifications 6 and 7 . Here we see a significant increase which explains the zero-effect in the aggregate homicide rates during Post2. A straightforward explanation could be that the reaction of NoDelay states reflects two different channels through which increased handgun ownership can affect homicides. One would be a lethality effect by which random acts of aggression or anger turn into the shooting and killing of another person. The other effect would be a substitution effect whereby homicides are simply carried out by handguns instead of other weapons with no aggregate effect. Our results are indicative of both effects as non-handgun homicides significantly increase in Post2, but we also observe a significant increase in aggregate homicides in Post1. Since our main interest are delay laws' aggregate effects, the remainder of this 
paper focuses on the lethality effect and the impact of delay laws on handgun-related homicides during the Post1 period.

\subsection{Robustness Checks}

We run similar checks as in Section 5.2 to establish the validity of our identification strategy. First, we investigate the possibility of non-linear pre-trends using an eventstudy design. Figure 6 indeed does not show any systematic effect for handgun-induced homicides before the onset of the treatment. During our treatment period Post1, however, there is a clear negative impact for November 2012, December 2012 and March $2013 .{ }^{25}$ The strong and significant homicide effect in November is rather noteworthy, as Figure 5 showed a negative effect for handgun sales for November, but only displayed individual statistical significance for December onwards. Furthermore, the significant effect on homicides in March does not coincide with a similar effect on gun sales. One possible explanation could be that individuals purchasing handguns directly after the shock in November are especially impulsive, such that purchases translate into homicides rather quickly. Individuals buying within the next two months may be less impulsive so that it would take longer for their impulsiveness to also translate into a homicide. Our data unfortunately does not allow us to test such a conjecture and thus entirely rule out alternative explanations. Table 6 shows that also our findings on handgun homicide rates are not a by-product of underlying preferences for firearms or the existence of other restrictive gun laws. In Appendix Section B.2, we discuss and report placebo checks, state-level results and sensitivity analyses of our sample composition, data transformation and weighting choices.

\subsection{Mechanisms}

Our previous analyses in Section 5.3 have provided tentative evidence that impulsive consumers are likely to drive the differences in handgun sale background checks between Delay and NoDelay states. In this section we try to provide evidence that also our results on homicides can be traced back to impulsive behavior. We do so by taking a closer look

\footnotetext{
${ }^{25}$ Appendix Figure 23 further shows no systematic effect on non-handgun homicides before or during our treatment. The positive effect observed during Post2 in the baseline regressions applies to all months during this period, but is only statistically significant for July 2013.
} 


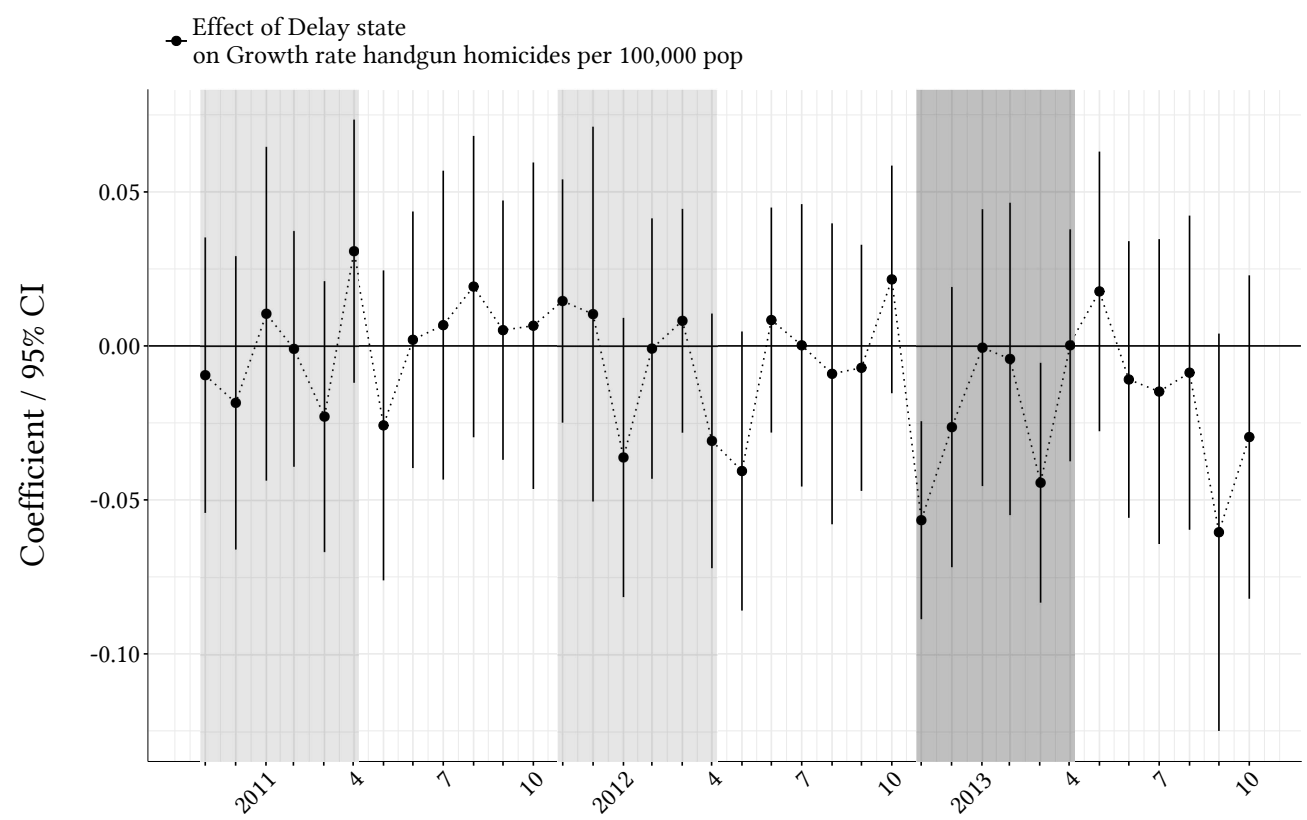

Figure 6: EvENT STUDY GRAPH FOR HANDGUN HOMICIDE RATE

Coefficients and $95 \%$ confidence intervals for the effect of being in a Delay state on $\Delta_{12}$ Log handgun homicide per 100,000 inhabitants for each month between November 2010 and October 2013. The dark grey-shaded area includes the first six months after the 2012 election, i.e. November 2012 to April 2013. Light grey-shaded areas are marking the same period for preceding years.

TABle 6: HANDGUn homicide RATES (GUN PREFERENCES \& OtHeR GUN LAWS)

\begin{tabular}{|c|c|c|c|c|c|c|c|c|c|c|}
\hline \multirow{3}{*}{$\begin{array}{l}\text { Confounder } \\
\text { represents... }\end{array}$} & \multicolumn{10}{|c|}{$\Delta_{12} \log$ of handgun homicides per 100,000 inhabitants } \\
\hline & \multirow[b]{2}{*}{ (1) } & \multirow[b]{2}{*}{ (2) } & \multicolumn{2}{|c|}{$\begin{array}{l}\text { Gun Owners } \\
\text { p.c. }\end{array}$} & \multicolumn{2}{|c|}{$\begin{array}{l}\text { Gun Stores } \\
\text { p.c. }\end{array}$} & \multicolumn{2}{|c|}{$\begin{array}{l}\text { No Stand-your- } \\
\text { ground law }=1\end{array}$} & \multicolumn{2}{|c|}{$\begin{array}{l}\text { Domestic Abu- } \\
\text { ser's Law }=1\end{array}$} \\
\hline & & & $(3)$ & $(4)$ & $(5)$ & (6) & $(7)$ & (8) & (9) & (10) \\
\hline Delay $\times$ Post 1 & $\begin{array}{c}-0.022^{* *} \\
(0.008)\end{array}$ & $\begin{array}{c}* * 0.019^{* *} \\
(0.010)\end{array}$ & $\begin{array}{l}-0.020^{* *} \\
(0.008)\end{array}$ & $\begin{array}{c}{ }^{*}-0.022^{* *} \\
(0.010)\end{array}$ & $\begin{array}{c}{ }^{*}-0.022^{* x} \\
(0.008)\end{array}$ & $\begin{array}{r}* * 0.020^{*} \\
(0.010)\end{array}$ & $\begin{array}{c}-0.018^{* *} \\
(0.006)\end{array}$ & $\begin{array}{c}{ }^{* *}-0.019^{* *} \\
(0.008)\end{array}$ & $\begin{array}{c}-0.022^{* *} \\
(0.007)\end{array}$ & $\begin{array}{c}* *-021^{* *} \\
(0.009)\end{array}$ \\
\hline Delay $\times$ Post2 & $\begin{array}{c}-0.018 \\
(0.015)\end{array}$ & $\begin{array}{l}-0.015 \\
(0.018)\end{array}$ & $\begin{array}{l}-0.013 \\
(0.013)\end{array}$ & $\begin{array}{l}-0.015 \\
(0.016)\end{array}$ & $\begin{array}{c}-0.017 \\
(0.015)\end{array}$ & $\begin{array}{c}-0.015 \\
(0.018)\end{array}$ & $\begin{array}{l}-0.014 \\
(0.012)\end{array}$ & $\begin{array}{l}-0.015 \\
(0.015)\end{array}$ & $\begin{array}{l}-0.017 \\
(0.016)\end{array}$ & $\begin{array}{c}-0.017 \\
(0.019)\end{array}$ \\
\hline Confounder $\times$ Post 1 & & & $\begin{array}{c}0.021 \\
(0.043)\end{array}$ & $\begin{array}{l}-0.023 \\
(0.056)\end{array}$ & $\begin{array}{c}-0.000 \\
(0.000)\end{array}$ & $\begin{array}{c}-0.000 \\
(0.000)\end{array}$ & $\begin{array}{l}-0.008 \\
(0.009)\end{array}$ & $\begin{array}{l}-0.000 \\
(0.011)\end{array}$ & $\begin{array}{c}0.000 \\
(0.007)\end{array}$ & $\begin{array}{c}0.009 \\
(0.011)\end{array}$ \\
\hline Confounder $\times$ Post 2 & & & $\begin{array}{c}0.048 \\
(0.058)\end{array}$ & $\begin{array}{c}0.004 \\
(0.065)\end{array}$ & $\begin{array}{c}0.000 \\
(0.000)\end{array}$ & $\begin{array}{c}0.000 \\
(0.000)\end{array}$ & $\begin{array}{l}-0.010 \\
(0.011)\end{array}$ & $\begin{array}{l}-0.002 \\
(0.013)\end{array}$ & $\begin{array}{c}-0.002 \\
(0.012)\end{array}$ & $\begin{array}{c}0.007 \\
(0.016)\end{array}$ \\
\hline Year-Month FE & $\mathrm{Y}$ & $\mathrm{Y}$ & $\mathrm{Y}$ & $\mathrm{Y}$ & $\mathrm{Y}$ & $\mathrm{Y}$ & Y & $\mathrm{Y}$ & $\mathrm{Y}$ & $\mathrm{Y}$ \\
\hline Controls & $\mathrm{Y}$ & $\mathrm{Y}$ & $\mathrm{Y}$ & $\mathrm{Y}$ & Y & $\mathrm{Y}$ & $\mathrm{Y}$ & $\mathrm{Y}$ & $\mathrm{Y}$ & $\mathrm{Y}$ \\
\hline County Trends & $\mathrm{N}$ & $\mathrm{Y}$ & $\mathrm{N}$ & $\mathrm{Y}$ & $\mathrm{N}$ & $\mathrm{Y}$ & $\mathrm{N}$ & $\mathrm{Y}$ & $\mathrm{N}$ & $\mathrm{Y}$ \\
\hline $\mathrm{R}^{2}$ & 0.008 & 0.019 & 0.008 & 0.019 & 0.008 & 0.019 & 0.008 & 0.019 & 0.008 & 0.019 \\
\hline
\end{tabular}

Notes: All regressions use 109,692 observations from 3,047 counties. The sample period is November 2010 until October 2013, i.e. an asymmetric 36-month window 2 years before and 1 year after the 2012 election. Where no seasonal differencing is applied, the nominal sample period starts in November 2009. Standard errors clustered at the state-level are in parentheses: ${ }^{*} \mathrm{p}<0.1 ;{ }^{* *} \mathrm{p}<0.05 ;{ }^{* * *} \mathrm{p}<0.01$. Included control variables are $\log$ (population), \% rural, \% below poverty line, \% blacks and \% hispanics. All variables are as of 2010 and interacted with Month FE. Regressions are weighted by the county population. 
TABle 7: Effect on homicide RATES: Victim SEX

\begin{tabular}{|c|c|c|c|c|c|c|c|c|c|c|}
\hline \multirow{4}{*}{$\begin{array}{l}\text { Victim sex } \\
\text { Victim age }\end{array}$} & \multicolumn{10}{|c|}{$\Delta_{12} \log$ of handgun homicides per 100,000 inhabitants } \\
\hline & \multirow{2}{*}{\multicolumn{2}{|c|}{$\begin{array}{l}\text { Any } \\
\text { Any }\end{array}$}} & \multicolumn{4}{|c|}{ Male } & \multicolumn{4}{|c|}{ Female } \\
\hline & & & \multicolumn{2}{|c|}{ Any } & \multicolumn{2}{|c|}{$20-29$} & \multicolumn{2}{|c|}{ Any } & \multicolumn{2}{|c|}{$20-29$} \\
\hline & $(1)$ & $(2)$ & $(3)$ & $(4)$ & $(5)$ & (6) & $(7)$ & $(8)$ & $(9)$ & $(10)$ \\
\hline Delay $\times$ Post 1 & $\begin{array}{c}-0.022^{* *} \\
(0.008)\end{array}$ & $\begin{array}{c}* *-0.019^{* *} \\
(0.010)\end{array}$ & $\begin{array}{c}-0.013 \\
(0.008)\end{array}$ & $\begin{array}{c}-0.011 \\
(0.009)\end{array}$ & $\begin{array}{c}-0.011^{*} \\
(0.006)\end{array}$ & $\begin{array}{c}-0.008 \\
(0.006)\end{array}$ & $\begin{array}{c}-0.009^{* *} \\
(0.003)\end{array}$ & $\begin{array}{r}-0.008^{*} \\
(0.005)\end{array}$ & $\begin{array}{c}-0.006^{* *} \\
(0.002)\end{array}$ & $\begin{array}{c}* * 0.006^{* *} \\
(0.002)\end{array}$ \\
\hline Delay $\times$ Post 2 & $\begin{array}{l}-0.018 \\
(0.015)\end{array}$ & $\begin{array}{c}-0.015 \\
(0.018)\end{array}$ & $\begin{array}{c}-0.018 \\
(0.013)\end{array}$ & $\begin{array}{l}-0.016 \\
(0.015)\end{array}$ & $\begin{array}{c}0.002 \\
(0.007)\end{array}$ & $\begin{array}{c}0.005 \\
(0.008)\end{array}$ & $\begin{array}{c}0.002 \\
(0.005)\end{array}$ & $\begin{array}{c}0.002 \\
(0.007)\end{array}$ & $\begin{array}{c}-0.002 \\
(0.002)\end{array}$ & $\begin{array}{l}-0.002 \\
(0.003)\end{array}$ \\
\hline Year-Month FE & $\mathrm{Y}$ & $\mathrm{Y}$ & $\mathrm{Y}$ & $\mathrm{Y}$ & $\mathrm{Y}$ & Y & Y & $\mathrm{Y}$ & $\mathrm{Y}$ & $\mathrm{Y}$ \\
\hline Controls & Y & $\mathrm{Y}$ & $\mathrm{Y}$ & $\mathrm{Y}$ & $\mathrm{Y}$ & $\mathrm{Y}$ & Y & $\mathrm{Y}$ & $\mathrm{Y}$ & $\mathrm{Y}$ \\
\hline County Trends & $\mathrm{N}$ & $\mathrm{Y}$ & $\mathrm{N}$ & $\mathrm{Y}$ & $\mathrm{N}$ & $\mathrm{Y}$ & $\mathrm{N}$ & Y & $\mathrm{N}$ & $\mathrm{Y}$ \\
\hline $\mathrm{R}^{2}$ & 0.008 & 0.019 & 0.008 & 0.020 & 0.012 & 0.023 & 0.005 & 0.014 & 0.007 & 0.016 \\
\hline
\end{tabular}

Notes: All regressions use 109,692 observations from 3,047 counties. The sample period is November 2010 until October 2013, i.e. an asymmetric 36-month window 2 years before and 1 year after the 2012 election. Where no seasonal differencing is applied, the nominal sample period starts in November 2009. Standard errors clustered at the state-level are in parentheses: ${ }^{*} \mathrm{p}<0.1 ;{ }^{* *} \mathrm{p}<0.05 ;{ }^{* * *} \mathrm{p}<0.01$. Included control variables are $\log$ (population), $\%$ rural, $\%$ below poverty line, $\%$ blacks and $\%$ hispanics. All variables are as of 2010 and interacted with Month FE. Regressions are weighted by the county population.

at the type of additional handgun homicides in NoDelay states (or equivalently which were "prevented" in Delay states).

Table 7 presents the results split up by victim sex with a particular focus on the 20 to 29 age group, into which the majority of first-time buyers should fall. ${ }^{26}$ The results show that men make up about $2 / 3$ of the victims while women account for $1 / 3$. The coefficients for female victims, however, are more precisely estimated. Both male and female victims are predominantly aged 20 to 29 . These findings suggest that female victims are overrepresented, as less than $10 \%$ of overall homicide victims are women in our data. Given this and our evidence on impulsive consumers, we investigate the role of domestic violence. To do so, we split the handgun homicide victims into those who were shot in their home and those who were assaulted elsewhere. Table 8 reports the corresponding results. For the male victims we find that the entire effect is driven by attacks outside their home. Female victims, on the other hand, are predominantly assaulted in their place of living, consistent with instances of domestic violence.

In order to obtain more evidence that points towards domestic killings, we present results using the UCR SHR data on homicide circumstances in Table 9. ${ }^{27}$ Columns 1 to

\footnotetext{
${ }^{26}$ Appendix Table 23 shows corresponding results for all other age groups. We also report victim splits by race in Appendix Table 24 and show that, in line with the overall demographics of homicide victims in the United States, victims tend to be almost evenly categorized as 'White' and 'Black'.

${ }^{27}$ As outlined in Section 3.2, this data exhibits a more restricted coverage. Appendix Table 25 shows that the UCR SHR data yield qualitatively similar estimates compared to the NVSS data in our Post1
} 
TABle 8: EfFect on homicide Rates: Place of ASSAult

\begin{tabular}{|c|c|c|c|c|c|c|c|c|}
\hline \multirow{4}{*}{$\begin{array}{l}\text { Victim sex } \\
\text { Place of assault }\end{array}$} & \multicolumn{8}{|c|}{$\Delta_{12} \log$ of handgun homicides per 100,000 inhabitants } \\
\hline & \multicolumn{4}{|c|}{ Male } & \multicolumn{4}{|c|}{ Female } \\
\hline & \multicolumn{2}{|c|}{ Home } & \multicolumn{2}{|c|}{ Not Home } & \multicolumn{2}{|c|}{ Home } & \multicolumn{2}{|c|}{ Not Home } \\
\hline & (1) & (2) & (3) & (4) & (5) & (6) & (7) & (8) \\
\hline Delay $\times$ Post 1 & $\begin{array}{c}0.006 \\
(0.008)\end{array}$ & $\begin{array}{c}0.004 \\
(0.008)\end{array}$ & $\begin{array}{r}-0.018^{*} \\
(0.009)\end{array}$ & $\begin{array}{c}-0.014 \\
(0.011)\end{array}$ & $\begin{array}{l}-0.007^{* *} \\
(0.003)\end{array}$ & $\begin{array}{l}-0.008^{* *} \\
(0.004)\end{array}$ & $\begin{array}{c}-0.001 \\
(0.002)\end{array}$ & $\begin{array}{c}0.000 \\
(0.003)\end{array}$ \\
\hline Delay $\times$ Post 2 & $\begin{array}{c}-0.012^{*} \\
(0.007)\end{array}$ & $\begin{array}{c}-0.014^{*} \\
(0.008)\end{array}$ & $\begin{array}{c}-0.009 \\
(0.011)\end{array}$ & $\begin{array}{c}-0.004 \\
(0.012)\end{array}$ & $\begin{array}{c}0.002 \\
(0.005)\end{array}$ & $\begin{array}{c}0.001 \\
(0.006)\end{array}$ & $\begin{array}{c}0.000 \\
(0.002)\end{array}$ & $\begin{array}{c}0.001 \\
(0.003)\end{array}$ \\
\hline Year-Month FE & $\mathrm{Y}$ & $\mathrm{Y}$ & $\mathrm{Y}$ & $\mathrm{Y}$ & $\mathrm{Y}$ & $\mathrm{Y}$ & Y & $\mathrm{Y}$ \\
\hline Controls & $\mathrm{Y}$ & $\mathrm{Y}$ & $\mathrm{Y}$ & $\mathrm{Y}$ & $\mathrm{Y}$ & $\mathrm{Y}$ & $\mathrm{Y}$ & $\mathrm{Y}$ \\
\hline County Trends & $\mathrm{N}$ & $\mathrm{Y}$ & $\mathrm{N}$ & $\mathrm{Y}$ & $\mathrm{N}$ & $\mathrm{Y}$ & $\mathrm{N}$ & $\mathrm{Y}$ \\
\hline $\mathrm{R}^{2}$ & 0.006 & 0.017 & 0.011 & 0.023 & 0.004 & 0.014 & 0.006 & 0.016 \\
\hline
\end{tabular}

Notes: All regressions use 109,692 observations from 3,047 counties. The sample period is November 2010 until October 2013, i.e. an asymmetric 36-month window 2 years before and 1 year after the 2012 election. Where no seasonal differencing is applied, the nominal sample period starts in November 2009. Standard errors clustered at the state-level are in parentheses: ${ }^{*} \mathrm{p}<0.1 ;{ }^{* *} \mathrm{p}<0.05 ;{ }^{* * *} \mathrm{p}<0.01$. Included control variables are $\log$ (population), $\%$ rural, \% below poverty line, \% blacks and \% hispanics. All variables are as of 2010 and interacted with Month FE. Regressions are weighted by the county population.

2 show the baseline specification for handgun homicides reported in the UCR SHR and then split these into specific murder circumstances. The results for aggregate handgun homicides have the same sign as those using the NVSS data but are only about $2 / 3$ in size and insignificant, likely due to the more limited coverage and data quality. The results in columns 3 and 4, however, indicate that deadly assaults related to arguments account for the main part of the additional handgun homicides in NoDelay states. Unlike for the aggregate handgun murder rate, this effect is also highly significant. All other types of homicide circumstances such as brawls, (organized) crime and defense as well as other/undetermined, do not seem to be systematically affected during the Post1 period. These findings lend further support to the hypothesis that impulsive consumers are driving the differences in handgun homicides during the demand shock.

Summarizing these findings, we observe that the additional homicides of females in NoDelay states primarily happened inside their home, predominantly to women between 20 and 29, and often as a result of arguments. Homicides of men, instead, happened primarily outside their home, but also largely because of arguments. Similar to women, male victims are typically 20-29 years old. In terms of mechanisms, our findings suggest domestic violence and other heat of the moment murders as a possible explanation for the observed differences in homicides between Delay and NoDelay states. These

period of interest. A map illustrating the exact coverage for the UCR data is shown in Appendix Figure 14. 
TABle 9: Murder Reports: Circumstances

\begin{tabular}{|c|c|c|c|c|c|c|c|c|c|c|}
\hline \multirow{3}{*}{ Circumstances } & \multicolumn{10}{|c|}{$\Delta_{12} \log$ of handgun murders per 100,000 inhabitants } \\
\hline & \multicolumn{2}{|c|}{ Any } & \multicolumn{2}{|c|}{ Arguments } & \multicolumn{2}{|c|}{ Brawls } & \multicolumn{2}{|c|}{$\begin{array}{c}\text { Gang, Felony } \\
\text { or Defense }\end{array}$} & \multicolumn{2}{|c|}{ All Other } \\
\hline & (1) & (2) & (3) & (4) & (5) & (6) & (7) & (8) & (9) & (10) \\
\hline \multirow[t]{2}{*}{ Delay $\times$ Post 1} & -0.014 & -0.013 & $-0.010^{* * *}$ & ${ }^{*}-0.016^{* * *}$ & * 0.002 & 0.002 & -0.000 & -0.008 & -0.008 & 0.005 \\
\hline & $(0.011)$ & $(0.013)$ & $(0.004)$ & $(0.006)$ & $(0.001)$ & $(0.001)$ & $(0.009)$ & $(0.010)$ & $(0.011)$ & (0.009) \\
\hline Delay $\times$ Post 2 & $\begin{array}{c}0.003 \\
(0.019)\end{array}$ & $\begin{array}{c}0.004 \\
(0.025)\end{array}$ & $\begin{array}{l}-0.007 \\
(0.005)\end{array}$ & $\begin{array}{c}-0.013 \\
(0.008)\end{array}$ & $\begin{array}{c}-0.000 \\
(0.001)\end{array}$ & $\begin{array}{l}-0.000 \\
(0.001)\end{array}$ & $\begin{array}{l}-0.006 \\
(0.008)\end{array}$ & $\begin{array}{c}-0.014 \\
(0.013)\end{array}$ & $\begin{array}{c}0.018 \\
(0.013)\end{array}$ & $\begin{array}{r}0.031^{*} \\
(0.017)\end{array}$ \\
\hline Year-Month FE & $\mathrm{Y}$ & $\mathrm{Y}$ & Y & $\mathrm{Y}$ & $\mathrm{Y}$ & $\mathrm{Y}$ & $\mathrm{Y}$ & $\mathrm{Y}$ & Y & Y \\
\hline Controls & $\mathrm{Y}$ & $\mathrm{Y}$ & Y & $\mathrm{Y}$ & $\mathrm{Y}$ & $\mathrm{Y}$ & Y & Y & Y & Y \\
\hline County Trends & $\mathrm{N}$ & $\mathrm{Y}$ & $\mathrm{N}$ & $\mathrm{Y}$ & $\mathrm{N}$ & $\mathrm{Y}$ & $\mathrm{N}$ & $\mathrm{Y}$ & $\mathrm{N}$ & Y \\
\hline $\mathrm{R}^{2}$ & 0.010 & 0.021 & 0.009 & 0.020 & 0.013 & 0.023 & 0.020 & 0.041 & 0.010 & 0.027 \\
\hline $\begin{array}{l}\text { Notes: All re } \\
\text { county-month-le } \\
\text { window } 2 \text { years b } \\
\text { sample period sta } \\
{ }^{* *} \mathrm{p}<0.05 ;{ }^{* * *} \mathrm{p}<0 \\
\text { and } \% \text { hispanics. } \\
\text { county populatio }\end{array}$ & $\begin{array}{l}\text { essions } \\
\text { The s } \\
\text { ore and } \\
\text { s in Nor } \\
1 . \text { Inclu }\end{array}$ & $\begin{array}{l}\text { use } 80,2 \\
\text { ample per } \\
\text { year afte } \\
\text { ember } 20 \\
\text { ded contr }\end{array}$ & $\begin{array}{l}244 \text { obser } \\
\text { eriod is No } \\
\text { er the } 2012 \\
\text { 009. Standa } \\
\text { rol variable }\end{array}$ & $\begin{array}{l}\text { cvations } \\
2 \text { election. } \\
\text { lard errors } \\
\text { es are } \log (\end{array}$ & $\begin{array}{l}\text { from } 2,2 \\
010 \text { until } \\
\text { Where } n \\
\text { s clustere } \\
\text { (populati }\end{array}$ & $\begin{array}{l}29 \text { coun } \\
\text { October } \\
\text { o seasona } \\
\text { d at the st } \\
\text { on), \% ru }\end{array}$ & $\begin{array}{l}\text { ties. } \\
\text { 2013, i.e. } \\
\text { l differen } \\
\text { ate-level } \\
\text { ral, \% be }\end{array}$ & $\begin{array}{l}\text { Observat } \\
\text { an asy } \\
\text { cing is at } \\
\text { are in pe } \\
\text { low pov }\end{array}$ & $\begin{array}{l}\text { ons are } \\
\text { imetric } 3 \\
\text { olied, the } \\
\text { entheses: } \\
\text { rty line, }\end{array}$ & $\begin{array}{l}\text { at the } \\
\text { month } \\
\text { ominal } \\
\mathrm{p}<0.1 \text {; } \\
\text { blacks }\end{array}$ \\
\hline
\end{tabular}

interpretations are in line with insights by Tangney, Baumeister, and Boone (2004) that impulsiveness is correlated across domains.

\section{Conclusion}

In light of the persistently high rate of firearm homicides in the United States, understanding the consequences of legislation limiting access to guns is imperative. One of the main arguments used by proponents of gun rights are that gun laws do not substantially affect violent crime but impose excessive burdens on law-abiding gun owners. In this study we focus on the effects of a specific type of policy measure, handgun purchase delay laws, and provide evidence that, while not infringing with Second Amendment rights, these laws can substantially reduce homicides through the prevention of impulsive purchases.

We present empirical evidence that states with delay laws in place saw comparatively smaller handgun sales during a demand shock after the re-election of President Obama in 2012 and the shooting at Sandy Hook Elementary School. Further results show that purchase delays have strong effects even when they are very short and did not affect intentions to buy a firearm but only the likelihood of consumers of making an actual handgun purchase. In the second part of our analysis, we investigate delay laws' effect 
on homicide rates. Using detailed micro-data on mortality, we find a significant effect of delay laws on handgun-related homicides during the period of the demand shock. The effect size is about $2 \%$ which in turn implies that about 200 homicides could have been "prevented" during the six-month Post1 period if all U.S. states had had some sort of purchase delay law in place. These additional homicides encompass both genders, and indicate that arguments as well as domestic violence constitute some of the main channels through which handgun ownership by impulsive individuals may affect homicide rates.

We see our study as a good starting point for more nuanced investigations into the relation between gun ownership and crime. First, additional direct evidence on the circumstances linking gun sales to violent crime is needed. While our results were able to point in the direction of arguments and domestic violence, the results are far from clearcut. With increasing coverage of the FBI's National Incident-Based Reporting System $(N I B R S)$, more detailed information on particular crime incidents could be utilized to study similar future firearm demand shocks. Second, given the absence of accurate data on how county-level gun ownership evolves over time, our study cannot pin down an exact gun-homicide elasticity. The NICS data is very noisy and makes cross-state comparison impossible at times. We thus stress the need for a more transparent, countylevel version of handgun sales than what is currently available. Finally, we believe that more research is needed to evaluate costs and benefits of specific gun laws. As shown in this study, the positive effects of purchase delays may be understated. Rigorous analyses of gun laws may therefore help foster a more informed debate on gun policy. 


\section{References}

Andrés, Antonio Rodríguez and Katherine Hempstead. 2011. "Gun control and suicide: The impact of state firearm regulations in the United States, 1995-2004." Health Policy 101 (1):95-103.

Anglemyer, Andrew, Tara Horvath, and George Rutherford. 2014. "The accessibility of firearms and risk for suicide and homicide victimization among household members: a systematic review and meta-analysis." Annals of Internal Medicine 160 (2):101-110.

Bernheim, Douglas B and Dmitry Taubinsky. 2018. "Behavioral public economics." In

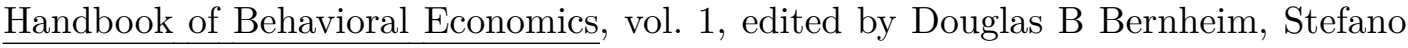
DellaVigna, and David Laibson. New York: Elsevier.

Burbidge, John B., Lonnie Magee, and A. Leslie Robb. 1988. "Alternative Transformations to Handle Extreme Values of the Dependent Variable." Journal of the American Statistical Association 83 (401):123-127.

Bureau of Alcohol, Tobacco, Firearms and Explosives. 2010. "List of Federal Firearms Licensees (FFLS) December 2010." https://web.archive.org/web/20111023171235/http: //atf.gov/about/foia/download/ffl-list-2010/ffl-list/12/1210-ffl-list.xls.

Card, David and Gordon B Dahl. 2011. "Family violence and football: The effect of unexpected emotional cues on violent behavior." Quarterly Journal of Economics $126(1): 103-143$.

Cherney, Samantha, Andrew R Moral, and Terry L Schell. 2018. "RAND State Firearm Law Database." https://www.rand.org/pubs/tools/TL283.html.

Chetty, Raj. 2015. "Behavioral economics and public policy: A pragmatic perspective." American Economic Review 105 (5):1-33.

CNBC. 2012. "The Sandy Hook Effect: Gun Sales Rise as Stocks Fall." http: //www.cnbc.com/id/100325110.

CNN. 2008. "Gun sales surge after Obama's election." http://edition.cnn.com/2008/ CRIME/11/11/obama.gun.sales/. 
CNN Money. 2012. "Obama's re-election drives gun sales." http://money.cnn.com/2012/ 11/09/news/economy/gun-control-obama/.

Cook, Philip. 1978. The effect of gun availability on robbery and robbery murder: a cross-section study of 50 cities. Center for the Study of Justice Policy, Institute of Policy Sciences and Public Affairs, Duke University.

Cook, Philip J and Jens Ludwig. 2006. "The social costs of gun ownership." Journal of Public Economics 90 (1):379-391.

Dahl, Gordon and Stefano DellaVigna. 2009. "Does movie violence increase violent crime?" Quarterly Journal of Economics 124 (2):677-734.

Depetris-Chauvin, Emilio. 2015. "Fear of Obama: An empirical study of the demand for guns and the US 2008 presidential election." Journal of Public Economics 130:66-79.

Duggan, Mark. 2001. "More Guns, More Crime." Journal of Political Economy 109 (5):1086-1114.

Duggan, Mark, Randi Hjalmarsson, and Brian A Jacob. 2011. "The short-term and localized effect of gun shows: Evidence from California and Texas." Review of Economics and Statistics 93 (3):786-799.

Durante, Ruben and Ekaterina Zhuravskaya. 2018. "Attack When the World Is Not Watching? US News and the Israeli-Palestinian Conflict." Journal of Political Economy 126 (3):1085-1133.

Edwards, Griffin Sims, Erik Nesson, Joshua J Robinson, and Fredrick E Vars. 2018. "Looking down the barrel of a loaded gun: The effect of mandatory handgun purchase delays on homicide and suicide." Economic Journal 128 (616):3117-3140.

Fabio, Anthony, Jessica Duell, Kathleen Creppage, Kerry O'Donnell, and Ron Laporte. 2016. "Gaps continue in firearm Surveillance: Evidence from a large US city Bureau of Police." Social Medicine 10 (1):13-21.

Federal Bureau of Investigation. 2016. "2016 Crime in the United States, Expanded Homicide Data Table 4." https://ucr.fbi.gov/crime-in-the-u.s/2016/crime-in-theu.s.-2016/tables/expanded-homicide-data-table-4.xls. 
Fowler, Katherine A, Linda L Dahlberg, Tadesse Haileyesus, and Joseph L Annest. 2015. "Firearm injuries in the United States." Preventive Medicine 79:5-14.

Giffords Law Center to Prevent Gun Violence. 2018. "Gun Laws by State." http: //lawcenter.giffords.org/search-gun-law-by-state/.

Heller, Sara B, Anuj K Shah, Jonathan Guryan, Jens Ludwig, Sendhil Mullainathan, and Harold A Pollack. 2017. "Thinking, fast and slow? Some field experiments to reduce crime and dropout in Chicago." Quarterly Journal of Economics 132 (1):1-54.

Hepburn, Lisa M and David Hemenway. 2004. "Firearm availability and homicide: A review of the literature." Aggression and Violent Behavior 9 (4):417-440.

Huffington Post. 2013. "Gun Sales Exploded In The Year After Newtown Shooting." http://www.huffingtonpost.com/2013/12/06/gun-sales-newtown_n_4394185.html.

International Business Times. 2012. "Romney So 'Shellshocked' By Election Loss He Didn't Write A Concession Speech." http://www.ibtimes.com/romney-soshellshocked-election-loss-he-didnt-write-concession-speech-866316.

Kalesan, Bindu, Marcos Villarreal, Katherine Keyes, and Sandro Galea. 2015. "Gun ownership and social gun culture." Injury Prevention 22 (3):216-220.

Kleck, Gary. 2004. "Measures of gun ownership levels for macro-level crime and violence research." Journal of Research in Crime and Delinquency 41 (1):3-36.

. 2015. "The impact of gun ownership rates on crime rates: A methodological review of the evidence." Journal of Criminal Justice 43 (1):40-48.

Klonsky, David E and Alexis Ml May. 2015. "Impulsivity and Suicide Risk: Review and Clinical Implications." Psychiatric Times 32 (8):13-21.

Kovandzic, Tomislav, Mark E Schaffer, and Gary Kleck. 2013. "Estimating the causal effect of gun prevalence on homicide rates: A local average treatment effect approach." Journal of Quantitative Criminology 29 (4):477-541.

Lang, Matthew. 2013. "Firearm Background Checks and Suicide." Economic Journal 123 (573):1085-1099. 
2016. "State Firearm Sales and Criminal Activity: Evidence from Firearm Background Checks." Southern Economic Journal 83 (1):45-68.

Law Center to Prevent Gun Violence. 2012a. "Licensing of Gun Owners \& Purchasers Policy Summary." https://web.archive.org/web/20120724070411/http: //smartgunlaws.org/licensing-of-gun-owners-purchasers-policy-summary/.

_. 2012b. "Licensing of Gun Owners \& Purchasers Policy Summary." https://web.archive.org/web/20120724070411/http://smartgunlaws.org/licensingof-gun-owners-purchasers-policy-summary/.

Levine, Phillip B. and Robin McKnight. 2017. "Firearms and accidental deaths: Evidence from the aftermath of the Sandy Hook school shooting." Science 358 (6368):1324-1328.

Luca, Michael, Deepak Malhotra, and Christopher Poliquin. 2017. "Handgun waiting periods reduce gun deaths." Proceedings of the National Academy of Sciences 114 (46):12162-12165.

Ludwig, Jens and Philip J Cook. 2000. "Homicide and Suicide Rates Associated With Implementation of the Brady Handgun Violence Prevention Act." Journal of the American Medical Association 284 (5):585-591.

Maltz, Michael D. and Joseph Targonski. 2002. "A Note on the Use of County-Level UCR Data." Journal of Quantitative Criminology 18 (3):297-318.

Miller, Matthew, Deborah Azrael, and David Hemenway. 2002. "Firearm availability and suicide, homicide, and unintentional firearm deaths among women." Journal of Urban Health 79 (1):26-38.

Miller, Matthew, David Hemenway, and Deborah Azrael. 2007. "State-level homicide victimization rates in the US in relation to survey measures of household firearm ownership, 2001-2003." Social Science \& Medicine 64 (3):656-664.

Miller, Matthew, Lisa Hepburn, and Deborah Azrael. 2017. "Firearm acquisition without background checks: results of a national survey." Annals of Internal Medicine $166(4): 233-239$. 
Moody, Carlisle E and Thomas B Marvell. 2005. "Guns and crime." Southern Economic Journal $71(4): 720-736$.

Mueller, David G and Ronald Frandsen. 2017. "Trends in firearm background check applications and denials." Journal of Public Affairs 17 (3):e1616.

New York Times. 2015. "What Happens After Calls for New Gun Restrictions? Sales Go Up." https://www.nytimes.com/interactive/2015/12/10/us/gun-sales-terrorismobama-restrictions.html.

New Yorker. 2014. "The reckoning." http://www.newyorker.com/magazine/2014/03/17/ the-reckoning.

NRA. 2018. "Institute for Legislative Action." https://www.nraila.org/.

Real Clear Politics. 2012. "Polls: General Election: Romney vs. Obama." https://www.realclearpolitics.com/epolls/2012/president/us/ general_election_romney_vs_obama-1171.html.

Rudolph, Kara E, Elizabeth A Stuart, Jon S Vernick, and Daniel W Webster. 2015. "Association between Connecticut's permit-to-purchase handgun law and homicides." American Journal of Public Health 105 (8):e49-e54.

Scott, Steven L. and Hal R. Varian. 2014. "Bayesian Variable Selection for Nowcasting Economic Time Series." In Economic Analysis of the Digital Economy, NBER Chapters. National Bureau of Economic Research, Inc, 119-135.

Siegel, Michael, Molly Pahn, Ziming Xuan, Craig S. Ross, Sandro Galea, Bindu Kalesan, Eric Fleegler, and Kristin A. Goss. 2017. "Firearm-Related Laws in All 50 US States, 1991-2016." American Journal of Public Health 107 (7):1122-1129.

Siegel, Michael, Craig S Ross, and Charles King. 2013. "The relationship between gun ownership and firearm homicide rates in the United States, 1981-2010." American Journal of Public Health 103 (11):2098-2105.

Silver, Nate. 2012. "When Internal Polls Mislead, a Whole Campaign May Be to Blame." https://fivethirtyeight.blogs.nytimes.com/2012/12/01/when-internalpolls-mislead-a-whole-campaign-may-be-to-blame/. 
Studdert, David M, Yifan Zhang, Jonathan A Rodden, Rob J Hyndman, and Garen J Wintemute. 2017. "Handgun acquisitions in California after two mass shootings." Annals of Internal Medicine 166 (10):698-706.

Tangney, June P, Roy F Baumeister, and Angie Luzio Boone. 2004. "High self-control predicts good adjustment, less pathology, better grades, and interpersonal success." Journal of Personality 72 (2):271-324.

Targonski, Joseph Robert. 2011. A comparison of imputation methodologies in the offenses-known Uniform Crime Reports. Ph.D. thesis, University of Illinois at Chicago.

The Intercept. 2015. "Gun Industry Executives Say Mass Shootings Are Good for Business." https://theintercept.com/2015/12/03/mass-shooting-wall-st/.

U.S. Department of Justice. 2005. "Survey of State Procedures Related to Firearm Sales, 2005." https://www.bjs.gov/content/pub/pdf/ssprfs05.pdf.

Vox. 2016. "What happens after a mass shooting? Americans buy more guns." http: //www.vox.com/2016/6/15/11936494/after-mass-shooting-americans-buy-more-guns.

Wolfers, Justin. 2006. "Did unilateral divorce laws raise divorce rates? A reconciliation and new results." American Economic Review 96 (5):1802-1820. 


\section{FOR ONLINE PUBLICATION}

\section{A Coding and Data Cleaning}

\section{A.1 Firearm Purchase Delays}

As already stated in the main text, there is substantial heterogeneity in firearm purchasing and sales restrictions imposed by the states. For example, many states invoke restrictions on the prerequisites and responsibilities of gun dealers, such as whether they require an additional state license to operate their business or whether they are supposed to keep centrally stored electronic records of transactions. Other legal restrictions concern buyers, as states can for instance decide if they want buyers to be able to purchase guns in bulk, if buyers need a permit prior to purchase, if they have to undergo background checks (for transactions exempted from federal background check requirements), or if buyers are required to wait a certain amount of time between purchasing and receiving their gun. Finally, there exists legislation concerned with restrictions on carrying firearms in public places, including schools and the workplace.

For this study, we are primarily interested in restrictions that delay the purchase of a handgun. These are mandatory waiting periods and firearm purchasing (or ownership) permits. Between November 2009 and October 2013, the period of our study, nine states and the District of Columbia had imposed mandatory waiting periods. California and D.C. require 10 days, Hawaii 14 days, Rhode Island 7 days and Illinois between 24 hours (long guns) to 72 hours (handguns) on all firearm purchases. Minnesota is the only state to require 7 days wait between purchase and pickup of handguns and assault rifles only. Maryland and New Jersey impose 7 days for handguns, while Florida and Iowa impose a 3 day waiting period for handguns. Wisconsin repealed its 48 hour waiting time on handguns in 2015.

Furthermore, some states require a license to possess or buy a firearm prior to the actual purchase, which due to bureaucratic hurdles can also impose a waiting time. In Connecticut, a handgun eligibility certificate may take up to 60 days before being issued. Before buying a gun in Hawaii, prospective gun owners have to obtain a permit to purchase which can take up to 20 days to be issued. Buyers in Illinois have to obtain a Firearm Owner's Identification card (FOID) before being allowed to purchase an unlimited number of firearms in the following ten years. Obtaining an FOID can take 
up to 30 days. The state of Maryland requires buyers to hold a Handgun Qualification License which will be issued or denied within 30 days of application. In Massachusetts, authorities may take up to 40 days to process a request for a license to carry or a Firearm Identification Card (FID), where the former allows unlimited purchases of any firearms without additional paperwork and the latter is restricted to rifles and shotguns. Nebraska requires potential buyers of handguns to be in possession of a handgun certificate or a concealed carry permit, which may take up to 2 days to be issued. The permit allows unlimited purchase of handguns in a 3 year period. Residents of New Jersey in turn must obtain a permit to purchase a handgun for each purchase separately, while they can purchase unlimited shotguns and rifles with a Firearms Purchaser Identification Card (FPIC). Authorities may take up to 30 days to issue such a permit. In New York, a license to possess or carry a handgun is necessary for each gun and obtaining one can take up to six months. In North Carolina, a license to purchase a handgun can take up to 30 days to be issued, and it is valid for one gun only.

Our starting point is the classification of the 50 U.S. states as having waiting periods or permit requirements for handgun sales between 2009 to 2013 according to Siegel et al. (2017). We then complement this data with information on the District of Columbia and actual delay length using Cherney, Moral, and Schell (2018). Finally, we cross-check the data with classifications provided by Law Center to Prevent Gun Violence (2012a,b). Any conflicting categorizations across the three sources are then resolved by looking up the precise wording of the respective law. The final classification is summarized in Table 10 . 
TABle 10: Sources USED FOR DETERMINING DELAY LAWS DURING THE SAMPLE PERIOD

\begin{tabular}{|c|c|c|c|c|}
\hline State & $\begin{array}{l}\text { Waiting } \\
\text { Period }\end{array}$ & Source & $\begin{array}{l}\text { Permit } \\
\text { Delay }\end{array}$ & Source \\
\hline$\overline{\mathrm{AL}}$ & $\overline{0}$ & SFL (2017) & $\overline{0}$ & SFL (2017) \\
\hline AK & 0 & SFL (2017) & 0 & SFL (2017) \\
\hline $\mathrm{AZ}$ & 0 & SFL (2017) & 0 & SFL (2017) \\
\hline $\mathrm{AR}$ & 0 & SFL (2017) & 0 & SFL (2017) \\
\hline $\mathrm{CA}$ & 10 & SFL (2017), RAND (2018) & 0 & SFL (2017), RAND (2018) \\
\hline $\mathrm{CO}$ & 0 & SFL (2017) & 0 & SFL (2017) \\
\hline $\mathrm{CT}$ & 0 & SFL (2017) & 60 & SFL (2017), RAND (2018) \\
\hline $\mathrm{DC}$ & 10 & RAND (2018) & 0 & RAND (2018) \\
\hline $\mathrm{DE}$ & 0 & SFL (2017) & 0 & SFL (2017) \\
\hline FL & 3 & RAND (2018) & 0 & SFL (2017) \\
\hline GA & 0 & SFL (2017) & 0 & SFL (2017) \\
\hline $\mathrm{HI}$ & 14 & SFL (2017), RAND (2018) & 20 & SFL (2017), RAND (2018) \\
\hline ID & 0 & SFL (2017) & 0 & SFL (2017) \\
\hline IL & 3 & SFL (2017), RAND (2018) & 30 & SFL (2017), * \\
\hline IN & 0 & SFL (2017) & 0 & SFL (2017) \\
\hline IA & 3 & RAND (2018) & 0 & RAND (2018) \\
\hline KS & 0 & SFL (2017) & 0 & SFL (2017) \\
\hline KY & 0 & SFL (2017) & 0 & SFL (2017) \\
\hline LA & 0 & SFL (2017) & 0 & SFL (2017) \\
\hline $\mathrm{ME}$ & 0 & SFL (2017) & 0 & SFL (2017) \\
\hline MD & 7 & SFL (2017), RAND (2018) & 30 & SFL (2017), BJS (2005) \\
\hline MA & 0 & SFL (2017) & 40 & SFL $(2017),{ }^{\dagger}$ \\
\hline MI & 0 & SFL (2017) & 5 & SFL (2017), BJS (2005) \\
\hline $\mathrm{MN}$ & 7 & SFL (2017), RAND (2018) & 0 & RAND (2018) \\
\hline MS & 0 & SFL (2017) & 0 & SFL (2017) \\
\hline $\mathrm{MO}$ & 0 & SFL (2017) & 0 & SFL (2017) \\
\hline MT & 0 & SFL (2017) & 0 & SFL (2017) \\
\hline $\mathrm{NE}$ & 0 & SFL (2017) & 2 & SFL (2017), RAND (2018) \\
\hline NV & 0 & SFL (2017) & 0 & SFL (2017) \\
\hline $\mathrm{NH}$ & 0 & SFL (2017) & 0 & SFL (2017) \\
\hline NJ & 7 & SFL $(2017),{ }^{\ddagger}$ & 30 & SFL (2017), RAND (2018) \\
\hline NM & 0 & SFL (2017) & 0 & SFL (2017) \\
\hline NY & 0 & SFL (2017) & 180 & SFL (2017), RAND (2018) \\
\hline $\mathrm{NC}$ & 0 & SFL (2017) & 30 & SFL (2017), RAND (2018), $§$ \\
\hline ND & 0 & SFL (2017) & 0 & SFL (2017) \\
\hline $\mathrm{OH}$ & 0 & SFL (2017) & 0 & SFL (2017) \\
\hline OK & 0 & SFL (2017) & 0 & SFL (2017) \\
\hline OR & 0 & SFL (2017) & 0 & SFL (2017) \\
\hline $\mathrm{PA}$ & 0 & SFL (2017), ๆ & 0 & SFL (2017) \\
\hline $\mathrm{RI}$ & 7 & SFL (2017), RAND (2018) & 0 & SFL (2017), RAND (2018) \\
\hline $\mathrm{SC}$ & 0 & SFL (2017) & 0 & SFL (2017) \\
\hline SD & 0 & SFL (2017) & 0 & SFL (2017) \\
\hline $\mathrm{TN}$ & 0 & SFL (2017) & 0 & SFL (2017) \\
\hline TX & 0 & SFL (2017) & 0 & SFL (2017) \\
\hline $\mathrm{UT}$ & 0 & SFL (2017) & 0 & SFL (2017) \\
\hline VT & 0 & SFL (2017) & 0 & SFL (2017) \\
\hline VA & 0 & SFL (2017) & 0 & SFL (2017) \\
\hline WA & 0 & SFL (2017) & 0 & SFL (2017) \\
\hline WV & 0 & SFL (2017) & 0 & SFL (2017) \\
\hline WI & 2 & SFL (2017), RAND (2018) & 0 & SFL (2017) \\
\hline WY & 0 & SFL (2017) & 0 & SFL (2017) \\
\hline
\end{tabular}

SFL $(2017)=$ Siegel et al. $(2017)$

RAND (2018)=Cherney, Moral, and Schell (2018)

BJS $(2005)=$ U.S. Department of Justice $(2005)$

*=http://www.ilga.gov/legislation/ilcs/ilcs3.asp?ActID=1657

$\dagger=$ https://malegislature.gov/Laws/GeneralLaws/PartI/TitleXX/Chapter140/

Section 131

$\ddagger=$ https://law.justia.com/codes/new-jersey/2009/title-2c/2c-58/2c-58-2/

$\S=$ https://www.ncleg.gov/enactedlegislation/sessionlaws/html/2013-2014/sl2013-

369.html

I=https: //www.psp.pa.gov/firearms-information/Pages/Pennsylvania-Instant-

Checks-System---PICS.aspx 


\section{A.2 Cleaning Procedure for NICS Data}

To remove as many inaccuracies and problematic observations from the NICS sample as possible, we apply the following approach. First, we discard Hawaii, Illinois and Massachusetts, where permit checks also include those for long guns. In order to remove outliers, we drop Kentucky, Pennsylvania and Utah, as well as parts of the series for Iowa, Maryland and Wisconsin from the sample. Kentucky performs monthly rechecks of existing permit holders, artificially inflating the data (Lang, 2013, 2016). Pennsylvania did not record a single handgun sale background check from November 2009 until August 2012. Utah performed quarterly rechecks of existing permit holders in 2011 leading to strong spikes in background checks from January 2010 to August $2011 .{ }^{28}$ Iowa changed their gun laws in 2011, removing a requirement for demonstrating firearm proficiency before a firearm could be acquired. This led to unusual background check jumps between November 2010 and June 2011. Maryland changed its gun laws with respect to licensing in 2013, leading to a massive background check increase in September and October 2013 (New York Times, 2015). Finally, Wisconsin passed a concealed-carry bill in 2011 leading to a jump in background checks from November 2011 to May 2012. ${ }^{29}$

\footnotetext{
${ }^{28}$ Our implicit rule was to drop an entire state series if outliers covered at least 12 consecutive months between November 2009 and October 2013.

${ }^{29}$ In Appendix A.3 we plot the temporal variation in handgun sale and permit NICS background checks for each state separately and specifically highlight the data irregularities for these states.
} 


\section{A.3 NICS Background Checks per State}
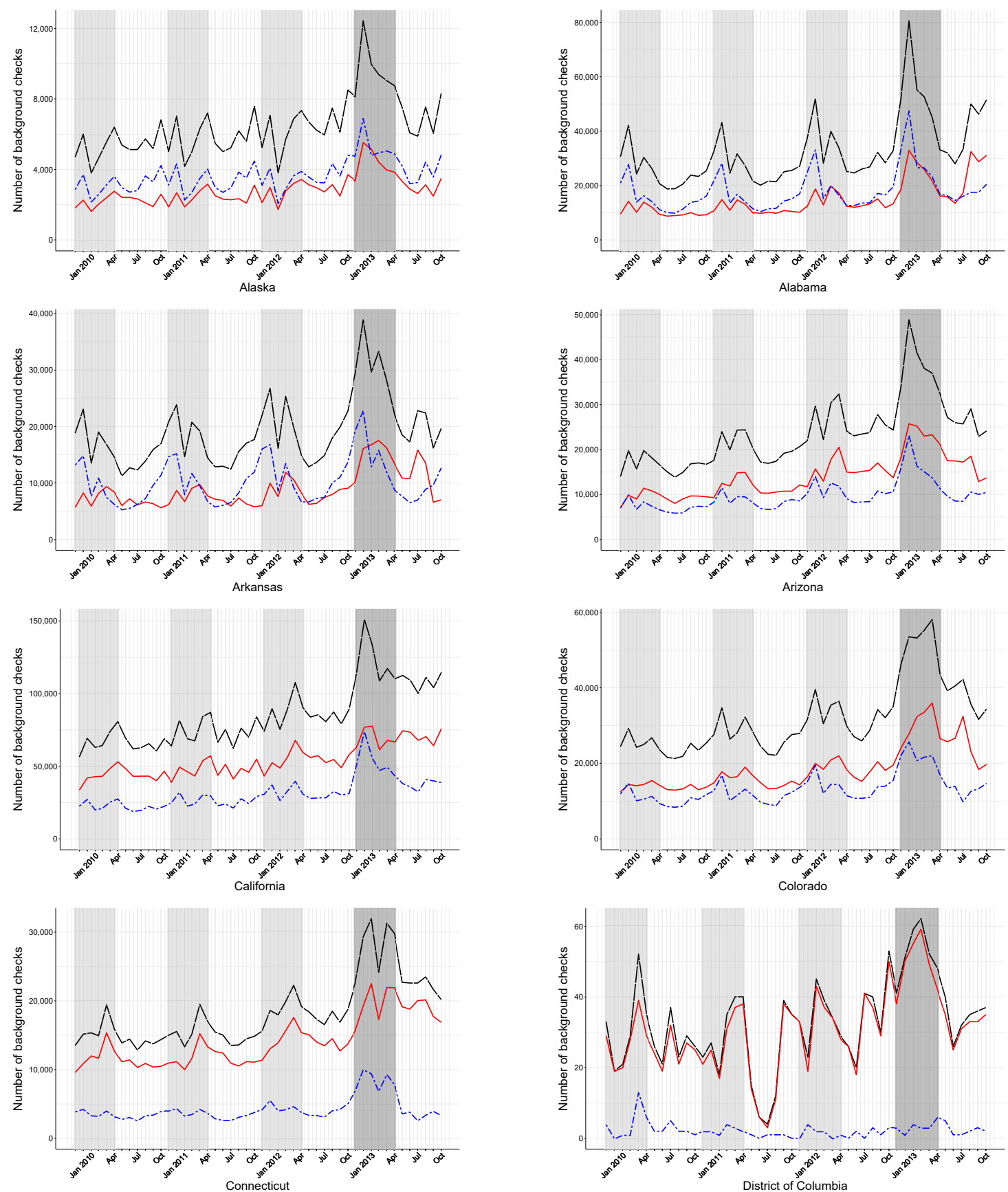

Figure 7: Monthly NICS BaCkground CheCKS, AL to DC

Monthly state-wise NICS background checks plotted over time between November 2009 and October 2013 in absolute numbers. The red line shows background check for handguns, the blue line displays non-handgun checks, and the black line equals the sum of the two. The dark grey-shaded area includes the first six months after the 2012 election, i.e. November 2012 to April 2013. Light grey-shaded areas are marking the same period for preceding years. Series of states removed from the NICS data as well as outlier dates are highlighted in yellow. 

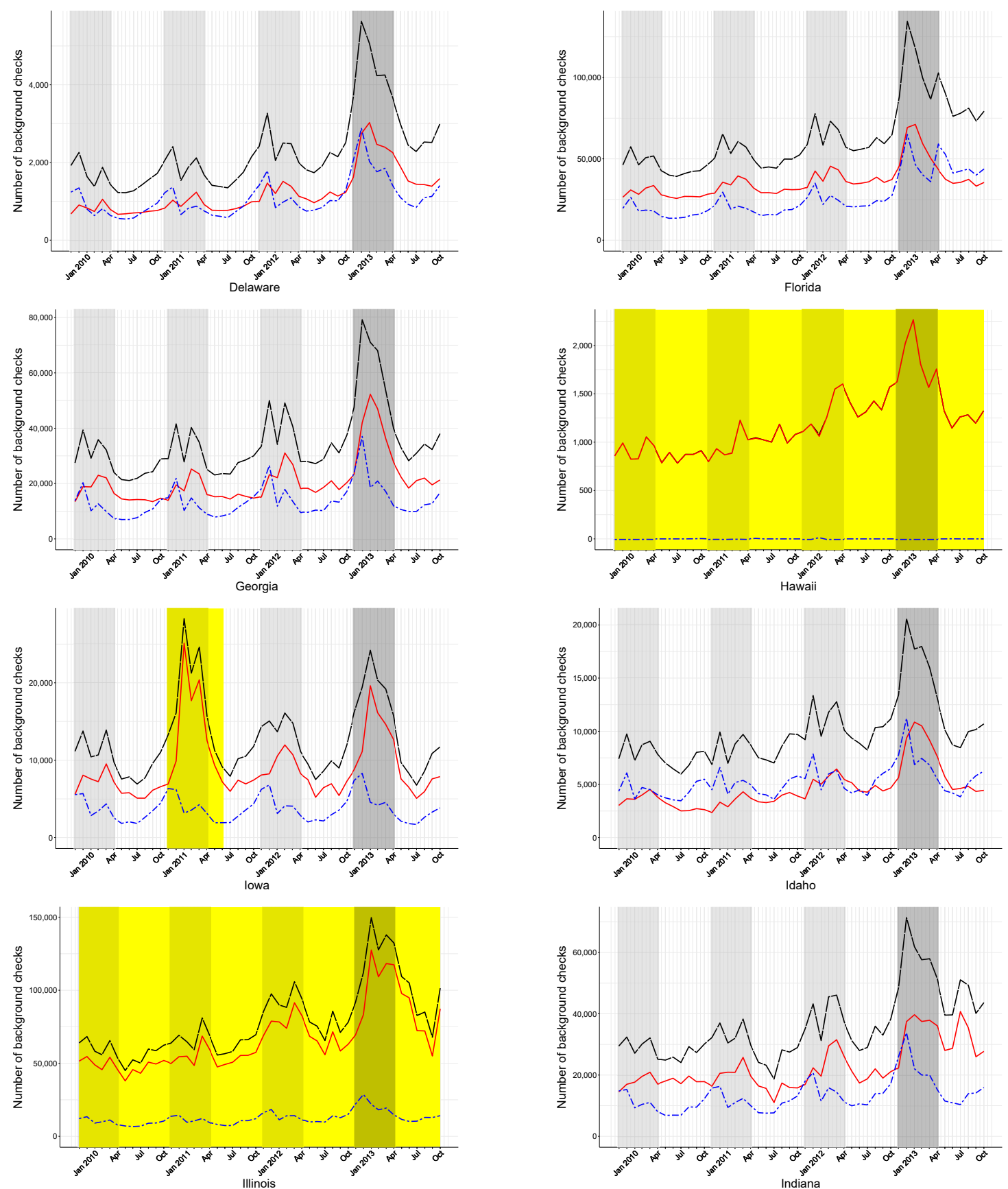

Figure 8: Monthly NICS BACKGround CheCKs, DE to IN

Monthly state-wise NICS background checks plotted over time between November 2009 and October 2013 in absolute numbers. The red line shows background check for handguns, the blue line displays non-handgun checks, and the black line equals the sum of the two. The dark grey-shaded area includes the first six months after the 2012 election, i.e. November 2012 to April 2013. Light grey-shaded areas are marking the same period for preceding years. Series of states removed from the NICS data as well as outlier dates are highlighted in yellow. 

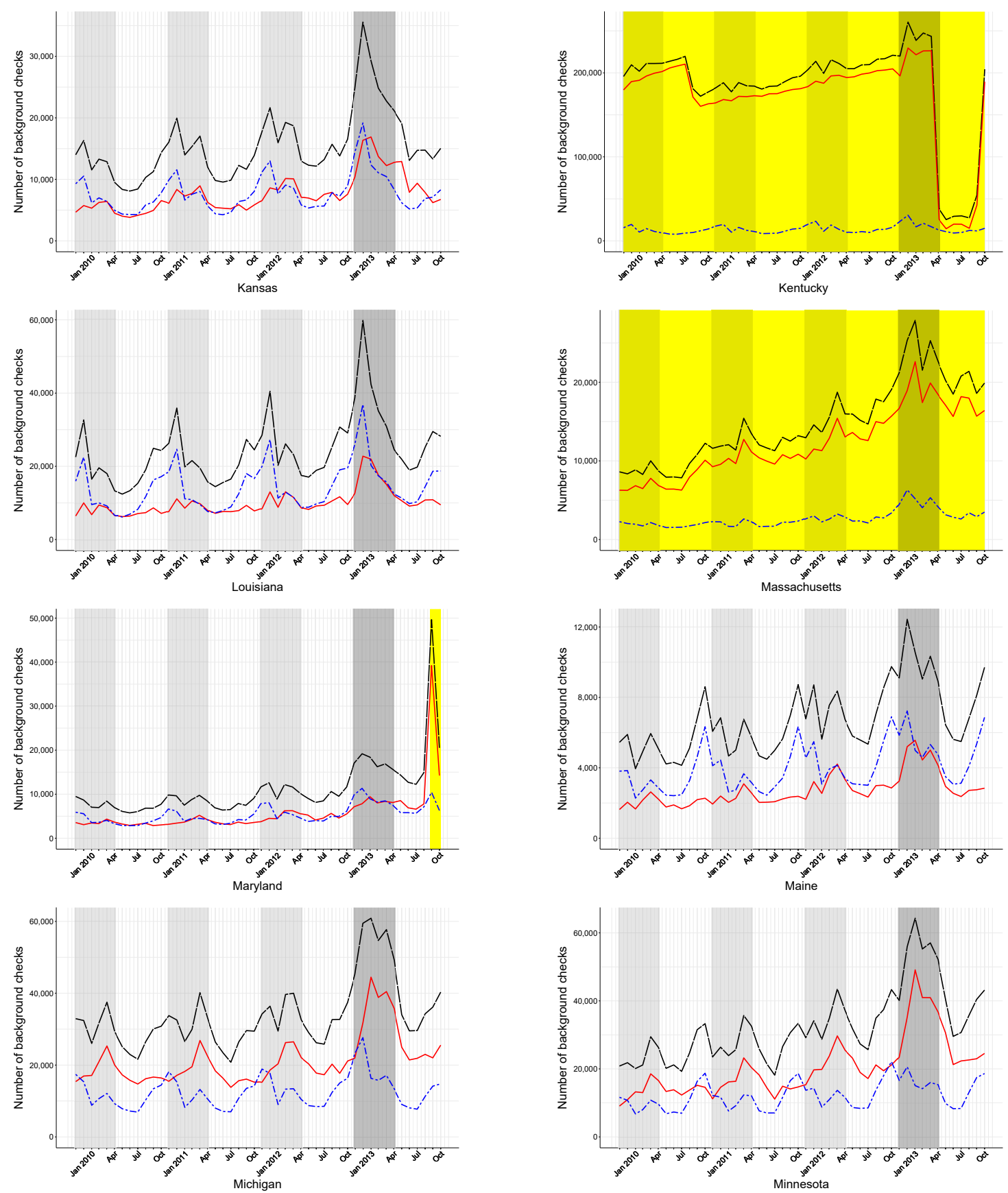

Figure 9: Monthly NICS BACKGround CheCKS, KS TO MN

Monthly state-wise NICS background checks plotted over time between November 2009 and October 2013 in absolute numbers. The red line shows background check for handguns, the blue line displays non-handgun checks, and the black line equals the sum of the two. The dark grey-shaded area includes the first six months after the 2012 election, i.e. November 2012 to April 2013. Light grey-shaded areas are marking the same period for preceding years. Series of states removed from the NICS data as well as outlier dates are highlighted in yellow. 

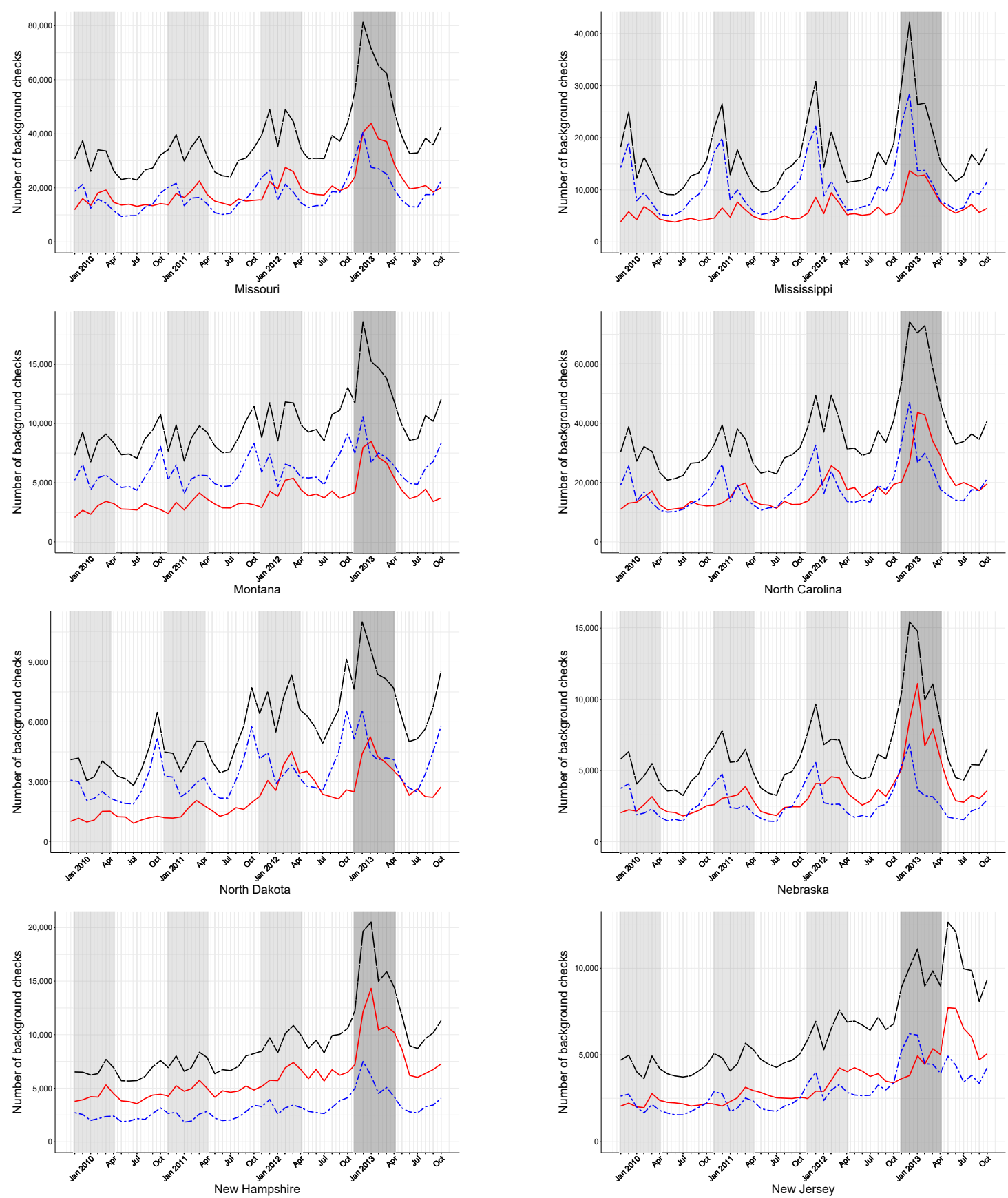

Figure 10: Monthly NICS BACKGRound CheCKS, MO TO NJ

Monthly state-wise NICS background checks plotted over time between November 2009 and October 2013 in absolute numbers. The red line shows background check for handguns, the blue line displays non-handgun checks, and the black line equals the sum of the two. The dark grey-shaded area includes the first six months after the 2012 election, i.e. November 2012 to April 2013. Light grey-shaded areas are marking the same period for preceding years. Series of states removed from the NICS data as well as outlier dates are highlighted in yellow. 

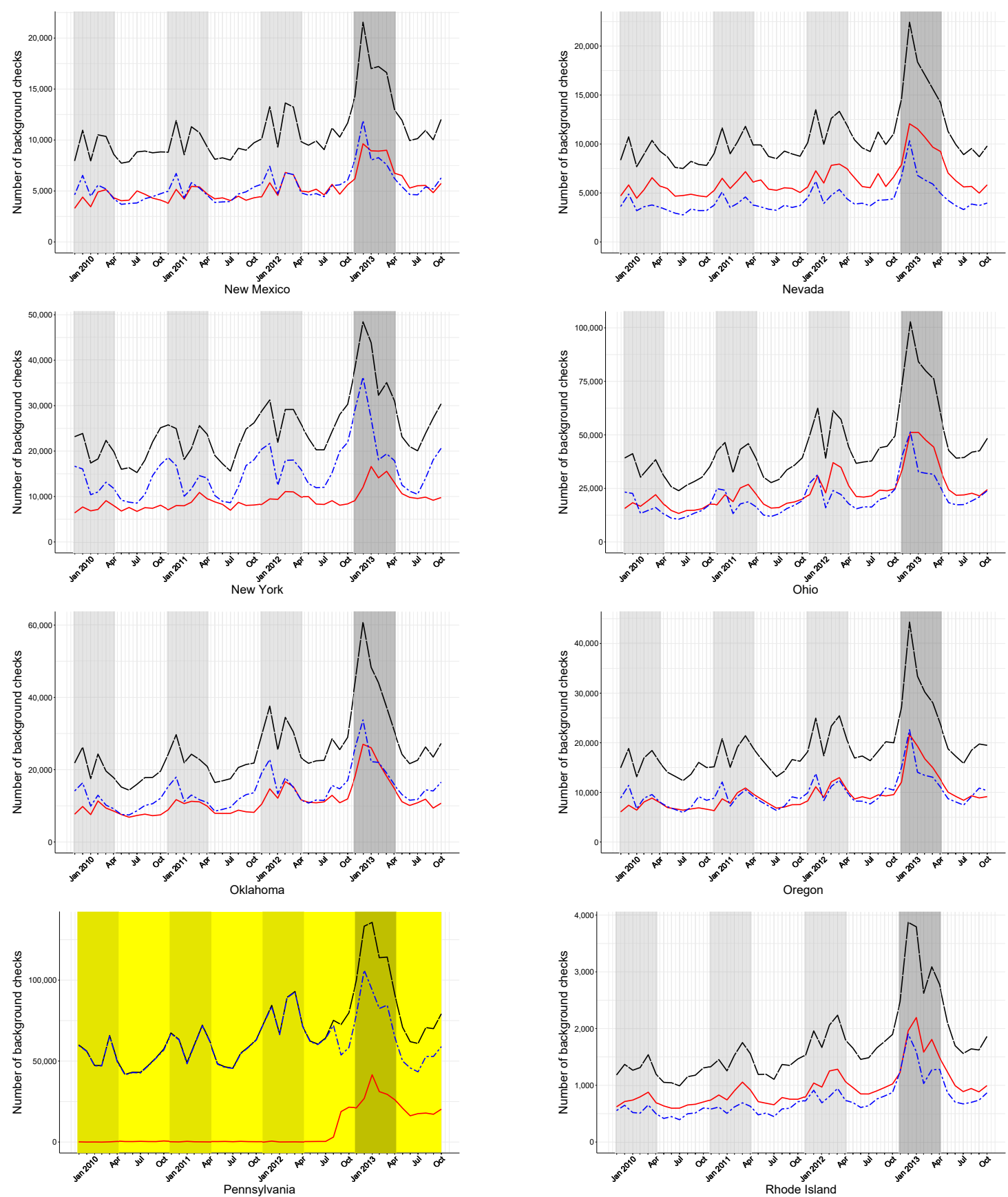

Figure 11: Monthly NICS BACKGround CheCKs, NM to RI

Monthly state-wise NICS background checks plotted over time between November 2009 and October 2013 in absolute numbers. The red line shows background check for handguns, the blue line displays non-handgun checks, and the black line equals the sum of the two. The dark grey-shaded area includes the first six months after the 2012 election, i.e. November 2012 to April 2013. Light grey-shaded areas are marking the same period for preceding years. Series of states removed from the NICS data as well as outlier dates are highlighted in yellow. 

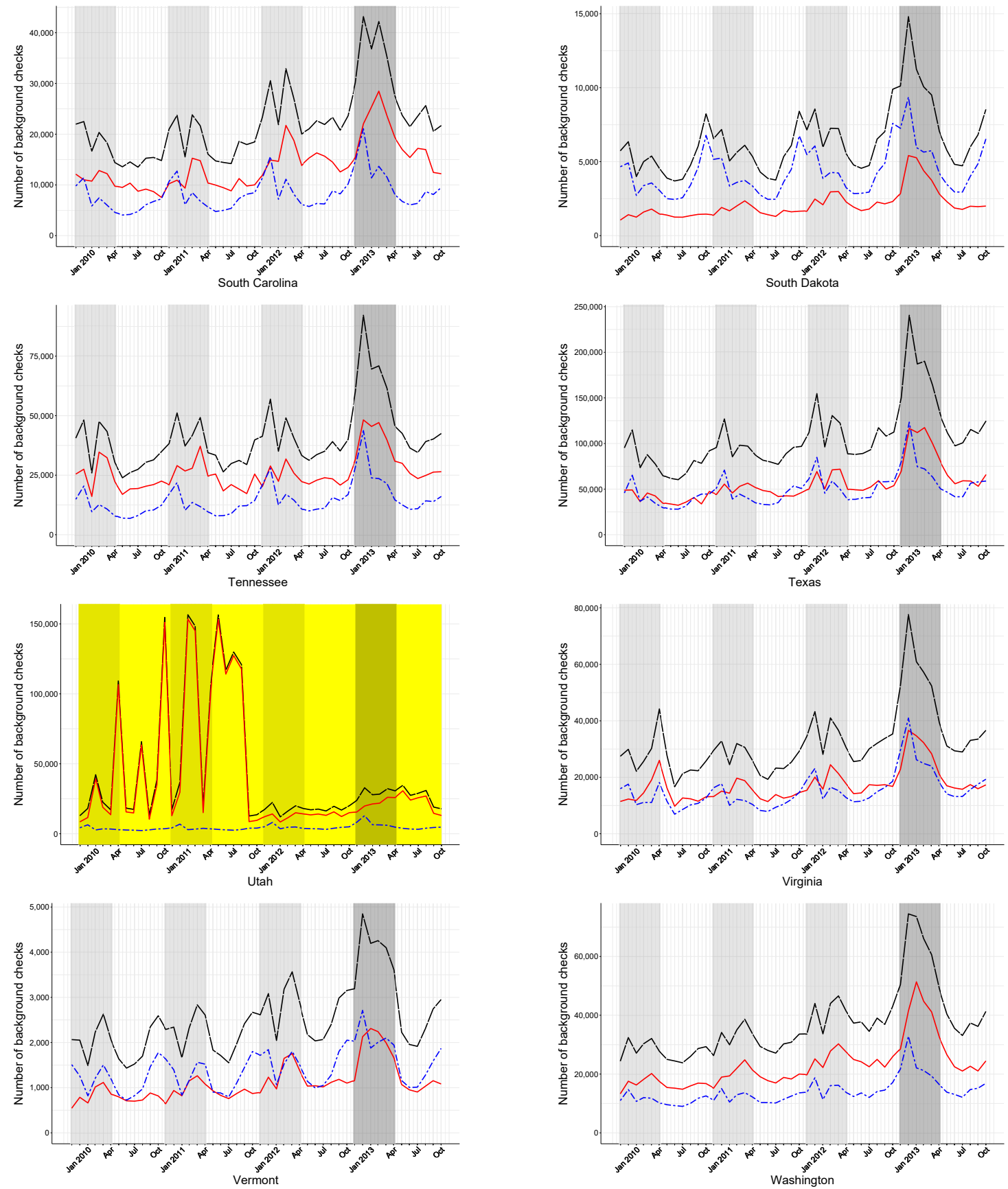

Figure 12: Monthly NICS BaCkground CheCks, SC to WA

Monthly state-wise NICS background checks plotted over time between November 2009 and October 2013 in absolute numbers. The red line shows background check for handguns, the blue line displays non-handgun checks, and the black line equals the sum of the two. The dark grey-shaded area includes the first six months after the 2012 election, i.e. November 2012 to April 2013. Light grey-shaded areas are marking the same period for preceding years. Series of states removed from the NICS data as well as outlier dates are highlighted in yellow. 

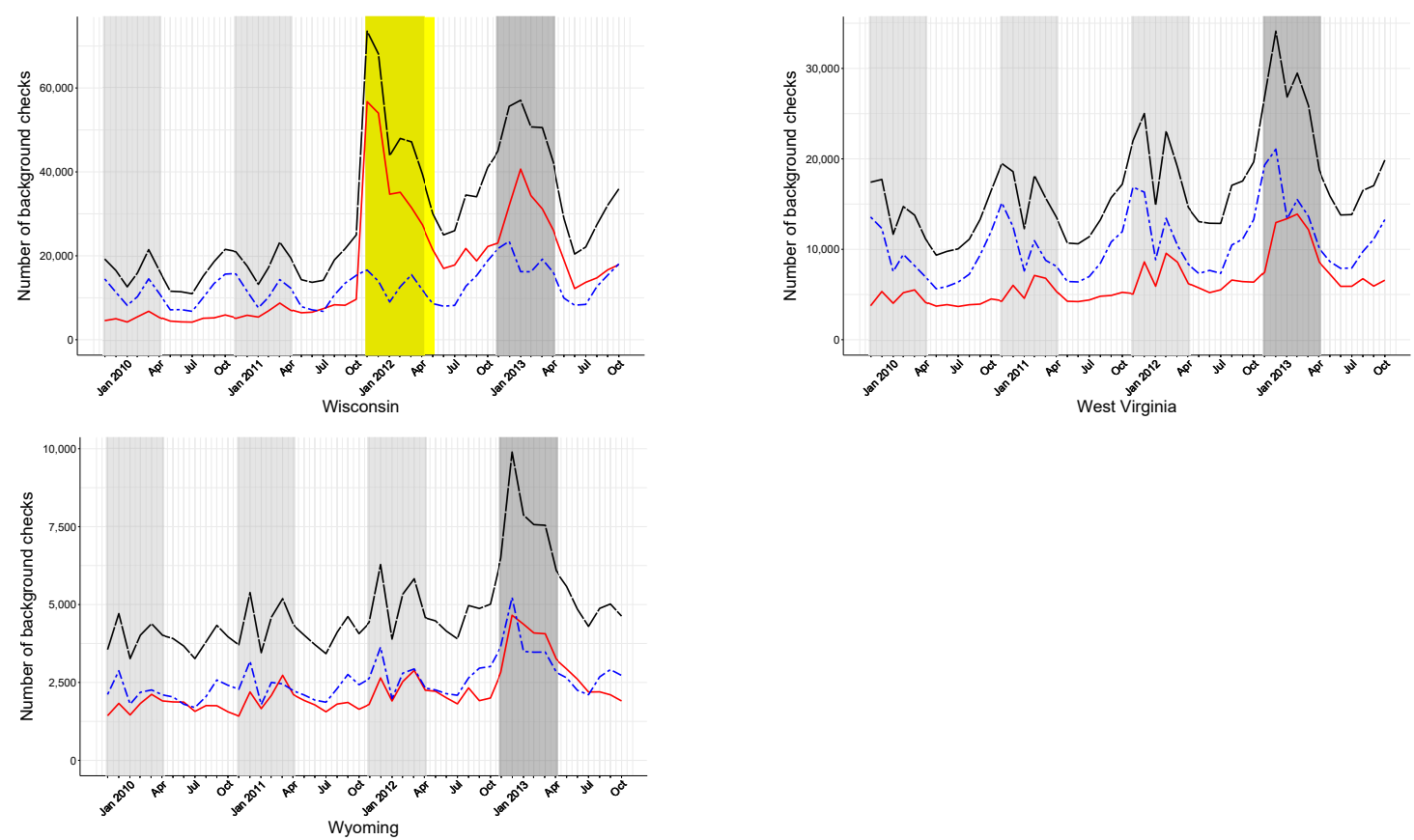

Figure 13: Monthly NICS BaCkground CheCKs, WI to WY

Monthly state-wise NICS background checks plotted over time between November 2009 and October 2013 in absolute numbers. The red line shows background check for handguns, the blue line displays non-handgun checks, and the black line equals the sum of the two. The dark grey-shaded area includes the first six months after the 2012 election, i.e. November 2012 to April 2013. Light grey-shaded areas are marking the same period for preceding years. Series of states removed from the NICS data as well as outlier dates are highlighted in yellow. 


\section{A.4 Cleaning Procedure for UCR Data}

The UCR crime data suffers from inconsistent reporting by some participating agencies. Common reporting mistakes include large negative absolute values for crimes, or continuously reporting zero crimes. These obvious problems of the UCR data have led some scholars to conclude that the data should not be used in empirical analysis (Maltz and Targonski, 2002). We take a more pragmatic approach and use the UCR data only in supplementary analyses after applying the following data cleaning guidelines set out in Targonski (2011).

First, we determine truly missing data points. An entry of zero could either mean that no crimes occurred, or that the agency was not reporting any crimes. An additional reporting variable however indirectly indicates, whether data was submitted. If no data was submitted, this reporting variable will have missing values for that specific date. We thus exclude all observations showing zero crimes, where the additional reporting variable contains missing values. Second, there are some obvious cases of data bunching, as there exist agencies that report their data only quarterly or (semi)annually, but no data in the months between. We identify those observations using an algorithm designed by Targonski and we also exclude them from the analysis. ${ }^{30}$ Third, some smaller agencies choose to not report crimes themselves, but through another agency. In that case, they show up as reporting zeroes, although their counts are reflected in the data of the reporting agency. We drop those observations. Fourth, we apply the rule of 20 to identify wrongly reported zero crimes. Whenever an agency reports on average 20 or more crimes per month, it seems unlikely they experienced zero crime in any given month. Such data points are also excluded from our analysis. Fifth, we delete all observations with outlier values 999, 9999 and 99999 from the sample. Sixth, we remove all data containing negative values smaller than $-3 .{ }^{31}$

In addition to the cleaning procedure above, we drop data from all counties which do not report consistently over the full sample period and report zero crimes throughout. In order to ensure sufficient coverage and representativeness we also drop counties if the consistently reporting agencies cover less than $50 \%$ of the county's population in 2010.

\footnotetext{
${ }^{30}$ The algorithm is not part of Targonski (2011) but we received instructions and rules for the algorithm from Joe Targonski in a personal email exchange. The algorithm basically identifies any county (with absolute annual crime reports above 10) that report crimes only in March, June, September and December (or a subset of those for (semi-)annually reporters), and zero crimes in all other months.

${ }^{31}$ In line with Targonski (2011) we ignore small negative values of at least -3 . Those are usually corrections for misreporting in previous months.
} 


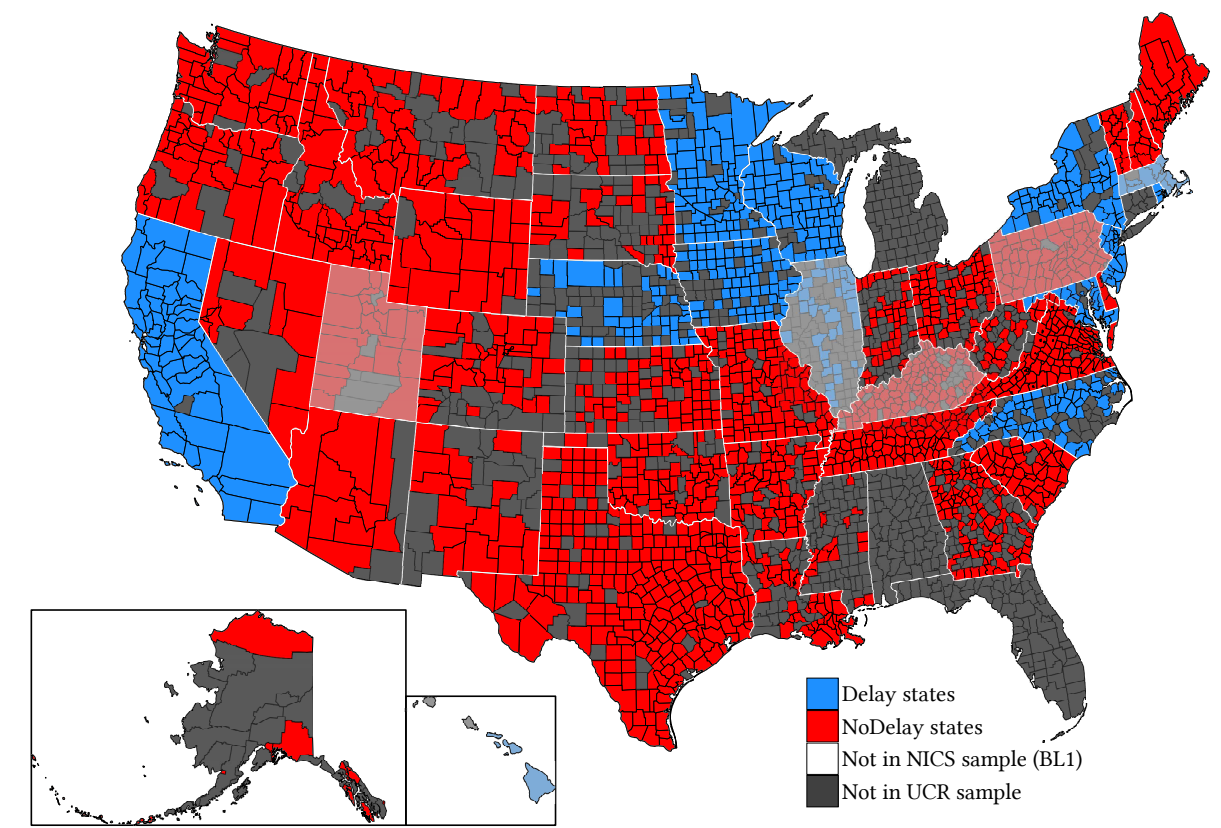

Figure 14: States And Counties RePresented in the NICS AND UCR SAMPLeS

Map of the United States showing the states contained in the NICS background check data and counties contained in the cleaned UCR crime data. Red counties are located in NoDelay states. Blue counties are located in Delay states. Shaded states are dropped in their entirety from the NICS sample. Dark grey counties are not present in the UCR sample. Note that the NVSS sample covers all counties in all states apart from Michigan and Connecticut.

\section{A.5 Data Construction of Google Search Volume}

Google search data is not available at an absolute level and always scaled on a 0-100 interval with respect to the maximum volume within the specified time and geographic area. In order to circumvent this issue, we first queried relative searches for a given expression like "gun store" across U.S. states from 01/01/2008 until 31/12/2016 and divided the numbers by 100 to construct a pseudo-ranking of states. Next, we obtained the relative monthly search volume for each state individually over the same time period and divided again by 100. Multiplying the results from these two stages already offers a coherent monthly state-panel for the relative search volume from 2008 until the end of 2016. In order to zoom further into the monthly variation, we then queried the relative daily search volume for each state in 3 month intervals, re-scaled each month to a 0-100 interval and finally multiplied each month's daily volumes with the state-month weights constructed before. Finally, we aggregated each state's series by week in order to reduce noise. 


\section{B Additional Analyses}

\section{B.1 Robustness and Sensitivity of Firearm Purchase Results}

This section reports and discusses additional robustness and sensitivity checks for the gun sale results in Section 5.1. In Table 11, we assess remaining concerns about seasonality by running placebo regressions shifting both sample and treatment period several years backward. Overall, the placebo regressions do not produce any significant results. There appears to be a similar effect of even higher magnitude for the period after the first Obama election in 2008 which is, however, far from statistical significance at conventional levels.

In Table 12 we show how results would change for other plausible sample definitions. Specifications 3 to 6 add the two states omitted from the baseline sample for other reasons than outliers - Connecticut and Michigan. The coefficients remain stable. In columns 7 and 8 , we drop all states which featured at least one outlier value during our baseline sample and obtain qualitatively similar results. Finally, columns 9 and 10 use the baseline sample definition of our homicide results which effectively adds all NICS outlier values to the regression. While the estimates still have the expected sign, they become very noisy and uninformative since we incorporate states with significant measurement error in the outcome variable.

Figure 15 explores the sensitivity of our baseline findings with respect to the exclusion of specific states. While showing rather similar coefficients throughout, the results seem sensitive to the inclusion of Texas. The same analysis for the Delay $\times$ Post $2_{t}$ coefficient in Figure 16, however, reveals that the exclusion of Texas did not reduce the effect but shifted it partly into the Post2 period. As argued in Section 3, the NICS data is prone to substantial measurement error which can also happen temporally due to delays in permit processing times. Excluding the most populous state in the control group may thus have shifted the weights of the regression towards states suffering more from this type of mis-measurement. In line with this argument, we do not observe such attenuation in our gun homicide results in Figure 17, where measurement error of the above kind can be ruled out.

Table 13 shows results when using the outcome variable in levels and/or applying a within-transformation instead of seasonal differencing to account for time-invariant heterogeneity. In virtually all specifications, our coefficient of interest remains highly 
significant. The only exception is when using logs in a standard within transformation which seems to be doing a worse job than others at accounting for trends in the data. Once these are included, the main coefficient turns significant and rises to a similar magnitude as in the baseline specification.

Finally, Table 14 explores weighting by adult instead of total population or no weighting at all. Adult population weights in specifications 3 and 4 leave the coefficients almost unchanged. Using no weights, however, renders our main coefficient insignificant. This shows that our effect is driven by more populated states. 
TABle 11: HandGun BACKGround CheCKS (Placebo REgressions)

\begin{tabular}{|c|c|c|c|c|c|c|c|c|}
\hline & \multicolumn{8}{|c|}{$\Delta_{12} \log$ of handgun background checks per 100,000 inhabitants } \\
\hline & \multicolumn{2}{|c|}{ Baseline (2010-2013) } & \multicolumn{2}{|c|}{-1 Year (2009-2012) } & \multicolumn{2}{|c|}{-2 Years (2008-2011) } & \multicolumn{2}{|c|}{ Obama I (2006-2009) } \\
\hline & (1) & $(2)$ & $(3)$ & (4) & $(5)$ & (6) & $(7)$ & $(8)$ \\
\hline \multirow[t]{2}{*}{ Delay $\times$ Post1 } & $-0.081^{*}$ & $-0.073^{* *}$ & -0.001 & 0.025 & -0.007 & 0.052 & -0.174 & -0.164 \\
\hline & $(0.044)$ & $(0.033)$ & $(0.029)$ & $(0.046)$ & $(0.020)$ & $(0.038)$ & $(0.119)$ & $(0.129)$ \\
\hline \multirow{2}{*}{ Delay $\times$ Post 2} & 0.010 & 0.007 & 0.033 & 0.050 & -0.003 & 0.054 & -0.030 & -0.020 \\
\hline & $(0.064)$ & $(0.084)$ & $(0.054)$ & $(0.067)$ & $(0.055)$ & $(0.062)$ & $(0.057)$ & $(0.071)$ \\
\hline Year-Month FE & $\mathrm{Y}$ & $\mathrm{Y}$ & $\mathrm{Y}$ & $\mathrm{Y}$ & $\mathrm{Y}$ & $\mathrm{Y}$ & $\mathrm{Y}$ & $\mathrm{Y}$ \\
\hline Controls & $\mathrm{Y}$ & $\mathrm{Y}$ & $\mathrm{Y}$ & $\mathrm{Y}$ & $\mathrm{Y}$ & $\mathrm{Y}$ & $\mathrm{Y}$ & $\mathrm{Y}$ \\
\hline State Trends & $\mathrm{N}$ & $\mathrm{Y}$ & $\mathrm{N}$ & Y & $\mathrm{N}$ & $\mathrm{Y}$ & $\mathrm{N}$ & Y \\
\hline States & 43 & 43 & 43 & 43 & 43 & 43 & 43 & 43 \\
\hline Observations & 1,516 & 1,516 & 1,525 & 1,525 & 1,540 & 1,540 & 1,548 & 1,548 \\
\hline $\mathrm{R}^{2}$ & 0.539 & 0.594 & 0.545 & 0.582 & 0.565 & 0.626 & 0.449 & 0.497 \\
\hline
\end{tabular}

Notes: Observations are at the state-month-level. The sample period is November $x-2$ until October $x+1$, i.e. an asymmetric 36-month window 2 years before and 1 year after November of the year used as the event $(x)$. Where no seasonal differencing is applied, the nominal sample period starts in November 2009. Standard errors clustered at the state-level are in parentheses: ${ }^{*} \mathrm{p}<0.1 ;{ }^{* *} \mathrm{p}<0.05 ;{ }^{* *} \mathrm{p}<0.01$. Included control variables are $\log$ (population), \% rural, \% below poverty line, \% blacks and \% hispanics. All variables are as of 2010 and interacted with Month FE. Regressions are weighted by the state population.

TABle 12: Handgun BaCkground Checks (VARYing the SAMPle)

\begin{tabular}{|c|c|c|c|c|c|c|c|c|c|c|}
\hline \multirow[b]{4}{*}{ Delay $\times$ Post1 } & \multicolumn{10}{|c|}{$\Delta_{12}$ Log of handgun sale background checks per 100,000 inhabitants } \\
\hline & \multicolumn{2}{|c|}{$\begin{array}{c}\text { NICS data } \\
\text { w/o outliers } \\
\text { - CT\&MI (=BL1) }\end{array}$} & \multicolumn{2}{|c|}{$\mathrm{BL} 1+\mathrm{CT}$} & \multicolumn{2}{|c|}{$\begin{array}{c}\text { BL1 + MI w/ } \\
\text { law change }\end{array}$} & \multicolumn{2}{|c|}{$\begin{array}{c}\text { BL1 - states } \\
\text { w/ NICS } \\
\text { outliers }\end{array}$} & \multicolumn{2}{|c|}{$\begin{array}{c}\text { Full NICS data } \\
\text { - CT\&MI } \\
(=\text { BL2) }\end{array}$} \\
\hline & $(1)$ & $(2)$ & $(3)$ & (4) & $(5)$ & $(6)$ & (7) & (8) & (9) & (10) \\
\hline & $-0.081^{*}$ & $-0.073^{* *}$ & $-0.083^{*}$ & $-0.072^{* *}$ & $-0.084^{*}$ & $-0.081^{* *}$ & -0.079 & $-0.066^{* *}$ & * -0.779 & -0.790 \\
\hline & $(0.044)$ & $(0.033)$ & $(0.043)$ & $(0.032)$ & $(0.043)$ & $(0.033)$ & $(0.048)$ & $(0.034)$ & $(0.542)$ & $(0.521)$ \\
\hline \multirow[t]{2}{*}{ Delay $\times$ Post2 } & 0.010 & 0.007 & 0.014 & 0.013 & -0.000 & -0.010 & 0.046 & 0.058 & -0.375 & -0.386 \\
\hline & $(0.064)$ & $(0.084)$ & $(0.064)$ & $(0.083)$ & $(0.065)$ & $(0.085)$ & $(0.058)$ & $(0.070)$ & $(0.310)$ & $(0.290)$ \\
\hline Year-Month FE & $\mathrm{Y}$ & $\mathrm{Y}$ & Y & Y & $\mathrm{Y}$ & Y & Y & $\mathrm{Y}$ & $\mathrm{Y}$ & $\mathrm{Y}$ \\
\hline Controls & $\mathrm{Y}$ & $\mathrm{Y}$ & $\mathrm{Y}$ & $\mathrm{Y}$ & $\mathrm{Y}$ & $\mathrm{Y}$ & $\mathrm{Y}$ & Y & $\mathrm{Y}$ & $\mathrm{Y}$ \\
\hline State Trends & $\mathrm{N}$ & $\mathrm{Y}$ & $\mathrm{N}$ & $\mathrm{Y}$ & $\mathrm{N}$ & $\mathrm{Y}$ & $\mathrm{N}$ & $\mathrm{Y}$ & $\mathrm{N}$ & Y \\
\hline States & 43 & 43 & 44 & 44 & 44 & 44 & 40 & 40 & 49 & 49 \\
\hline Observations & 1,516 & 1,516 & 1,552 & 1,552 & 1,552 & 1,552 & 1,440 & 1,440 & 1,764 & 1,764 \\
\hline $\mathrm{R}^{2}$ & 0.539 & 0.594 & 0.535 & 0.591 & 0.545 & 0.598 & 0.577 & 0.622 & 0.261 & 0.433 \\
\hline
\end{tabular}

Notes: Observations are at the state-month-level. The sample period is November 2010 until October 2013, i.e. an asymmetric 36-month window 2 years before and 1 year after the 2012 election. Where no seasonal differencing is applied, the nominal sample period starts in November 2009. Standard errors clustered at the state-level are in parentheses: ${ }^{*} \mathrm{p}<0.1 ;{ }^{* *} \mathrm{p}<0.05 ;{ }^{* *} \mathrm{p}<0.01$. Included control variables are $\log ($ population), $\%$ rural, $\%$ below poverty line, $\%$ blacks and $\%$ hispanics. All variables are as of 2010 and interacted with Month FE. Regressions are weighted by the state population. 


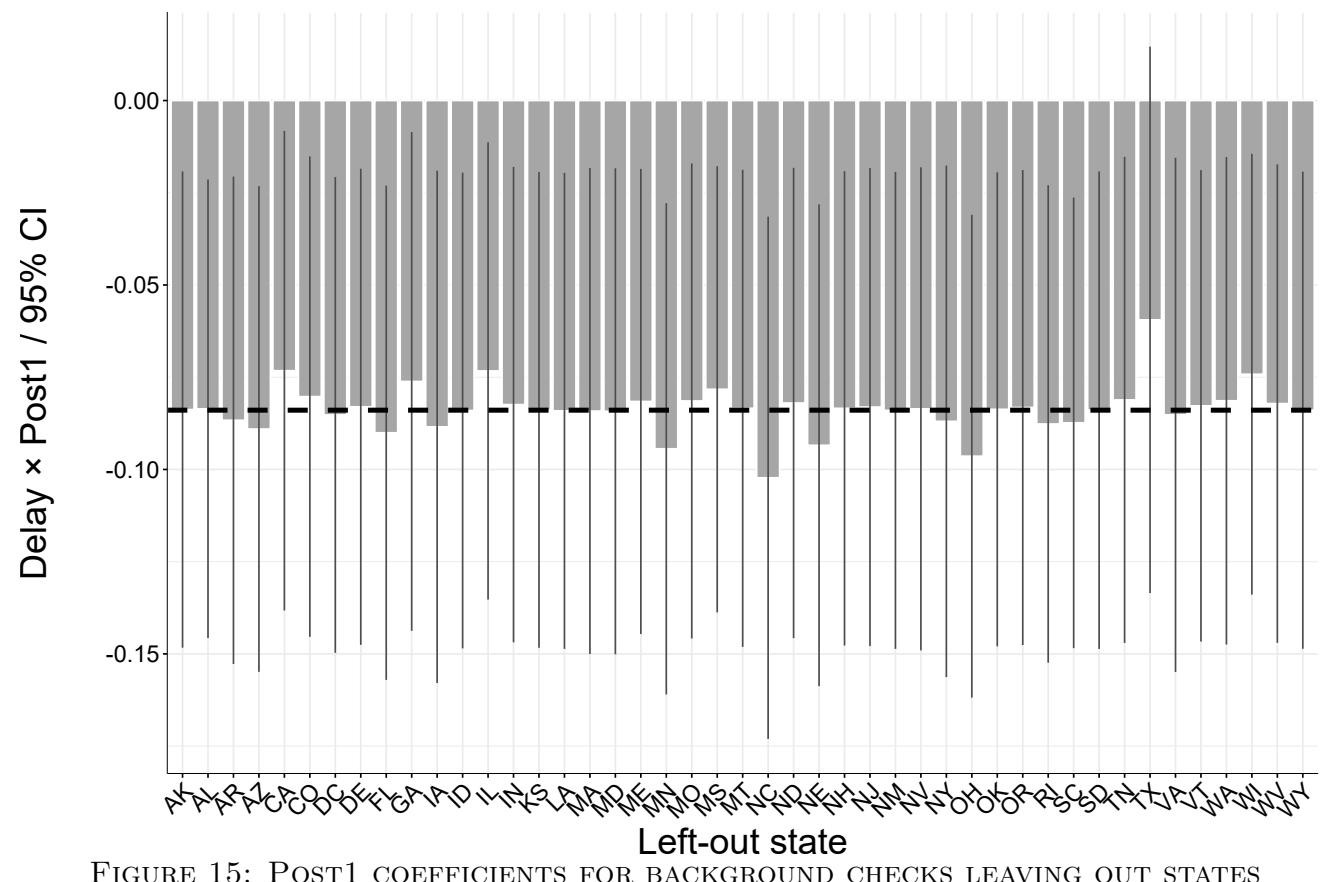

Bars represent coefficients for $\Delta_{12} \log$ handgun sale background checks after removing a single state (denoted on the x-axis) from the sample and corresponding $95 \%$ confidence intervals. The dashed line indicates our baseline, i.e. the magnitude when excluding no state.

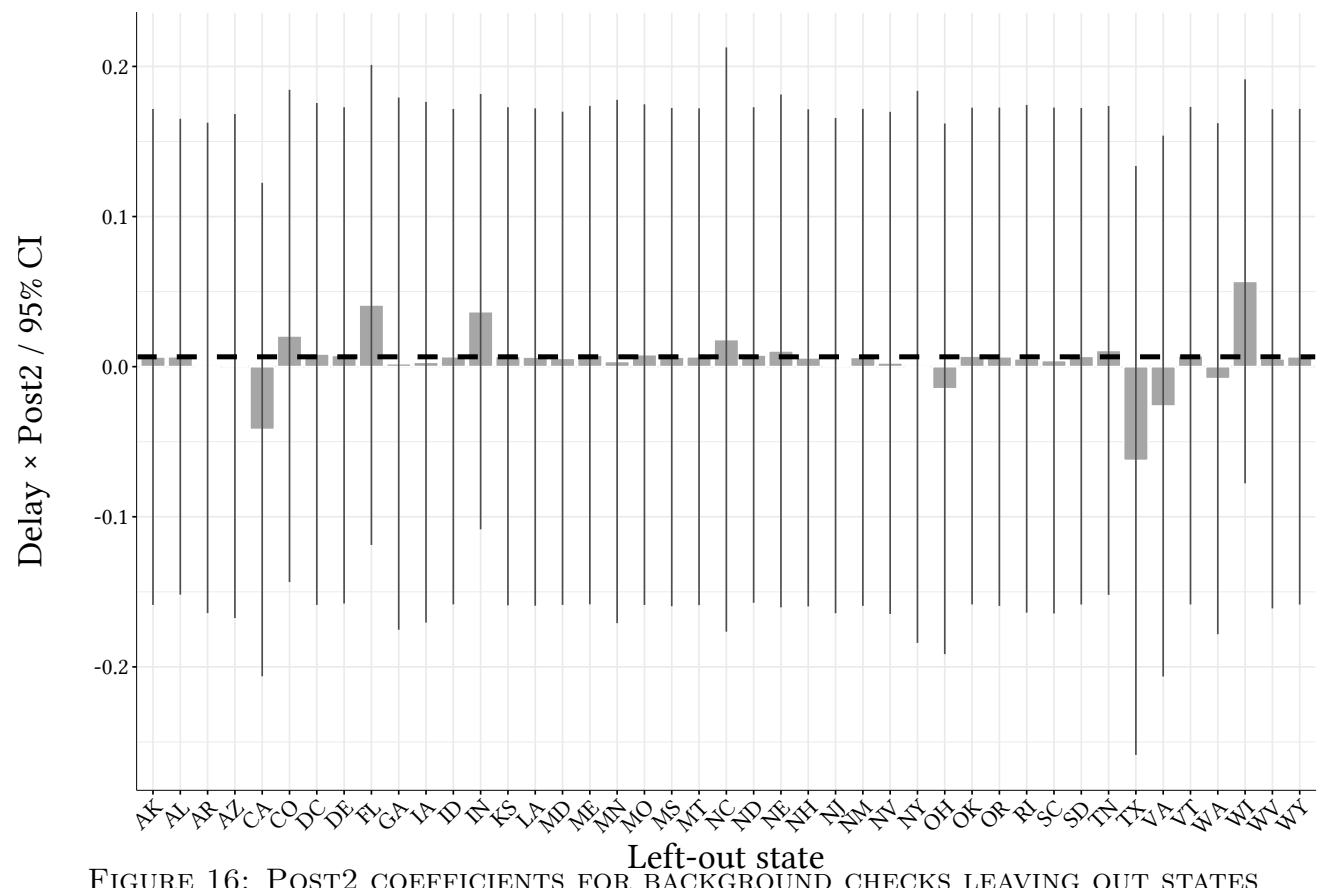

Bars represent coefficients for $\Delta_{12}$ Log handgun sale background checks after removing a single state (denoted on the x-axis) from the sample and corresponding $95 \%$ confidence intervals. The dashed line indicates our baseline, i.e. the magnitude when excluding no state. 
TABle 13: HANdGun BACKGROUND CHECKS (LOGS AND LEVELS)

\begin{tabular}{|c|c|c|c|c|c|c|c|c|}
\hline & \multicolumn{8}{|c|}{ Handgun background checks per 100,000 inhabitants } \\
\hline & \multicolumn{4}{|c|}{ Seasonal differencing (Baseline) } & \multicolumn{4}{|c|}{ Within transformation } \\
\hline & \multicolumn{2}{|c|}{ Logs (Baseline) } & \multicolumn{2}{|c|}{ Levels } & \multicolumn{2}{|c|}{ Logs } & \multicolumn{2}{|c|}{ Levels } \\
\hline & $(1)$ & (2) & $(3)$ & $(4)$ & $(5)$ & $(6)$ & $(7)$ & $(8)$ \\
\hline Delay $\times$ Post 1 & $\begin{array}{c}-0.081^{*} \\
(0.044)\end{array}$ & $\begin{array}{l}-0.073^{* *} \\
(0.033)\end{array}$ & $\begin{array}{l}-66.211^{\text {** }} \\
(23.895)\end{array}$ & $\begin{array}{l}-55.313^{* * *} \\
(19.723)\end{array}$ & $\begin{array}{c}-0.054 \\
(0.090)\end{array}$ & $\begin{array}{l}-0.107^{* *} \\
(0.045)\end{array}$ & $\begin{array}{l}-72.428^{* *} \\
(32.484)\end{array}$ & $\begin{array}{l}-68.820^{* * *} \\
(22.516)\end{array}$ \\
\hline Delay $\times$ Post 2 & $\begin{array}{c}0.010 \\
(0.064)\end{array}$ & $\begin{array}{c}0.007 \\
(0.084)\end{array}$ & $\begin{array}{l}-14.166 \\
(18.522)\end{array}$ & $\begin{array}{c}-4.637 \\
(21.528)\end{array}$ & $\begin{array}{c}0.073 \\
(0.079)\end{array}$ & $\begin{array}{c}0.005 \\
(0.083)\end{array}$ & $\begin{array}{c}-8.818 \\
(18.992)\end{array}$ & $\begin{array}{c}-3.972 \\
(21.428)\end{array}$ \\
\hline Year-Month FE & $\mathrm{Y}$ & $\mathrm{Y}$ & $\mathrm{Y}$ & Y & $\mathrm{Y}$ & $\mathrm{Y}$ & $\mathrm{Y}$ & Y \\
\hline Controls & $\mathrm{Y}$ & $\mathrm{Y}$ & $\mathrm{Y}$ & $\mathrm{Y}$ & $\mathrm{Y}$ & $\mathrm{Y}$ & $\mathrm{Y}$ & $\mathrm{Y}$ \\
\hline State Trends & $\mathrm{N}$ & $\mathrm{Y}$ & $\mathrm{N}$ & $\mathrm{Y}$ & $\mathrm{N}$ & $\mathrm{Y}$ & $\mathrm{N}$ & $\mathrm{Y}$ \\
\hline States & 43 & 43 & 43 & 43 & 43 & 43 & 43 & 43 \\
\hline Observations & 1,516 & 1,516 & 1,516 & 1,516 & 2,047 & 2,047 & 2,047 & 2,047 \\
\hline Mean DV & 0.194 & 0.194 & 44.999 & 44.999 & 5.860 & 5.860 & 213.573 & 213.573 \\
\hline $\mathrm{R}^{2}$ & 0.539 & 0.594 & 0.636 & 0.695 & 0.970 & 0.979 & 0.921 & 0.942 \\
\hline
\end{tabular}

Notes: Observations are at the state-month-level. The sample period is November 2010 until October 2013, i.e. an asymmetric 36-month window 2 years before and 1 year after the 2012 election. Where no seasonal differencing is applied, the nominal sample period starts in November 2009. Standard errors clustered at the state-level are in parentheses: ${ }^{*} \mathrm{p}<0.1 ;{ }^{* *} \mathrm{p}<0.05 ;{ }^{* * *} \mathrm{p}<0.01$. Included control variables are $\log$ (population), $\%$ rural, \% below poverty line, $\%$ blacks and \% hispanics. All variables are as of 2010 and interacted with Month FE. Regressions are weighted by the state population.

TABle 14: Handgun BACKGRound CHECKS (DifFERENT Weights)

\begin{tabular}{|c|c|c|c|c|c|c|}
\hline \multirow{3}{*}{ Weights } & \multicolumn{6}{|c|}{$\Delta_{12}$ Log of handgun background checks per 100,000 inhabitants } \\
\hline & \multicolumn{2}{|c|}{ Population } & \multicolumn{2}{|c|}{ Adult population } & \multicolumn{2}{|c|}{ None } \\
\hline & (1) & $(2)$ & $(3)$ & $(4)$ & $(5)$ & $(6)$ \\
\hline Delay $\times$ Post 1 & $-0.081^{*}$ & $-0.073^{* *}$ & $-0.079^{*}$ & $-0.072^{* *}$ & -0.030 & -0.042 \\
\hline & $(0.044)$ & $(0.033)$ & $(0.044)$ & $(0.033)$ & $(0.042)$ & $(0.042)$ \\
\hline Delay $\times$ Post 2 & 0.010 & 0.007 & 0.009 & 0.004 & -0.029 & -0.055 \\
\hline & $(0.064)$ & $(0.084)$ & $(0.064)$ & $(0.084)$ & $(0.059)$ & $(0.081)$ \\
\hline Year-Month FE & Y & $\mathrm{Y}$ & $\mathrm{Y}$ & $\mathrm{Y}$ & $\mathrm{Y}$ & $\mathrm{Y}$ \\
\hline Controls & $\mathrm{Y}$ & $\mathrm{Y}$ & $\mathrm{Y}$ & $\mathrm{Y}$ & $\mathrm{Y}$ & $\mathrm{Y}$ \\
\hline State Trends & $\mathrm{N}$ & $\mathrm{Y}$ & $\mathrm{N}$ & $\mathrm{Y}$ & $\mathrm{N}$ & $\mathrm{Y}$ \\
\hline States & 43 & 43 & 43 & 43 & 43 & 43 \\
\hline Observations & 1,516 & 1,516 & 1,516 & 1,516 & 1,516 & 1,516 \\
\hline $\mathrm{R}^{2}$ & 0.539 & 0.594 & 0.538 & 0.593 & 0.561 & 0.608 \\
\hline
\end{tabular}

Notes: Observations are at the state-month-level. The sample period is November 2010 until October 2013, i.e. an asymmetric 36-month window 2 years before and 1 year after the 2012 election. Where no seasonal differencing is applied, the nominal sample period starts in November 2009. Standard errors clustered at the state-level are in parentheses: ${ }^{*} \mathrm{p}<0.1 ;{ }^{* *} \mathrm{p}<0.05 ;{ }^{* * *} \mathrm{p}<0.01$. Included control variables are $\log$ (population), $\%$ rural, \% below poverty line, \% blacks and \% hispanics. All variables are as of 2010 and interacted with Month FE. Weights change according to the specification. 


\section{B.2 Robustness and Sensitivity of Homicide Results}

We discuss further further robustness and sensitivity checks of our homicide results in Section 6.1. In Table 15, we run placebo regressions similar to those in Section B.1 where we pre-date our sample and treatment periods. Coefficients in other years are closer to zero and insignificant throughout, suggesting that the previously uncovered effect of delay laws on handgun-related homicides can only be observed during this specific treatment period. Pre-dating by 2 years, yields a rather high coefficient. This, however, seems to depend strongly on the inclusion of linear trends and is insignificant at all conventional levels.

Appendix Table 16 shows that our results hold for different sample definitions, such as including Connecticut or Michigan and using only the 43 states and dates with reliable background check data as in our baseline regressions on firearm purchases in Section 5.1. Also the exclusion of single states reported in Figure 17 does not seem to strongly affect our estimates. The inclusion of California, however, seems to attenuate our estimates.

Concerns about functional form and data transformation are addressed in Table 17. Results in levels are of very similar magnitude but become insignificant when adding trends. Using within-transformation leads to slightly larger, highly significant results throughout. In Table 18 we explore whether using adult population or using no weights affects our results. Consistent with Table 14, we find that adult population leaves the estimates unchanged while using no weights removes the entire effect. As for our firearm purchase results, also our homicide results are thus driven by more populated areas.

Finally, Table 19 uses NVSS data collapsed at the state-month level. Despite a severe drop in sample size from 109,692 to 1,764 observations and reduced statistical power, our results remain significant. The estimates are slightly higher in magnitude, which is likely due to imperfectly accounting for county heterogeneity. 
Table 15: Placebo Regressions of homicide Rates

\begin{tabular}{|c|c|c|c|c|c|c|c|c|}
\hline \multirow[b]{4}{*}{ Delay $\times$ Post 1} & \multicolumn{8}{|c|}{$\Delta_{12} \log$ of homicides per 100,000 inhabitants } \\
\hline & \multicolumn{2}{|c|}{ Baseline (2010-2013) } & \multicolumn{2}{|c|}{-1 Year (2009-2012) } & \multicolumn{2}{|c|}{-2 Years $(2008-2011)$} & \multicolumn{2}{|c|}{ Obama I (2006-2009) } \\
\hline & (1) & $(2)$ & (3) & $(4)$ & $(5)$ & (6) & (7) & (8) \\
\hline & 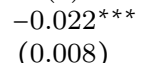 & $\begin{array}{c}-0.019^{* *} \\
(0.010)\end{array}$ & $\begin{array}{c}-0.001 \\
(0.014)\end{array}$ & $\begin{array}{c}-0.007 \\
(0.016)\end{array}$ & $\begin{array}{c}-0.008 \\
(0.011)\end{array}$ & $\begin{array}{c}-0.014 \\
(0.014)\end{array}$ & $\begin{array}{c}-0.004 \\
(0.011)\end{array}$ & $\begin{array}{c}-0.002 \\
(0.013)\end{array}$ \\
\hline Delay $\times$ Post 2 & $\begin{array}{l}-0.018 \\
(0.015)\end{array}$ & $\begin{array}{c}-0.015 \\
(0.018)\end{array}$ & $\begin{array}{c}-0.008 \\
(0.007)\end{array}$ & $\begin{array}{c}-0.014 \\
(0.010)\end{array}$ & $\begin{array}{c}0.006 \\
(0.011)\end{array}$ & $\begin{array}{c}0.001 \\
(0.015)\end{array}$ & $\begin{array}{c}0.001 \\
(0.012)\end{array}$ & $\begin{array}{c}0.003 \\
(0.014)\end{array}$ \\
\hline Year-Month FE & $\mathrm{Y}$ & $\mathrm{Y}$ & $\mathrm{Y}$ & $\mathrm{Y}$ & Y & Y & Y & Y \\
\hline Controls & $\mathrm{Y}$ & $\mathrm{Y}$ & $\mathrm{Y}$ & $\mathrm{Y}$ & $\mathrm{Y}$ & $\mathrm{Y}$ & Y & $\mathrm{Y}$ \\
\hline County Trends & $\mathrm{N}$ & $\mathrm{Y}$ & $\mathrm{N}$ & $\mathrm{Y}$ & $\mathrm{N}$ & $\mathrm{Y}$ & $\mathrm{N}$ & $\mathrm{Y}$ \\
\hline $\mathrm{R}^{2}$ & 0.008 & 0.019 & 0.008 & 0.019 & 0.009 & 0.021 & 0.044 & 0.056 \\
\hline
\end{tabular}

Notes: All regressions use 109,692 observations from 3,047 counties. The sample period is November $x-2$ until October $x+1$, i.e. an asymmetric 36-month window 2 years before and 1 year after November of the year used as the event $(x)$. Where no seasonal differencing is applied, the nominal sample period starts in November 2009. Standard errors clustered at the state-level are in parentheses: ${ }^{*} \mathrm{p}<0.1 ;{ }^{* *} \mathrm{p}<0.05 ;{ }^{* *} \mathrm{p}<0.01$. Included control variables are $\log$ (population), $\%$ rural, $\%$ below poverty line, $\%$ blacks and $\%$ hispanics. All variables are as of 2010 and interacted with Month FE. Regressions are weighted by the county population.

TABle 16: Handgun homicide RATES (VARying The SAMPle)

\begin{tabular}{|c|c|c|c|c|c|c|c|c|c|c|}
\hline \multirow[b]{4}{*}{ Delay $\times$ Post 1} & \multicolumn{10}{|c|}{$\Delta_{12} \log$ of handgun homicides per 100,000 inhabitants } \\
\hline & \multicolumn{2}{|c|}{$\begin{array}{c}\text { Full NVSS data } \\
\text { - CT\&MI } \\
(=\mathrm{BL} 2)\end{array}$} & \multicolumn{2}{|c|}{$\mathrm{BL} 2+\mathrm{CT}$} & \multicolumn{2}{|c|}{$\begin{array}{l}\text { BL2 }+ \text { MI w/ } \\
\text { law change }\end{array}$} & \multicolumn{2}{|c|}{$\begin{array}{c}\text { BL2 - states } \\
\text { w/ NICS } \\
\text { outliers }\end{array}$} & \multicolumn{2}{|c|}{$\begin{array}{c}\text { NVSS data } \\
\text { w/o NICS outliers } \\
\text { - CT\&MI (=BL1) }\end{array}$} \\
\hline & (1) & $(2)$ & (3) & (4) & (5) & (6) & (7) & (8) & (9) & (10) \\
\hline & $\begin{array}{l}-0.022^{* * *} \\
(0.008)\end{array}$ & $\begin{array}{l}-0.019^{* *} \\
(0.010)\end{array}$ & $\begin{array}{l}-0.021^{* * *} \\
(0.007)\end{array}$ & $\begin{array}{c}-0.019^{*} \\
(0.010)\end{array}$ & $\begin{array}{l}-0.021^{* * *} \\
(0.007)\end{array}$ & $\begin{array}{c}-0.017^{*} \\
(0.010)\end{array}$ & $\begin{array}{l}-0.023^{* * *} \\
(0.008)\end{array}$ & $\begin{array}{c}-0.020^{*} \\
(0.010)\end{array}$ & $\begin{array}{l}-0.022^{* * *} \\
(0.008)\end{array}$ & $\begin{array}{r}-0.018^{*} \\
(0.010)\end{array}$ \\
\hline Delay $\times$ Post 2 & $\begin{array}{l}-0.018 \\
(0.015)\end{array}$ & $\begin{array}{l}-0.015 \\
(0.018)\end{array}$ & $\begin{array}{l}-0.019 \\
(0.015)\end{array}$ & $\begin{array}{l}-0.017 \\
(0.018)\end{array}$ & $\begin{array}{c}-0.016 \\
(0.015)\end{array}$ & $\begin{array}{c}-0.012 \\
(0.018)\end{array}$ & $\begin{array}{c}-0.019 \\
(0.016)\end{array}$ & $\begin{array}{l}-0.016 \\
(0.019)\end{array}$ & $\begin{array}{c}-0.018 \\
(0.015)\end{array}$ & $\begin{array}{c}-0.015 \\
(0.018)\end{array}$ \\
\hline Year-Month FE & $\mathrm{Y}$ & Y & Y & Y & $\mathrm{Y}$ & $\mathrm{Y}$ & $\mathrm{Y}$ & Y & $\mathrm{Y}$ & $\mathrm{Y}$ \\
\hline Controls & $\mathrm{Y}$ & $\mathrm{Y}$ & Y & $\mathrm{Y}$ & $\mathrm{Y}$ & $\mathrm{Y}$ & $\mathrm{Y}$ & $\mathrm{Y}$ & $\mathrm{Y}$ & $\mathrm{Y}$ \\
\hline County Trends & $\mathrm{N}$ & $\mathrm{Y}$ & $\mathrm{N}$ & $\mathrm{Y}$ & $\mathrm{N}$ & $\mathrm{Y}$ & $\mathrm{N}$ & $\mathrm{Y}$ & $\mathrm{N}$ & $\mathrm{Y}$ \\
\hline Count & & 3,04 & & 3,05 & 3,130 & 3,130 & 2,823 & 2,823 & 3,047 & 3,047 \\
\hline Observations & 109,692 & 109,692 & 109,980 & 109,980 & 112,680 & 112,680 & 101,628 & 101,628 & 106,414 & 106,414 \\
\hline $\mathrm{R}^{2}$ & 0.008 & 0.019 & 0.008 & 0.018 & 0.008 & 0.019 & 0.008 & 0.019 & 0.008 & 0.019 \\
\hline
\end{tabular}

Notes: Observations are at the county-month-level. The sample period is November 2010 until October 2013, i.e. an asymmetric 36-month window 2 years before and 1 year after the 2012 election. Where no seasonal differencing is applied, the nominal sample period starts in November 2009. Standard errors clustered at the state-level are in parentheses: ${ }^{*} \mathrm{p}<0.1 ;{ }^{* *} \mathrm{p}<0.05 ;{ }^{* *} \mathrm{p}<0.01$. Included control variables are $\log$ (population), $\%$ rural, $\%$ below poverty line, $\%$ blacks and \% hispanics. All variables are as of 2010 and interacted with Month FE. Regressions are weighted by the county population. 


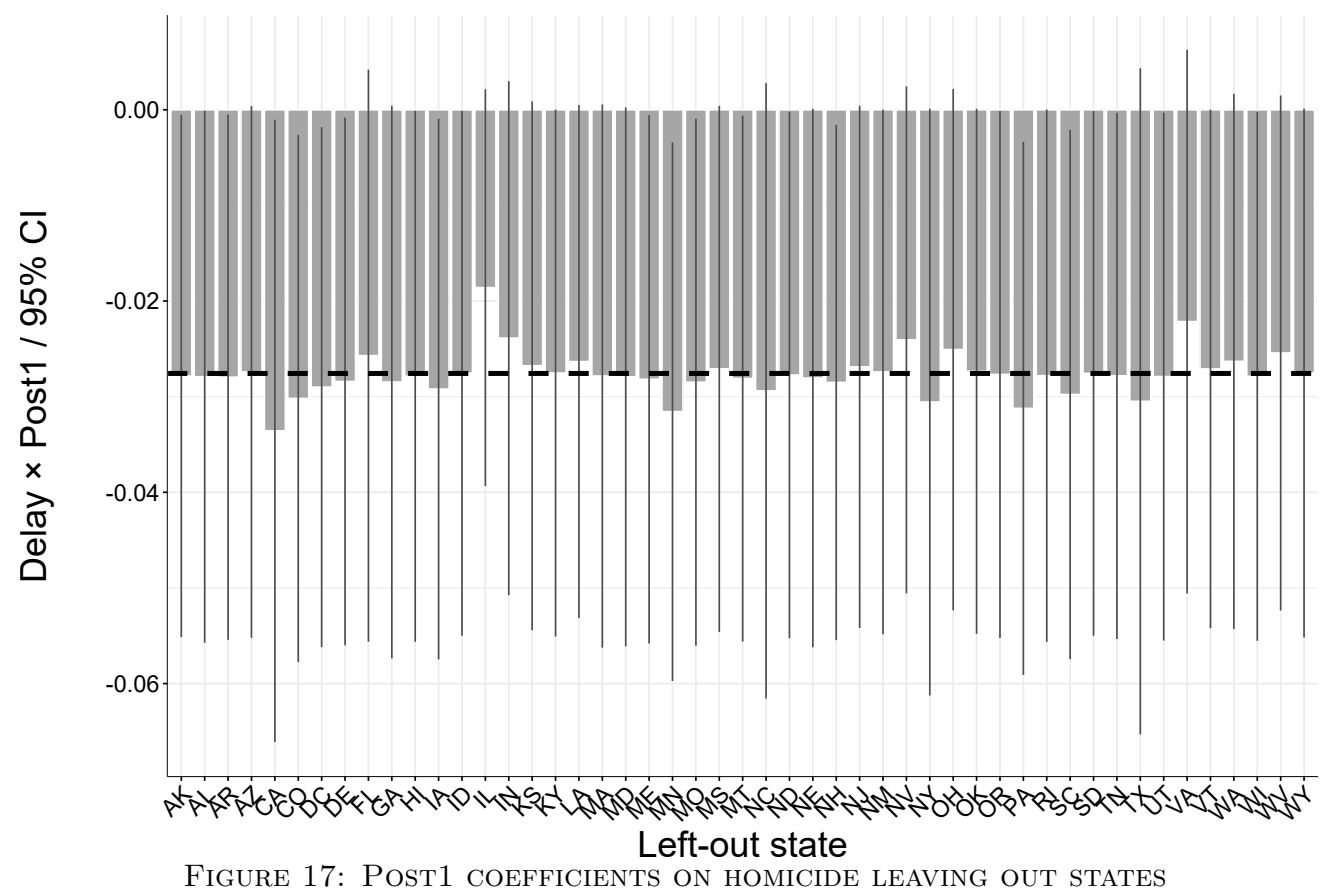

Bars represent coefficients for $\Delta_{12}$ Log handgun homicides per 100,000 inhabitants after removing a single state (denoted on the x-axis) from the sample and corresponding $95 \%$ confidence intervals. The dashed line indicates our baseline, i.e. the magnitude when excluding no state.

TABle 17: Homicide RAtes (LOGS AND LEVELS)

\begin{tabular}{|c|c|c|c|c|c|c|c|c|}
\hline & \multicolumn{8}{|c|}{ Handgun homicides per 100,000 inhabitants } \\
\hline & \multicolumn{4}{|c|}{ Seasonal differencing (Baseline) } & \multicolumn{4}{|c|}{ Within transformation } \\
\hline & \multicolumn{2}{|c|}{ Logs (Baseline) } & \multicolumn{2}{|c|}{ Levels } & \multicolumn{2}{|c|}{ Logs } & \multicolumn{2}{|c|}{ Levels } \\
\hline & (1) & $(2)$ & (3) & $(4)$ & $(5)$ & (6) & (7) & $(8)$ \\
\hline Delay $\times$ Post 1 & $\begin{array}{l}-0.022^{* * *} \\
(0.008)\end{array}$ & $\begin{array}{l}-0.019^{* *} \\
(0.010)\end{array}$ & $\begin{array}{l}-0.021^{* *} \\
(0.009)\end{array}$ & $\begin{array}{c}-0.017 \\
(0.012)\end{array}$ & $\begin{array}{l}-0.034^{* * *} \\
(0.009)\end{array}$ & $\begin{array}{c}-0.033^{* * *} \\
(0.011)\end{array}$ & $\begin{array}{l}-0.037^{* * *} \\
(0.010)\end{array}$ & $\begin{array}{l}-0.034^{* *} \\
(0.013)\end{array}$ \\
\hline Delay $\times$ Post 2 & $\begin{array}{c}-0.018 \\
(0.015)\end{array}$ & $\begin{array}{c}-0.015 \\
(0.018)\end{array}$ & $\begin{array}{c}-0.019 \\
(0.018)\end{array}$ & $\begin{array}{c}-0.015 \\
(0.021)\end{array}$ & $\begin{array}{c}-0.012 \\
(0.013)\end{array}$ & $\begin{array}{l}-0.011 \\
(0.019)\end{array}$ & $\begin{array}{l}-0.012 \\
(0.015)\end{array}$ & $\begin{array}{c}-0.008 \\
(0.022)\end{array}$ \\
\hline Year-Month FE & $\mathrm{Y}$ & $\mathrm{Y}$ & Y & $\mathrm{Y}$ & $\mathrm{Y}$ & $\mathrm{Y}$ & $\mathrm{Y}$ & $\mathrm{Y}$ \\
\hline Controls & $\mathrm{Y}$ & $\mathrm{Y}$ & $\mathrm{Y}$ & $\mathrm{Y}$ & $\mathrm{Y}$ & $\mathrm{Y}$ & $\mathrm{Y}$ & $\mathrm{Y}$ \\
\hline County Trends & $\mathrm{N}$ & $\mathrm{Y}$ & $\mathrm{N}$ & $\mathrm{Y}$ & $\mathrm{N}$ & $\mathrm{Y}$ & $\mathrm{N}$ & $\mathrm{Y}$ \\
\hline Counties & 3,047 & 3,047 & 3,047 & 3,047 & 3,047 & 3,047 & 3,047 & 3,047 \\
\hline Observations & 109,692 & 109,692 & 109,692 & 109,692 & 146,256 & 146,256 & 146,256 & 146,256 \\
\hline Mean DV & 0.000 & 0.000 & 0.001 & 0.001 & 0.245 & 0.245 & 0.287 & 0.287 \\
\hline $\mathrm{R}^{2}$ & 0.008 & 0.019 & 0.005 & 0.015 & 0.478 & 0.491 & 0.334 & 0.350 \\
\hline
\end{tabular}

Notes: Observations are at the county-month-level. The sample period is November 2010 until October 2013, i.e. an asymmetric 36-month window 2 years before and 1 year after the 2012 election. Where no seasonal differencing is applied, the nominal sample period starts in November 2009. Standard errors clustered at the state-level are in parentheses: ${ }^{*} \mathrm{p}<0.1 ;{ }^{* *} \mathrm{p}<0.05 ;{ }^{* * *} \mathrm{p}<0.01$. Included control variables are $\log$ (population), $\%$ rural, \% below poverty line, $\%$ blacks and \% hispanics. All variables are as of 2010 and interacted with Month FE. Regressions are weighted by the county population. 
TABle 18: Homicide RATes (Different Weights)

\begin{tabular}{|c|c|c|c|c|c|c|}
\hline \multirow{3}{*}{ Weights } & \multicolumn{6}{|c|}{$\Delta_{12}$ Log of handgun homicides per 100,000 inhabitants } \\
\hline & \multicolumn{2}{|c|}{ Population } & \multicolumn{2}{|c|}{ Adult population } & \multicolumn{2}{|c|}{ None } \\
\hline & (1) & $(2)$ & (3) & (4) & (5) & (6) \\
\hline \multirow[t]{2}{*}{ Delay $\times$ Post 1} & $-0.022^{* * *}$ & $-0.019^{* *}$ & $-0.022^{* * *}$ & $-0.019^{*}$ & 0.003 & 0.005 \\
\hline & $(0.008)$ & $(0.010)$ & $(0.007)$ & $(0.010)$ & $(0.007)$ & $(0.009)$ \\
\hline \multirow[t]{2}{*}{ Delay $\times$ Post 2} & -0.018 & -0.015 & -0.017 & -0.014 & $-0.014^{\star}$ & -0.011 \\
\hline & $(0.015)$ & $(0.018)$ & $(0.015)$ & $(0.018)$ & $(0.008)$ & $(0.010)$ \\
\hline Year-Month FE & $\mathrm{Y}$ & $\mathrm{Y}$ & $\mathrm{Y}$ & $\mathrm{Y}$ & $\mathrm{Y}$ & $\mathrm{Y}$ \\
\hline Controls & $\mathrm{Y}$ & $\mathrm{Y}$ & $\mathrm{Y}$ & $\mathrm{Y}$ & $\mathrm{Y}$ & $\mathrm{Y}$ \\
\hline County Trends & $\mathrm{N}$ & $\mathrm{Y}$ & $\mathrm{N}$ & $\mathrm{Y}$ & $\mathrm{N}$ & $\mathrm{Y}$ \\
\hline Counties & 3,047 & 3,047 & 3,047 & 3,047 & 3,047 & 3,047 \\
\hline Observations & 109,692 & 109,692 & 109,692 & 109,692 & 109,692 & 109,692 \\
\hline $\mathrm{R}^{2}$ & 0.008 & 0.019 & 0.008 & 0.019 & 0.002 & 0.012 \\
\hline
\end{tabular}

Notes: Observations are at the county-month-level. The sample period is November 2010 until October 2013 ,

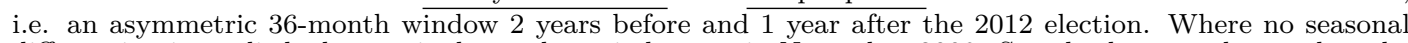
differencing is applied, the nominal sample period starts in November 2009. Standard errors clustered at the state-level are in parentheses: ${ }^{*} \mathrm{p}<0.1 ;{ }^{* *} \mathrm{p}<0.05 ;{ }^{* *} \mathrm{p}<0.01$. Included control variables are log(population), \% rural, \% below poverty line, \% blacks and \% hispanics. All variables are as of 2010 and interacted with Month FE. Weights change according to the specification.

TABle 19: Homicide RATES (STATE LEVEL)

\begin{tabular}{|c|c|c|c|c|c|c|c|}
\hline \multirow{5}{*}{ Delay $\times$ Post1 } & \multicolumn{7}{|c|}{$\Delta_{12} \log$ of homicides per 100,000 inhabitants } \\
\hline & \multicolumn{3}{|c|}{ Handgun } & \multicolumn{2}{|c|}{ Any } & \multicolumn{2}{|c|}{ Other } \\
\hline & (1) & (2) & (3) & (4) & (5) & (6) & (7) \\
\hline & $-0.023^{* *}$ & $-0.026^{* *}$ & $-0.028^{* *}$ & $-0.026^{*}$ & -0.027 & -0.003 & -0.002 \\
\hline & $(0.010)$ & $(0.010)$ & $(0.013)$ & $(0.013)$ & $(0.018)$ & $(0.011)$ & $(0.014)$ \\
\hline Delay $\times$ Post2 & -0.014 & -0.015 & -0.017 & 0.004 & 0.003 & $0.020^{*}$ & 0.021 \\
\hline & $(0.014)$ & $(0.015)$ & $(0.019)$ & $(0.020)$ & $(0.026)$ & $(0.011)$ & $(0.014)$ \\
\hline Year-Month FE & $\mathrm{Y}$ & $\mathrm{Y}$ & $\mathrm{Y}$ & Y & $\mathrm{Y}$ & $\mathrm{Y}$ & $\mathrm{Y}$ \\
\hline Controls & $\mathrm{N}$ & $\mathrm{Y}$ & $\mathrm{Y}$ & $\mathrm{Y}$ & $\mathrm{Y}$ & $\mathrm{Y}$ & $\mathrm{Y}$ \\
\hline State Trends & $\mathrm{N}$ & $\mathrm{N}$ & $\mathrm{Y}$ & $\mathrm{N}$ & Y & $\mathrm{N}$ & $\mathrm{Y}$ \\
\hline States & 49 & 49 & 49 & 49 & 49 & 49 & 49 \\
\hline Observations & 1,764 & 1,764 & 1,764 & 1,764 & 1,764 & 1,764 & 1,764 \\
\hline $\mathrm{R}^{2}$ & 0.036 & 0.150 & 0.162 & 0.134 & 0.145 & 0.135 & 0.143 \\
\hline
\end{tabular}

Notes: Observations are at the state-month-level. The sample period is November 2010 until October 2013, i.e. an asymmetric 36-month window 2 years before and 1 year after the 2012 election. Where no seasonal differencing is applied, the nominal sample period starts in November 2009. Standard errors clustered at the state-level are in parentheses: ${ }^{*} \mathrm{p}<0.1 ;{ }^{* *} \mathrm{p}<0.05 ;{ }^{* *} \mathrm{p}<0.01$. Included control variables are $\log$ (population), \% rural, \% below poverty line, \% blacks and \% hispanics. All variables are as of 2010 and interacted with Month FE. Regressions are weighted by the state population. 


\section{B.3 The Effect of Delay Laws on Suicides and Accidents}

In addition to homicides, the comparatively smaller increase in handgun ownership in Delay states may also have affected suicides and accidents involving a handgun which we discuss in this section. In Table 20 we use our baseline specification to create corresponding estimates for suicides and accidents. For accidents we find an insignificant and small relative increase in overall incidents in columns 1 and 2 while those related to a handgun in specifications 3 and 4 show no response. This does not fully support the findings of Levine and McKnight (2017) who report that gun-related fatal accidents strongly increased in relative terms after the shooting at Sandy Hook Elementary School. While our study differs along a few dimensions, including the fact that we use countylevel data and a slightly different treatment period, we do not think that these are the primary drivers for the observed differences across the two studies. Instead, a more likely explanation could be our use of handgun purchase delay laws instead of the 2012 Obama vote share as a shifter for the reaction in firearm sales. Our results thus indicate that the effects are not robust to this different, and in our view more credible, identification strategy. ${ }^{32}$

Columns 7 to 12 show the reaction of suicide rates. Importantly, those related to handguns do not show a significant reaction but are negative and thus point in the expected direction. Our findings are thus qualitatively in line with prior research which has argued that having a gun in the home is positively associated with suicide by firearm (Anglemyer, Horvath, and Rutherford, 2014). Concerning the size and lack of significance in columns 9 and 10, one has to bear in mind that our time window used is relatively small and only if a person is both suicidal and in the possession of a gun would a firearm-related suicide occur. ${ }^{33}$ Furthermore, medical research by Klonsky and May (2015) has failed to establish a relationship between impulsiveness and the tendency to act on suicidal thoughts, lending further corroboration to the idea that suicides should not react to the shock to a similar extent. Having said that, it seems plausible that additional suicides may materialize after a longer time period. It also seems unlikely that a person with suicidal thoughts would purchase a firearm due to the gun demand

\footnotetext{
${ }^{32}$ Section 5.3 shows that differences across Delay and NoDelay states only arise in handgun sales, not in the intention to purchase a firearm. We deem it unlikely to be the case for the 2012 Obama vote share to a similar extent.

${ }^{33}$ The two most prominent studies studying the relationship of firearm ownership and suicides, Edwards et al. (2018) and Lang (2013), utilize annual data and investigate substantially longer time horizons of several years.
} 
TABle 20: ACCIDENTS AND SUICIDES

\begin{tabular}{|c|c|c|c|c|c|c|c|c|c|c|c|c|}
\hline \multirow[b]{5}{*}{ Delay $\times$ Post 1} & \multicolumn{12}{|c|}{$\Delta_{12} \log$ of mortality rate per 100,000 inhabitants } \\
\hline & \multicolumn{6}{|c|}{ Accidents } & \multicolumn{6}{|c|}{ Suicides } \\
\hline & \multicolumn{2}{|c|}{ Any } & \multicolumn{2}{|c|}{ Handgun } & \multicolumn{2}{|c|}{ Other } & \multicolumn{2}{|c|}{ Any } & \multicolumn{2}{|c|}{ Handgun } & \multicolumn{2}{|c|}{ Other } \\
\hline & (1) & (2) & (3) & (4) & (5) & (6) & (7) & (8) & (9) & (10) & (11) & (12) \\
\hline & 0.011 & 0.008 & -0.000 & -0.000 & 0.012 & 0.009 & -0.008 & 0.004 & -0.014 & -0.004 & 0.002 & 0.008 \\
\hline & $(0.015)$ & $(0.015)$ & $(0.003)$ & $(0.004)$ & $(0.015)$ & $(0.015)$ & $(0.014)$ & $(0.018)$ & $(0.012)$ & $(0.013)$ & $(0.013)$ & $(0.016)$ \\
\hline \multirow[t]{2}{*}{ Delay $\times$ Post2 } & 0.009 & 0.005 & 0.001 & 0.001 & 0.009 & 0.005 & 0.002 & 0.013 & 0.003 & 0.013 & -0.000 & 0.005 \\
\hline & $(0.015)$ & $(0.019)$ & $(0.002)$ & $(0.003)$ & $(0.015)$ & $(0.019)$ & $(0.015)$ & $(0.018)$ & $(0.015)$ & $(0.017)$ & $(0.013)$ & $(0.017)$ \\
\hline Year-Month FE & $\mathrm{Y}$ & $\mathrm{Y}$ & $\mathrm{Y}$ & $\mathrm{Y}$ & $\mathrm{Y}$ & $\mathrm{Y}$ & $\mathrm{Y}$ & Y & $\mathrm{Y}$ & Y & $\mathrm{Y}$ & $\mathrm{Y}$ \\
\hline Controls & $\mathrm{Y}$ & $\mathrm{Y}$ & Y & $\mathrm{Y}$ & $\mathrm{Y}$ & Y & $\mathrm{Y}$ & $\mathrm{Y}$ & Y & Y & $\mathrm{Y}$ & $\mathrm{Y}$ \\
\hline County Trends & $\mathrm{N}$ & Y & $\mathrm{N}$ & Y & $\mathrm{N}$ & Y & $\mathrm{N}$ & $\mathrm{Y}$ & $\mathrm{N}$ & Y & $\mathrm{N}$ & Y \\
\hline $\mathrm{R}^{2}$ & 0.004 & 0.016 & 0.003 & 0.012 & 0.004 & 0.016 & 0.003 & 0.013 & 0.003 & 0.013 & 0.003 & 0.013 \\
\hline
\end{tabular}

Notes: All regressions use 109,692 observations from 3,047 counties. The sample period is November 2010 until October 2013, i.e. an asymmetric 36-month window 2 years before and 1 year after the 2012 election. Where no seasonal differencing is applied, the nominal sample period starts in November 2009. Standard errors clustered at the state-level are in parentheses: ${ }^{*} \mathrm{p}<0.1 ;{ }^{* *} \mathrm{p}<0.05 ;{ }^{* * *} \mathrm{p}<0.01$. Included control variables are $\log$ (population), $\%$ rural, $\%$ below poverty line, $\%$ blacks and $\%$ hispanics. All variables are as of 2010 and interacted with Month FE. Regressions are weighted by the county population.

shock where the primary motive was an increased perception of needing firearms for self-defense and expected limitations to future firearm access. 


\section{Figures}

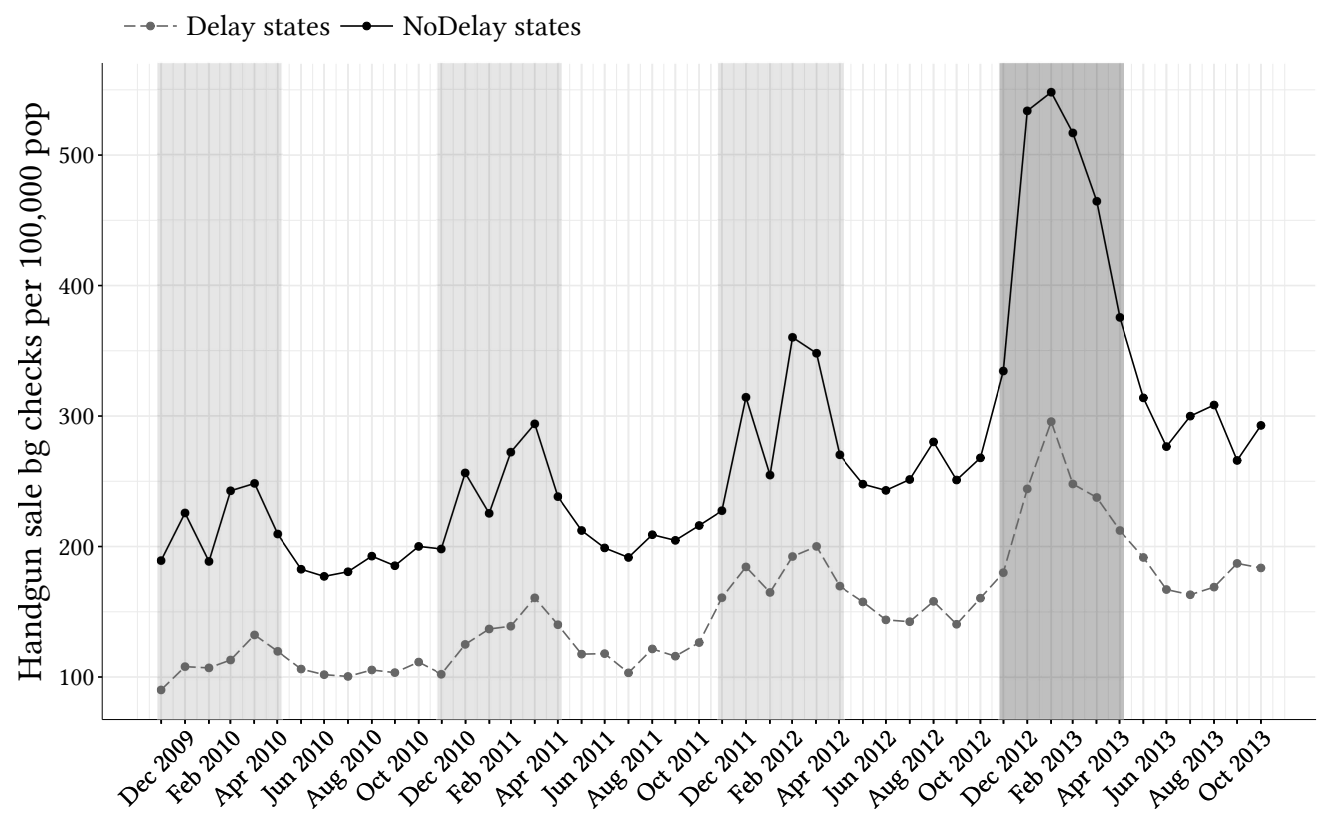

Figure 18: Background Checks for handguns in Delay vs NoDelay states (levels)

Monthly NICS handgun background checks per 100,000 inhabitants in Delay states and NoDelay states between November 2009 and October 2013. The sample encompasses data for all states consistently included in our main specification. The dark grey-shaded area includes the first six months after the 2012 election, i.e. November 2012 to April 2013. Light grey-shaded areas are marking the same period for preceding years.

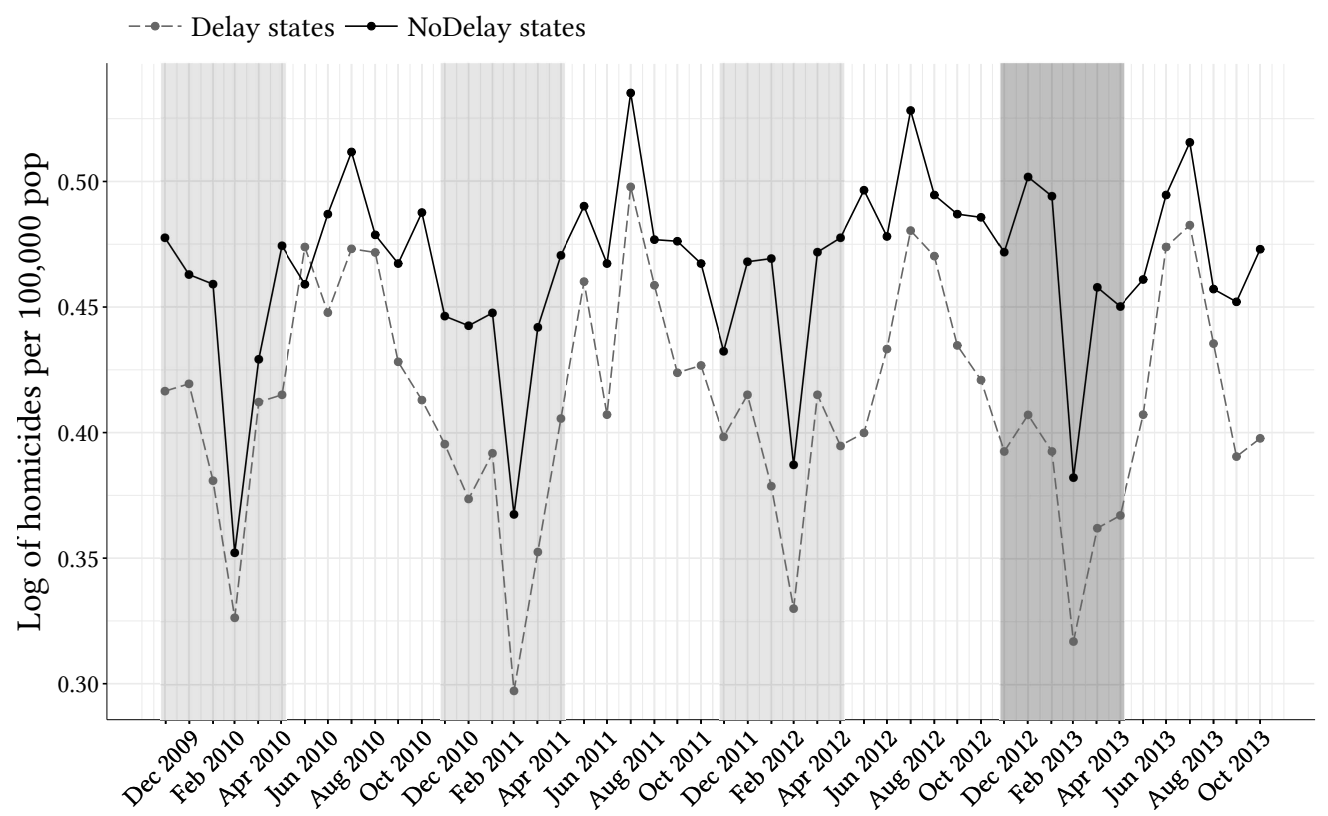

Figure 19: Homicide Rate in Delay vs NoDelay States (levels)

Monthly homicides per 100,000 inhabitants in Delay states and NoDelay states between November 2009 and October 2013. The sample encompasses data from all counties consistently included in our main specification. The dark grey-shaded area includes the first six months after the 2012 election, i.e. November 2012 to April 2013. Light grey-shaded areas are marking the same period for preceding years. 


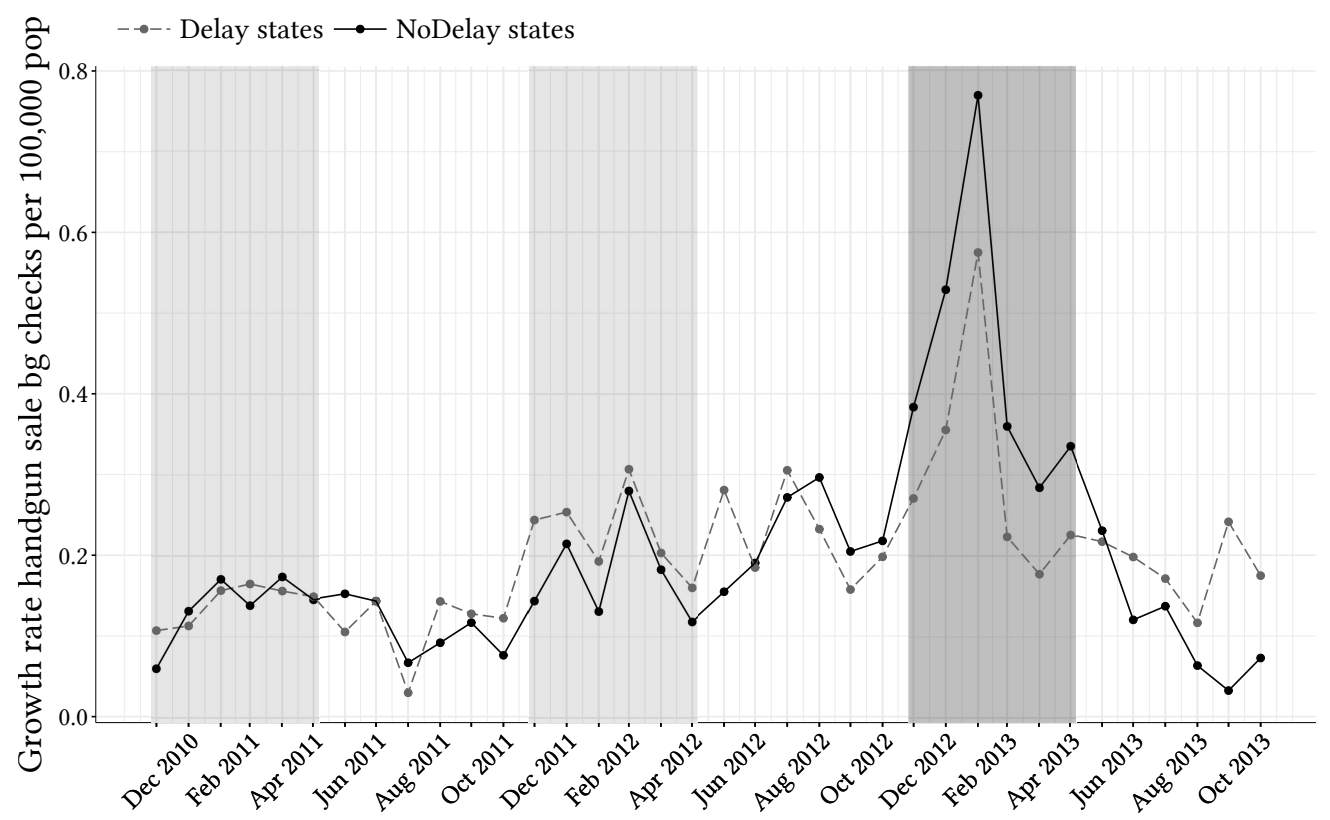

Figure 20: Background Check RATe for handguns in Delay vs NoDelay states (Growth RATE)

Growth rate of monthly NICS handgun background checks per 100,000 inhabitants in Delay states and NoDelay states between November 2009 and October 2013. The sample encompasses data for all states consistently included in our main specification. The dark grey-shaded area includes the first six months after the 2012 election, i.e. November 2012 to April 2013. Light grey-shaded areas are marking the same period for preceding years. For better visibility, each series has been re-scaled to 0 on the last observation before the treatment.

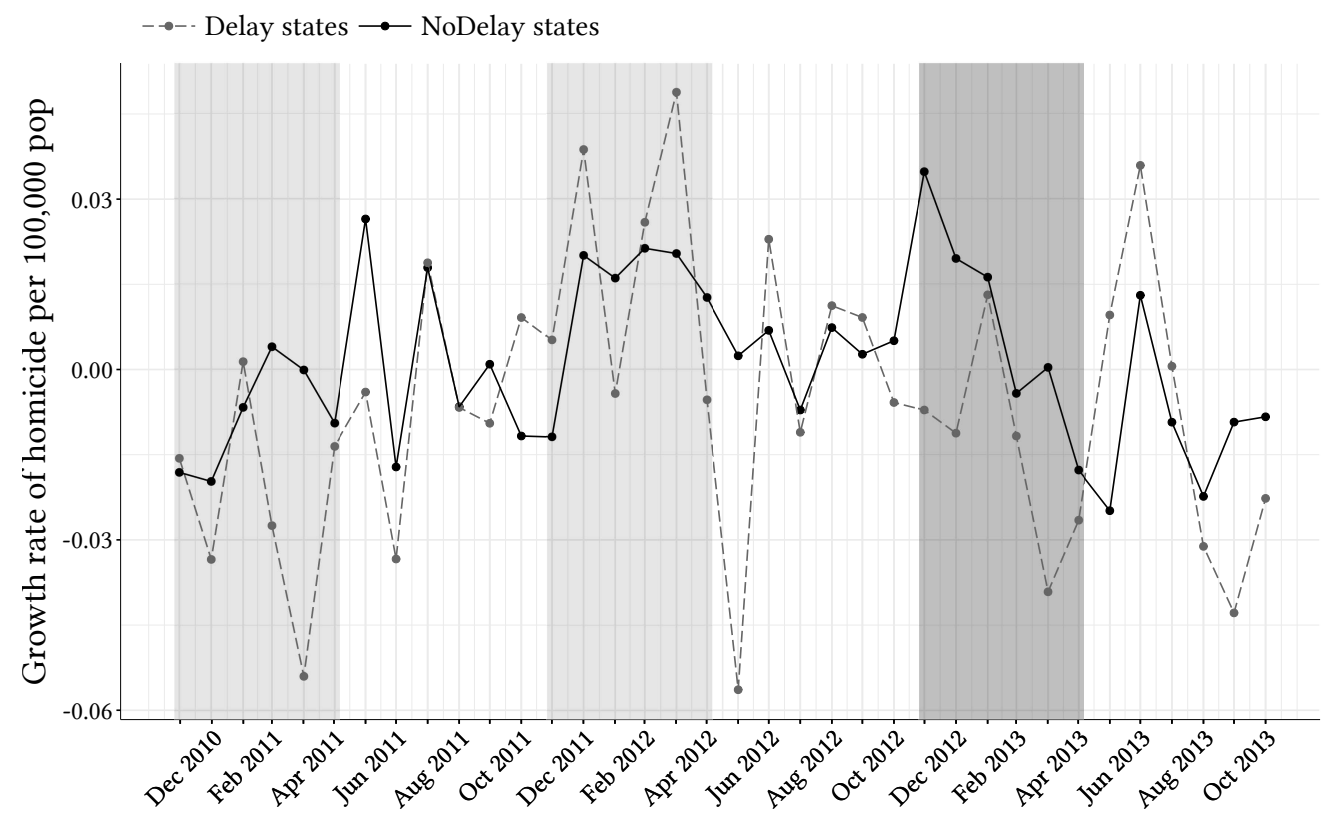

Figure 21: Homicide Rate in Delay vs NoDelay States (Growth RATe)

Growth rate of monthly homicides per 100,000 inhabitants in Delay states and NoDelay states between November 2009 and October 2013. The sample encompasses data from all counties consistently included in our main specification. The dark grey-shaded area includes the first six months after the 2012 election, i.e. November 2012 to April 2013. Light grey-shaded areas are marking the same period for preceding years. For better visibility, each series has been re-scaled to 0 on the last observation before the treatment. 


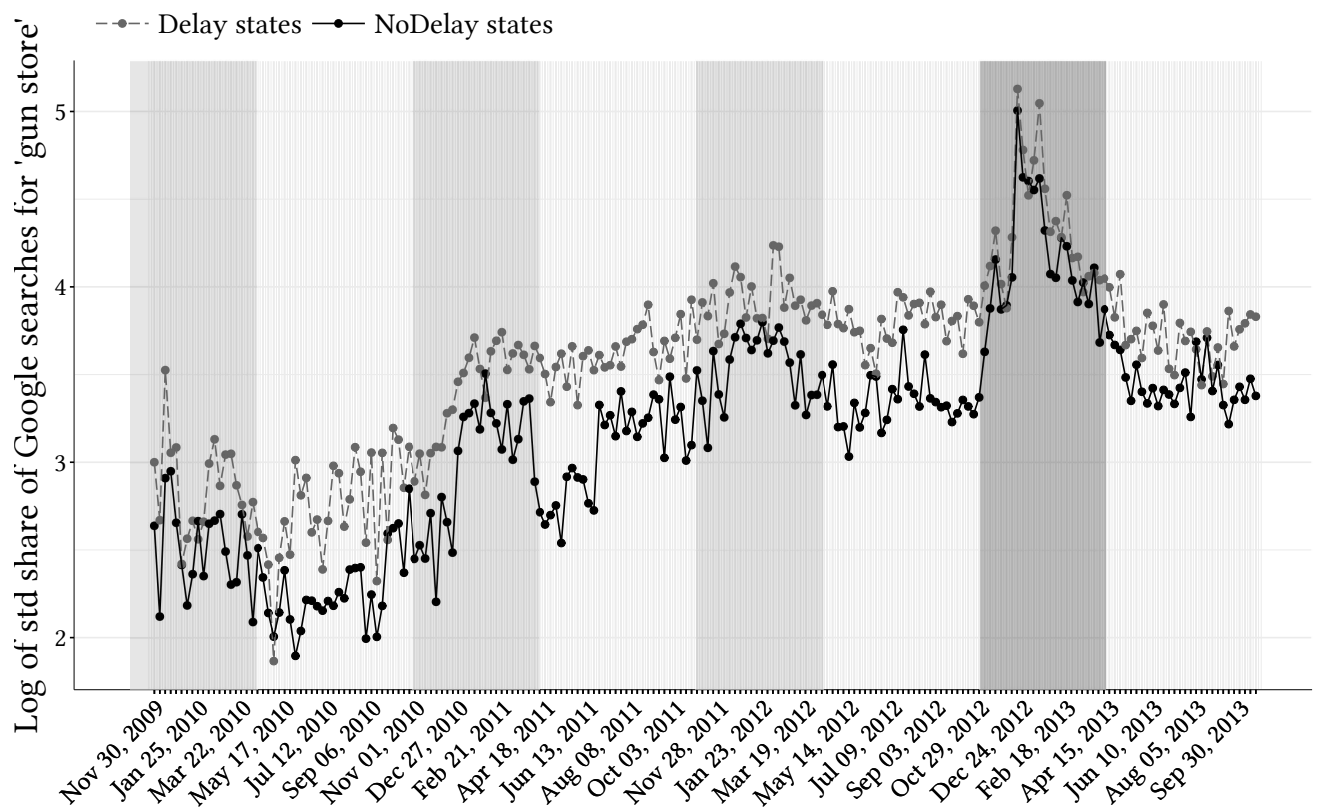

Figure 22: Log Google Searches for "Gun Store" in Delay vs NoDelay states

Log weekly averages of daily normalized Google searches for the expression "gun store" in Delay states and NoDelay states between November 2009 and October 2013. The sample encompasses data for all states consistently included in our main specification. The dark grey-shaded area includes the first six months after the 2012 election, i.e. November 2012 to April 2013. Light grey-shaded areas are marking the same period for preceding years.

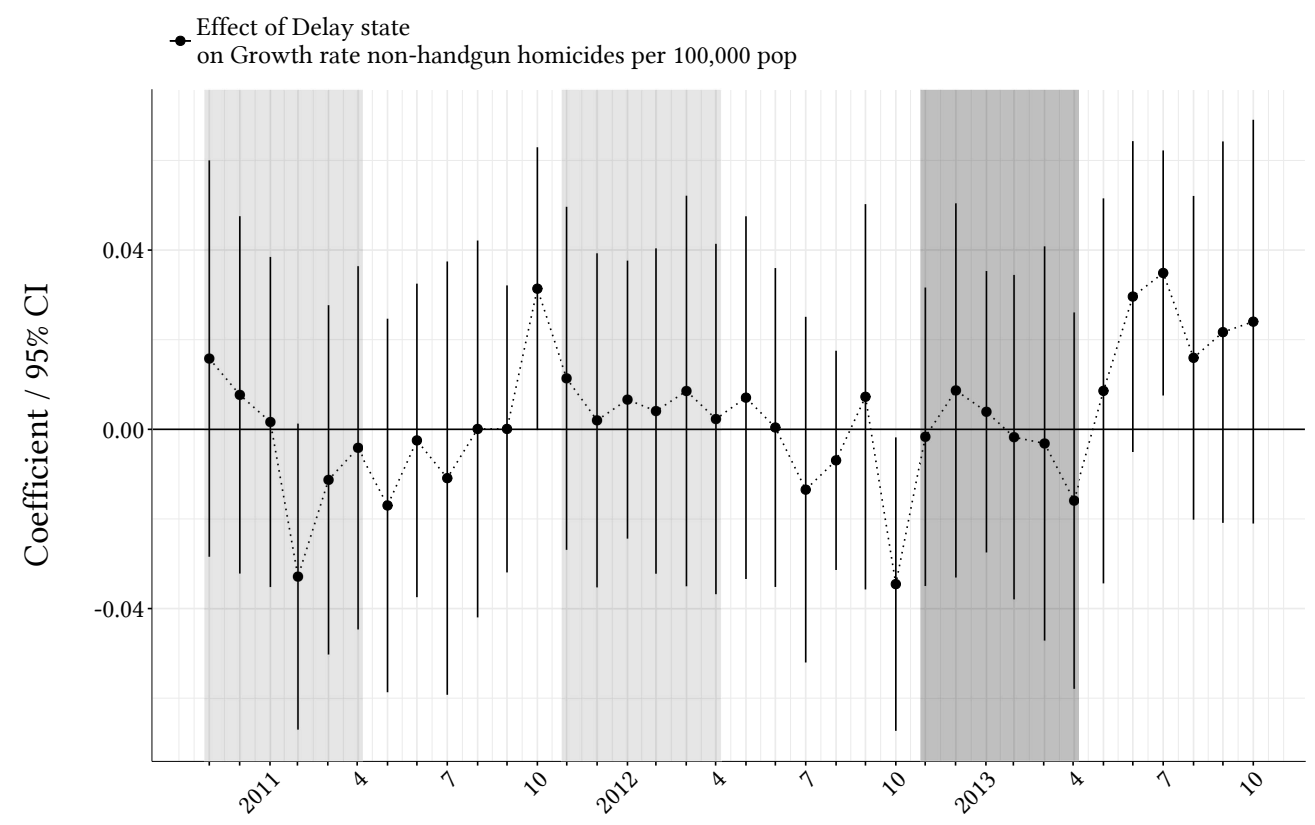

Figure 23: Event STUDY GRAPH FOR NON-HANDGUN HOMICIDE RATE

Coefficients and $95 \%$ confidence intervals for the effect of being in a Delay state on $\Delta_{12}$ Log non-handgun homicide per 100,000 inhabitants for each month between November 2010 and October 2013. The dark grey-shaded area includes the first six months after the 2012 election, i.e. November 2012 to April 2013. Light grey-shaded areas are marking the same period for preceding years. 


\section{Tables}

TABle 21: Google SEARChes for "Gun StOre" (LOGS AND LeVels)

\begin{tabular}{|c|c|c|c|c|c|c|c|c|}
\hline & \multicolumn{8}{|c|}{ Standardized share of Google searches for "gun store" } \\
\hline & \multicolumn{4}{|c|}{ Seasonal differencing (Baseline) } & \multicolumn{4}{|c|}{ Within transformation } \\
\hline & \multicolumn{2}{|c|}{ Logs (Baseline) } & \multicolumn{2}{|c|}{ Levels } & \multicolumn{2}{|c|}{ Logs } & \multicolumn{2}{|c|}{ Levels } \\
\hline & (1) & $(2)$ & (3) & (4) & (5) & (6) & $(7)$ & (8) \\
\hline Delay $\times$ Post 1 & $\begin{array}{c}0.037 \\
(0.082)\end{array}$ & $\begin{array}{c}-0.017 \\
(0.090)\end{array}$ & $\begin{array}{l}-1.046 \\
(3.611)\end{array}$ & $\begin{array}{c}-0.024 \\
(2.605)\end{array}$ & $\begin{array}{c}-0.283 \\
(0.181)\end{array}$ & $\begin{array}{c}0.035 \\
(0.073)\end{array}$ & $\begin{array}{l}-8.376 \\
(7.763)\end{array}$ & $\begin{array}{c}-2.459 \\
(3.848)\end{array}$ \\
\hline Delay $\times$ Post 2 & $\begin{array}{c}-0.027 \\
(0.097)\end{array}$ & $\begin{array}{c}-0.081 \\
(0.133)\end{array}$ & $\begin{array}{c}0.667 \\
(2.386)\end{array}$ & $\begin{array}{c}1.689 \\
(3.627)\end{array}$ & $\begin{array}{c}-0.353^{* *} \\
(0.173)\end{array}$ & $\begin{array}{c}-0.035 \\
(0.112)\end{array}$ & $\begin{array}{c}-5.371 \\
(4.509)\end{array}$ & $\begin{array}{c}0.546 \\
(2.267)\end{array}$ \\
\hline Year-Week FE & Y & Y & Y & $\mathrm{Y}$ & Y & Y & Y & Y \\
\hline Controls & Y & $\mathrm{Y}$ & $\mathrm{Y}$ & Y & $\mathrm{Y}$ & $\mathrm{Y}$ & $\mathrm{Y}$ & $\mathrm{Y}$ \\
\hline State Trends & $\mathrm{N}$ & $\mathrm{Y}$ & $\mathrm{N}$ & $\mathrm{Y}$ & $\mathrm{N}$ & $\mathrm{Y}$ & $\mathrm{N}$ & $\mathrm{Y}$ \\
\hline States & 49 & 49 & 49 & 49 & 49 & 49 & 49 & 49 \\
\hline Observations & 7,693 & 7,693 & 7,693 & 7,693 & 7,693 & 7,693 & 7,693 & 7,693 \\
\hline $\mathrm{R}^{2}$ & 0.230 & 0.247 & 0.419 & 0.441 & 0.511 & 0.665 & 0.440 & 0.802 \\
\hline
\end{tabular}

Notes: Observations are at the state-week-level. The sample period is November 2010 until October 2013, i.e. an asymmetric 36-month window 2 years before and 1 year after the 2012 election. Where no seasonal differencing is applied, the nominal sample period starts in November 2009. Standard errors clustered at the state-level are in parentheses: ${ }^{*} \mathrm{p}<0.1 ;{ }^{* *} \mathrm{p}<0.05 ;{ }^{* * *} \mathrm{p}<0.01$. Included control variables are $\log$ (population), $\%$ rural, $\%$ below poverty line, $\%$ blacks, $\%$ hispanics and \% with internet access. All variables are as of 2010 and interacted with Month FE. Regressions are weighted by the state population.

TABle 22: Handgun SALE TRAnsaCtion COSTS

\begin{tabular}{|c|c|c|c|c|c|c|c|c|}
\hline \multirow{3}{*}{ Threshold $\mathrm{X}=\ldots$} & \multicolumn{8}{|c|}{$\Delta_{12}$ Log of handgun background checks per 100,000 inhabitants } \\
\hline & \multirow[b]{2}{*}{ (1) } & \multirow[b]{2}{*}{ (2) } & \multicolumn{2}{|c|}{$1^{\text {st }}$ Quartile $(\$ 47)$} & \multicolumn{2}{|c|}{$2^{\text {nd }}$ Quartile $(\$ 67)$} & \multicolumn{2}{|c|}{$3^{\text {rd }}$ Quartile $(\$ 115)$} \\
\hline & & & $(3)$ & (4) & (5) & $(6)$ & (7) & (8) \\
\hline Delay $\times$ Post 1 & $\begin{array}{c}-0.081^{*} \\
(0.044)\end{array}$ & $\begin{array}{c}-0.073^{* *} \\
(0.033)\end{array}$ & $\begin{array}{c}-0.078^{*} \\
(0.044)\end{array}$ & $\begin{array}{l}-0.070^{* *} \\
(0.031)\end{array}$ & $\begin{array}{l}-0.106^{* *} \\
(0.045)\end{array}$ & $\begin{array}{l}-0.113^{* * *} \\
(0.032)\end{array}$ & $\begin{array}{c}-0.079^{*} \\
(0.044)\end{array}$ & $\begin{array}{l}-0.072^{* *} \\
(0.033)\end{array}$ \\
\hline Delay $\times$ Post 2 & 0.010 & 0.007 & 0.007 & 0.003 & -0.036 & -0.062 & 0.002 & -0.004 \\
\hline & $(0.064)$ & $(0.084)$ & $(0.063)$ & $(0.083)$ & $(0.067)$ & $(0.097)$ & $(0.057)$ & $(0.076)$ \\
\hline$($ Tr. Costs $>\mathrm{X}) \times$ Post 1 & & & 0.072 & 0.081 & $0.068^{* *}$ & $0.106^{* * *}$ & -0.026 & -0.003 \\
\hline & & & $(0.045)$ & $(0.053)$ & $(0.028)$ & $(0.034)$ & $(0.019)$ & $(0.033)^{* * *}$ \\
\hline$($ Tr. Costs $>\mathrm{X}) \times$ Post 2 & & & $\begin{array}{c}-0.142 \\
(0.153)\end{array}$ & $\begin{array}{c}-0.147 \\
(0.161)\end{array}$ & $\begin{array}{c}0.145 \\
(0.088)\end{array}$ & $\begin{array}{c}0.202^{*} \\
(0.109)\end{array}$ & $\begin{array}{l}0.136^{* *} \\
(0.058)\end{array}$ & $\begin{array}{l}0.164^{* * *} \\
(0.057)\end{array}$ \\
\hline Year-Mon & $\mathrm{Y}$ & $\mathrm{Y}$ & $\mathrm{Y}$ & $\mathrm{Y}$ & $\mathrm{Y}$ & $\mathrm{Y}$ & Y & $\mathrm{Y}$ \\
\hline Controls & $\mathrm{Y}$ & Y & Y & Y & Y & Y & Y & Y \\
\hline State Trends & $\mathrm{N}$ & Y & $\mathrm{N}$ & Y & $\mathrm{N}$ & Y & $\mathrm{N}$ & Y \\
\hline $\mathrm{R}^{2}$ & 0.539 & 0.594 & 0.543 & 0.599 & 0.554 & 0.615 & 0.554 & 0.611 \\
\hline
\end{tabular}

Notes: All regressions use 1,516 observations from 43 states. Observations are at the state-month-level. The sample period is November 2010 until October 2013, i.e. an asymmetric 36-month window 2 years before and 1 year after the 2012 election. Where no seasonal differencing is applied, the nominal sample period starts in November 2009. Standard errors clustered at the state-level are in parentheses: ${ }^{*} \mathrm{p}<0.1 ;{ }^{* *} \mathrm{p}<0.05 ;{ }^{* * *} \mathrm{p}<0.01$. Included control variables are $\log$ (population), \% rural, $\%$ below poverty line, $\%$ blacks and $\%$ hispanics. All variables are as of 2010 and interacted with Month FE. Regressions are weighted by the state population. 
TABle 23: EfFeCt on homicide RATES: Victim AGE

\begin{tabular}{|c|c|c|c|c|c|c|c|c|c|c|c|c|c|c|c|c|}
\hline \multirow{3}{*}{ Victim age } & \multicolumn{16}{|c|}{$\Delta_{12} \log$ of handgun homicides per 100,000 inhabitants } \\
\hline & \multicolumn{2}{|c|}{ Any } & \multicolumn{2}{|c|}{$<10$} & \multicolumn{2}{|c|}{$10-19$} & \multicolumn{2}{|c|}{$20-29$} & \multicolumn{2}{|c|}{$30-39$} & \multicolumn{2}{|c|}{$40-49$} & \multicolumn{2}{|c|}{$50-59$} & \multicolumn{2}{|c|}{$\geq 60$} \\
\hline & $(1)$ & $(2)$ & $(3)$ & $(4)$ & $(5)$ & $(6)$ & $(7)$ & $(8)$ & (9) & $(10)$ & $(11)$ & $(12)$ & $(13)$ & $(14)$ & $(15)$ & $(16)$ \\
\hline Delay $\times$ Post 1 & $\begin{array}{l}-0.022^{* * *} \\
(0.008)\end{array}$ & $\begin{array}{l}-0.019^{* *} \\
(0.010)\end{array}$ & $\begin{array}{l}-0.000 \\
(0.001)\end{array}$ & $\begin{array}{c}0.000 \\
(0.001)\end{array}$ & $\begin{array}{c}0.003 \\
(0.004)\end{array}$ & $\begin{array}{c}0.003 \\
(0.004)\end{array}$ & $\begin{array}{l}-0.017^{* *} \\
(0.006)\end{array}$ & $\begin{array}{l}-0.014^{* *} \\
(0.007)\end{array}$ & $\begin{array}{c}0.001 \\
(0.004)\end{array}$ & $\begin{array}{l}-0.002 \\
(0.004)\end{array}$ & $\begin{array}{c}-0.004 \\
(0.003)\end{array}$ & $\begin{array}{l}-0.005 \\
(0.004)\end{array}$ & $\begin{array}{l}-0.002 \\
(0.003)\end{array}$ & $\begin{array}{l}-0.004 \\
(0.004)\end{array}$ & $\begin{array}{l}-0.002 \\
(0.002)\end{array}$ & $\begin{array}{l}-0.003 \\
(0.003)\end{array}$ \\
\hline Delay $\times$ Post 2 & $\begin{array}{c}-0.018 \\
(0.015)\end{array}$ & $\begin{array}{l}-0.015 \\
(0.018)\end{array}$ & $\begin{array}{c}0.001 \\
(0.001)\end{array}$ & $\begin{array}{c}0.002 \\
(0.001)\end{array}$ & $\begin{array}{l}-0.009^{*} \\
(0.005)\end{array}$ & $\begin{array}{l}-0.009 \\
(0.005)\end{array}$ & $\begin{array}{l}-0.001 \\
(0.008)\end{array}$ & $\begin{array}{c}0.002 \\
(0.009)\end{array}$ & $\begin{array}{c}0.001 \\
(0.005)\end{array}$ & $\begin{array}{c}0.002 \\
(0.004)\end{array}$ & $\begin{array}{c}-0.005 \\
(0.006)\end{array}$ & $\begin{array}{l}-0.006 \\
(0.007)\end{array}$ & $\begin{array}{l}-0.002 \\
(0.004)\end{array}$ & $\begin{array}{c}-0.003 \\
(0.005)\end{array}$ & $\begin{array}{l}-0.003 \\
(0.003)\end{array}$ & $\begin{array}{l}-0.004 \\
(0.003)\end{array}$ \\
\hline Year-Month FE & Y & $\mathrm{Y}$ & Y & $\mathrm{Y}$ & Y & $\mathrm{Y}$ & Y & $\mathrm{Y}$ & Y & $\mathrm{Y}$ & Y & Y & $\mathrm{Y}$ & $\mathrm{Y}$ & Y & Y \\
\hline Controls & $\mathrm{Y}$ & $\mathrm{Y}$ & $\mathrm{Y}$ & $\mathrm{Y}$ & $\mathrm{Y}$ & $\mathrm{Y}$ & $\mathrm{Y}$ & $\mathrm{Y}$ & $\mathrm{Y}$ & Y & $\mathrm{Y}$ & $\mathrm{Y}$ & $\mathrm{Y}$ & $\mathrm{Y}$ & $\mathrm{Y}$ & $\mathrm{Y}$ \\
\hline $\mathrm{R}^{2}$ & 0.008 & 0.019 & 0.006 & 0.015 & 0.011 & 0.021 & 0.012 & 0.023 & 0.006 & 0.016 & 0.006 & 0.015 & 0.005 & 0.014 & 0.004 & 0.013 \\
\hline
\end{tabular}

Notes: All regressions use 109,692 observations from 3,047 counties. The sample period is November 2010 until October 2013, i.e. an asymmetric 36-month window 2 years before and 1 year after the 2012 election. Where no seasonal differencing is applied, the nominal sample period starts in November 2009. Standard errors clustered at the state-level are in parentheses: ${ }^{*} \mathrm{p}<0.1 ;{ }^{*} \mathrm{p}<0.05 ;{ }^{* *} \mathrm{p}<0.01$. Included control variables are $\log ($ population), $\%$ rural, $\%$ below poverty line, $\%$ blacks and $\%$ hispanics. All variables are as of 2010 and interacted with Month FE. Regressions are weighted by the county population. 
TAble 24: Effect on homicide RATES: Victim RACE

\begin{tabular}{|c|c|c|c|c|c|c|c|c|c|c|}
\hline \multirow{3}{*}{ Victim race } & \multicolumn{10}{|c|}{$\Delta_{12} \log$ of handgun homicides per 100,000 inhabitants } \\
\hline & \multicolumn{2}{|c|}{ Any } & \multicolumn{2}{|c|}{ White } & \multicolumn{2}{|c|}{ Black } & \multicolumn{2}{|c|}{ Hispanic } & \multicolumn{2}{|c|}{ Other } \\
\hline & (1) & (2) & (3) & (4) & (5) & (6) & (7) & (8) & (9) & (10) \\
\hline Delay $\times$ Post1 & $\begin{array}{c}-0.022^{* *} \\
(0.008)\end{array}$ & $\begin{array}{c}* * 0.019^{* *} \\
(0.010)\end{array}$ & $\begin{array}{c}-0.011^{* *} \\
(0.006)\end{array}$ & $\begin{array}{r}-0.012^{*} \\
(0.007)\end{array}$ & $\begin{array}{l}-0.014 \\
(0.008)\end{array}$ & $\begin{array}{c}-0.009 \\
(0.009)\end{array}$ & $\begin{array}{c}0.002 \\
(0.005)\end{array}$ & $\begin{array}{c}0.001 \\
(0.005)\end{array}$ & $\begin{array}{c}0.001 \\
(0.002)\end{array}$ & $\begin{array}{c}0.000 \\
(0.003)\end{array}$ \\
\hline Delay $\times$ Post 2 & $\begin{array}{c}-0.018 \\
(0.015)\end{array}$ & $\begin{array}{c}-0.015 \\
(0.018)\end{array}$ & $\begin{array}{c}-0.002 \\
(0.007)\end{array}$ & $\begin{array}{c}-0.003 \\
(0.008)\end{array}$ & $\begin{array}{l}-0.008 \\
(0.009)\end{array}$ & $\begin{array}{l}-0.004 \\
(0.010)\end{array}$ & $\begin{array}{l}-0.006 \\
(0.006)\end{array}$ & $\begin{array}{c}-0.007 \\
(0.007)\end{array}$ & $\begin{array}{c}-0.004 \\
(0.003)\end{array}$ & $\begin{array}{l}-0.004 \\
(0.003)\end{array}$ \\
\hline Year-Month FE & $\mathrm{Y}$ & Y & $\mathrm{Y}$ & Y & Y & $\mathrm{Y}$ & Y & $\mathrm{Y}$ & $\mathrm{Y}$ & $\mathrm{Y}$ \\
\hline Controls & $\mathrm{Y}$ & Y & $\mathrm{Y}$ & Y & $\mathrm{Y}$ & $\mathrm{Y}$ & $\mathrm{Y}$ & $\mathrm{Y}$ & $\mathrm{Y}$ & $\mathrm{Y}$ \\
\hline County Trends & $\mathrm{N}$ & Y & $\mathrm{N}$ & $\mathrm{Y}$ & $\mathrm{N}$ & $\mathrm{Y}$ & $\mathrm{N}$ & Y & $\mathrm{N}$ & Y \\
\hline $\mathrm{R}^{2}$ & 0.008 & 0.019 & 0.003 & 0.012 & 0.009 & 0.021 & 0.014 & 0.022 & 0.007 & 0.018 \\
\hline
\end{tabular}

Notes: All regressions use 109,692 observations from 3,047 counties. The sample period is November 2010 until October 2013, i.e. an asymmetric 36-month window 2 years before and 1 year after the 2012 election. Where no seasonal differencing is applied, the nominal sample period starts in November 2009. Standard errors clustered at the state-level are in parentheses: ${ }^{*} \mathrm{p}<0.1 ;{ }^{* *} \mathrm{p}<0.05 ;{ }^{* * *} \mathrm{p}<0.01$. Included control variables are $\log$ (population), \% rural, \% below poverty line, \% blacks and \% hispanics. All variables are as of 2010 and interacted with Month FE. Regressions are weighted by the county population. 
TABle 25: UCR/FBI Homicide Reports: COMPARABILITy

\begin{tabular}{|c|c|c|c|c|c|c|c|c|c|c|c|c|c|c|c|c|c|c|}
\hline \multirow{6}{*}{ Delay $\times$ Post 1} & \multicolumn{18}{|c|}{$\Delta_{12} \log$ of murders per 100,000 inhabitants } \\
\hline & \multicolumn{6}{|c|}{ UCR } & \multicolumn{6}{|c|}{ NVSS (UCR sample) } & \multicolumn{6}{|c|}{ NVSS (full sample) } \\
\hline & \multicolumn{2}{|c|}{ Handgun } & \multicolumn{2}{|c|}{ Any } & \multicolumn{2}{|c|}{ Other } & \multicolumn{2}{|c|}{ Handgun } & \multicolumn{2}{|c|}{ Any } & \multicolumn{2}{|c|}{ Other } & \multicolumn{2}{|c|}{ Handgun } & \multicolumn{2}{|c|}{ Any } & \multicolumn{2}{|c|}{ Other } \\
\hline & (1) & (2) & (3) & (4) & $(5)$ & (6) & (7) & (8) & (9) & (10) & (11) & (12) & (13) & $(14)$ & (15) & $(16)$ & (17) & $(18)$ \\
\hline & -0.014 & -0.013 & -0.017 & -0.016 & -0.001 & 0.000 & $-0.019^{* *}$ & -0.017 & $-0.023^{*}$ & -0.022 & -0.003 & -0.003 & $-0.022^{* * *}$ & $-0.019^{* *}$ & $-0.024^{* *}$ & -0.021 & -0.002 & -0.001 \\
\hline & $(0.011)$ & $(0.013)$ & $(0.013)$ & $(0.018)$ & $(0.010)$ & $(0.012)$ & $(0.009)$ & $(0.012)$ & $(0.013)$ & $(0.019)$ & $(0.012)$ & $(0.016)$ & $(0.008)$ & $(0.010)$ & $(0.012)$ & $(0.016)$ & $(0.010)$ & $(0.013)$ \\
\hline Delay $\times$ Post2 & 0.003 & 0.004 & 0.015 & 0.016 & 0.018 & 0.019 & -0.016 & -0.014 & 0.003 & 0.004 & $0.022^{*}$ & 0.021 & -0.018 & -0.015 & 0.002 & 0.005 & $0.022^{* * *}$ & $0.024^{* *}$ \\
\hline & $(0.019)$ & $(0.025)$ & $(0.022)$ & $(0.031)$ & $(0.011)$ & $(0.014)$ & $(0.017)$ & $(0.020)$ & $(0.021)$ & $(0.028)$ & $(0.012)$ & $(0.015)$ & $(0.015)$ & $(0.018)$ & $(0.017)$ & $(0.023)$ & $(0.008)$ & $(0.011)$ \\
\hline Year-Month FE & $\mathrm{Y}$ & $\mathrm{Y}$ & $\mathrm{Y}$ & Y & $\mathrm{Y}$ & Y & $\mathrm{Y}$ & $\mathrm{Y}$ & Y & $\mathrm{Y}$ & $\mathrm{Y}$ & $\mathrm{Y}$ & $\mathrm{Y}$ & $\mathrm{Y}$ & $\mathrm{Y}$ & $\mathrm{Y}$ & $\mathrm{Y}$ & $\mathrm{Y}$ \\
\hline Controls & Y & $\mathrm{Y}$ & $\mathrm{Y}$ & $\mathrm{Y}$ & $\mathrm{Y}$ & Y & $\mathrm{Y}$ & $\mathrm{Y}$ & $\mathrm{Y}$ & $\mathrm{Y}$ & $\mathrm{Y}$ & $\mathrm{Y}$ & $\mathrm{Y}$ & $\mathrm{Y}$ & $\mathrm{Y}$ & $\mathrm{Y}$ & $\mathrm{Y}$ & $\mathrm{Y}$ \\
\hline County Trends & $\mathrm{N}$ & $\mathrm{Y}$ & $\mathrm{N}$ & $\mathrm{Y}$ & $\mathrm{N}$ & $\mathrm{Y}$ & $\mathrm{N}$ & $\mathrm{Y}$ & $\mathrm{N}$ & $\mathrm{Y}$ & $\mathrm{N}$ & $\mathrm{Y}$ & $\mathrm{N}$ & $\mathrm{Y}$ & $\mathrm{N}$ & $\mathrm{Y}$ & $\mathrm{N}$ & $\mathrm{Y}$ \\
\hline Counties & 2,229 & 2,229 & 2,229 & 2,229 & 2,229 & 2,229 & 2,229 & 2,229 & 2,229 & 2,229 & 2,229 & 2,229 & 3,047 & 3,047 & 3,047 & 3,047 & 3,047 & 3,047 \\
\hline Observations & 80,244 & 80,244 & 80,244 & 80,244 & 80,244 & 80,244 & 80,244 & 80,244 & 80,244 & 80,244 & 80,244 & 80,244 & 109,692 & 109,692 & 109,692 & 109,692 & 109,692 & 109,692 \\
\hline $\mathrm{R}^{2}$ & 0.010 & 0.021 & 0.009 & 0.019 & 0.008 & 0.019 & 0.009 & 0.020 & 0.007 & 0.017 & 0.006 & 0.015 & 0.008 & 0.019 & 0.006 & 0.016 & 0.005 & 0.014 \\
\hline
\end{tabular}

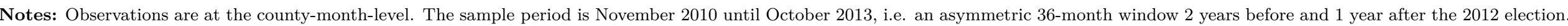

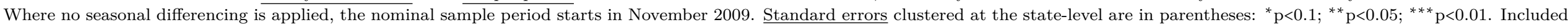

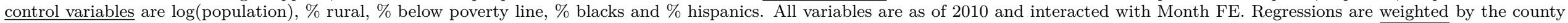
population. 